Florida International University

FIU Digital Commons

FIU Electronic Theses and Dissertations

University Graduate School

$6-27-2012$

\title{
The Effectiveness of a Conceptually-based Health and Wellness Course in Developing Health Related Factors, Exercise self-efficacy and Knowledge of Health Issues and Exercise Performance among Diverse College Students.
}

Ilida M. Medero

Florida International University, imedero@mdc.edu

DOI: $10.25148 /$ etd.FI12072707

Follow this and additional works at: https://digitalcommons.fiu.edu/etd

\section{Recommended Citation}

Medero, Ilida M., "The Effectiveness of a Conceptually-based Health and Wellness Course in Developing Health Related Factors, Exercise self-efficacy and Knowledge of Health Issues and Exercise Performance among Diverse College Students." (2012). FIU Electronic Theses and Dissertations. 671.

https://digitalcommons.fiu.edu/etd/671

This work is brought to you for free and open access by the University Graduate School at FIU Digital Commons. It has been accepted for inclusion in FIU Electronic Theses and Dissertations by an authorized administrator of FIU Digital Commons. For more information, please contact dcc@fiu.edu. 
FLORIDA INTERNATIONAL UNIVERSITY

Miami, Florida

THE EFFECTIVENESS OF A CONCEPTUALLY-BASED HEALTH AND WELLNESS COURSE IN DEVELOPING HEALTH RELATED FACTORS, EXERCISE SELF-EFFICACY AND KNOWLEDGE OF HEALTH ISSUES AND EXERCISE PERFORMANCE AMONG DIVERSE COLLEGE STUDENTS

A dissertation submitted in partial fulfillment of the requirements for the degree of DOCTOR OF EDUCATION in

HIGHER EDUCATION

Ilida Medero 
To: Dean Delia C. Garcia

College of Education

This dissertation, written by Ilida Medero, and entitled The Effectiveness of a Conceptually-based Health and Wellness Course in Developing Health Related Factors, Exercise Self-Efficacy and Knowledge on Health Issues and Exercise Performance Among Diverse College Students, having been approved in respect to style and intellectual content, is referred to you for judgment.

We have read this dissertation and recommend that it be approved.

Benjamin Baez

Charmaine DeFrancesco

Roger Geertz-Gonzalez

Glenda Droogsma Musoba, Major Professor

Date of Defense: June 27, 2012

The dissertation of Ilida Medero is approved.

Dean Delia C. Garcia

College of Education

Dean Lakshmi N. Reddi

University Graduate School

Florida International University, 2012 


\section{DEDICATION}

I dedicate this dissertation to my parents for having the courage to flee my country of origin in order to provide my brothers Hector, Rick and me with a better life. If it were not for their courage to risk it all for the benefit of their children, I would have never had the opportunity to earn a doctoral degree. Professionally, I would like to dedicate this dissertation to my mentor and advisor Dr. Joseph Brownholtz, Professor Emeritus at the University of Miami who has been my guiding light in all of the decisions I have made in my professional life. To him, I am eternally grateful. 


\section{ACKNOWLEDGMENTS}

I would like to thank the members of my committee Major Professor Dr. Glenda Droogsma Musoba, Dr. Benjamin Baez, Dr. Roger Geertz-Gonzalez and Dr. Charmaine DeFrancesco for their valuable ideas and suggestions. I am thankful for their involvement with my project. I am particularly indebted to Dr. Glenda Droogsma Musoba for her patience, suggestions, and constant support. She directed my steps, provided constructive criticism and was always there for me when I needed advice. I would like to thank her for the countless hours of revisions and advice on my dissertation. This has been one of the most interesting experiences in my educational process and without her assistance I would have never completed my post-graduate degree.

I would also like to give my deepest gratitude to Dr. Paulette Johnson for being my statistical consultant. Her assistance was instrumental in completing the statistical related chapters. Additionally, I would like to thank Dr. Maria Plakhotnik and Dr. Linda Bliss for their expertise and assistance with the APA portion of my dissertation.

I want to thank my family and friends for their constant support and patience throughout this process. To my colleagues Rene Garcia, Hanadi Saleh, Jocelyne Legrand, Robert Rothstein and Sandra Schultz, I owe my deepest gratitude. Special thanks to Keila Oliveira, Davonne Breedlove and Daniel Estape for reviewing material and assisting in countless ways. 
ABSTRACT OF THE DISSERTATION

THE EFFECTIVENESSS OF A CONCEPTUALLY-BASED HEALTH AND

WELLNESS COURSE IN DEVELOPING HEALTH RELATED FACTORS, EXERCISE SELF- EFFICACY AND KNOWLEDGE ON HEALTH ISSUES AND

EXERCISE PERFORMANCE AMONG DIVERSE COLLEGE STUDENTS

by

Ilida Medero

Florida International University, 2012

Miami, Florida

Professor Glenda Droogsma Musoba, Major Professor

The purpose of the study was to investigate the physiological and psychological benefits provided by a self-selected health and wellness course on a racially and ethnically diverse student population. It was designed to determine if students from a 2year Hispanic serving institution (HIS) from a large metropolitan area would enhance their capacity to perform physical activities, increase their knowledge of health topics and raise their exercise self-efficacy after completing a course that included educational and activity components for a period of 16 weeks.

A total of 185 students voluntarily agreed to participate in the study. An experimental group was selected from six sections of a health and wellness course, and a comparison group from students in a student life skills course. All participants were given anthropometric tests of physical fitness, a knowledge test, and an exercise self-efficacy scale was given at the beginning and at the conclusion of the semester. 
An ANCOVA analyses with the pretest scores being the covariate and the dependent variable being the difference score, indicated a significant improvement of the experimental group in five of the seven anthropometric tests over the comparison group. In addition, the experimental group increased in two of the three sections of the exercise self-efficacy scale indicating greater confidence to participate in physical activities in spite of barriers over the comparison group. The experimental group also increased in knowledge of health related topics over the comparison group at the .05 significance level.

Results indicated beneficial outcomes gained by students enrolled in a 16-week health and wellness course. The study has several implications for practitioners, faculty members, educational policy makers and researchers in terms of implementation of strategies to promote healthy behaviors in college students and, to encourage them to engage in regular physical activities throughout their college years. 


\section{TABLE OF CONTENTS}

CHAPTER

PAGE

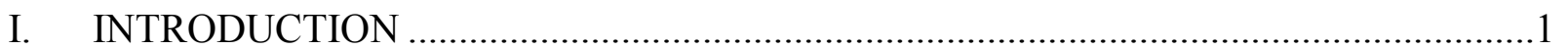

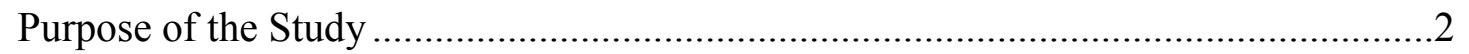

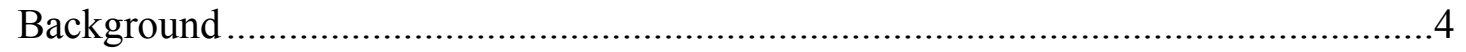

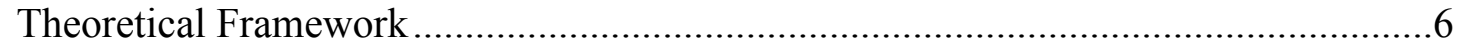

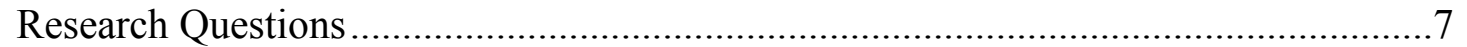

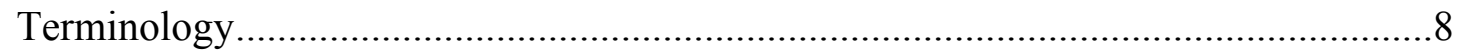

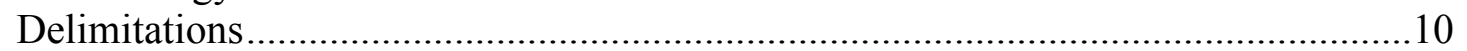

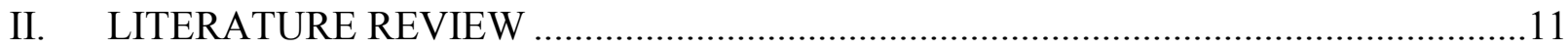

Status of Wellness Programs in Colleges and Universities in the United States ........................................................................................ 11

Relationship Between Fitness Self-efficacy and Exercise

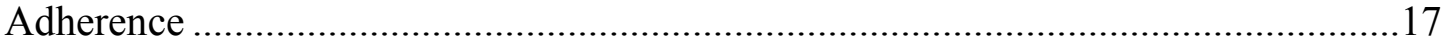

Relationship Between Knowledge of Fitness and Behavior for

Fitness of College Students.................................................................................28

Research on Impact of Fitness Classes on Fitness Behaviors of

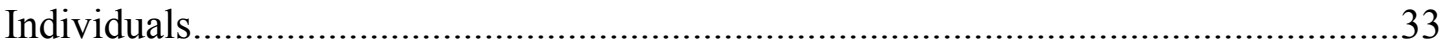

Impact of Fitness Classes on the Behavior of College Students...............................40

Physical Activity Patterns of Racial and Ethnic Minorities with

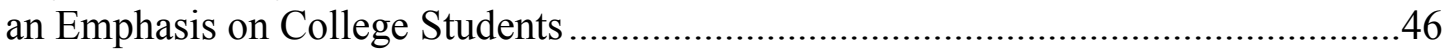

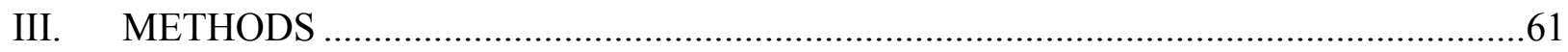

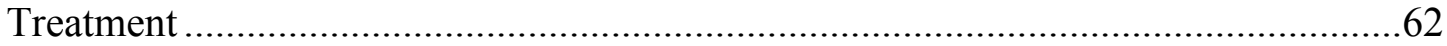

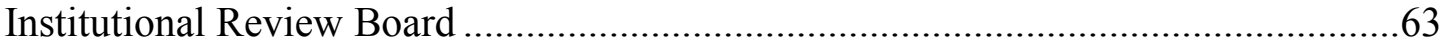

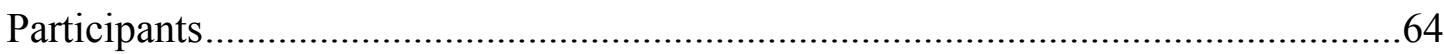

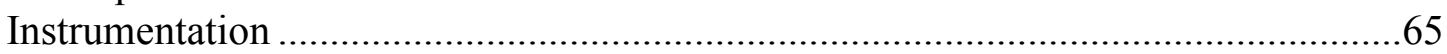

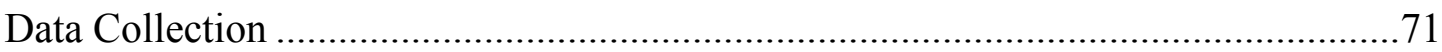

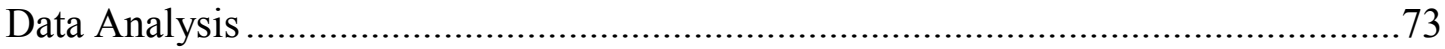

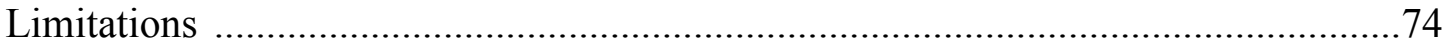

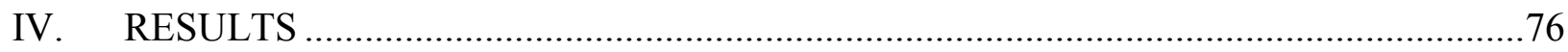

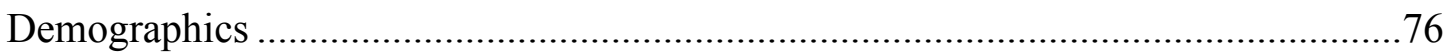

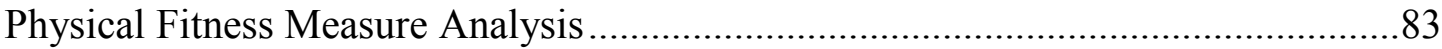

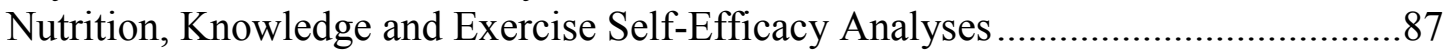

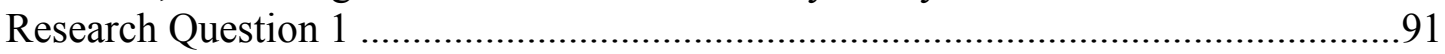

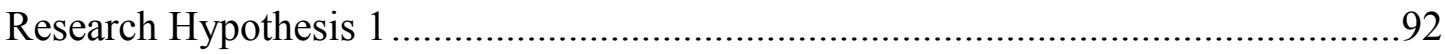

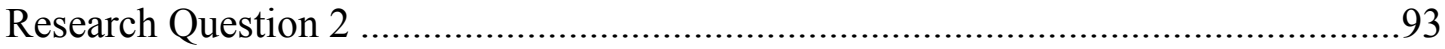

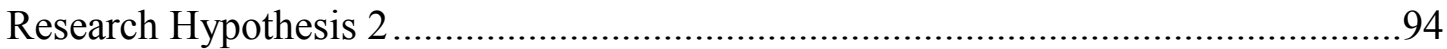

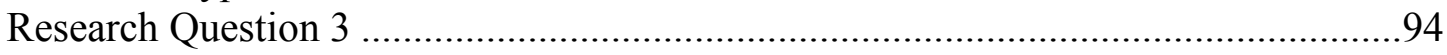

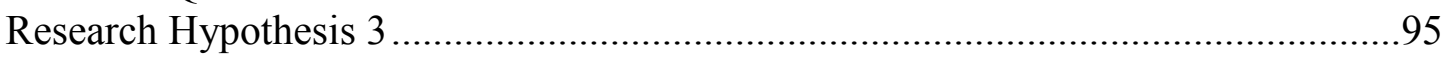




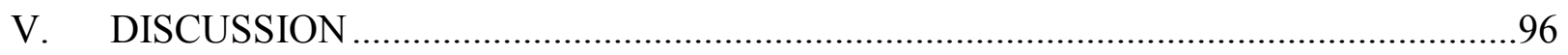

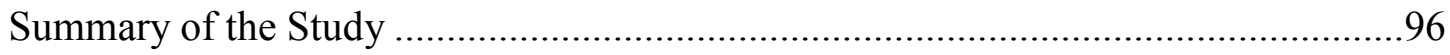

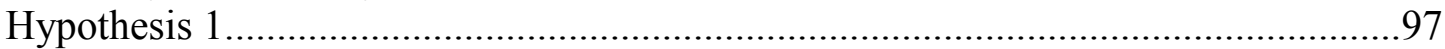

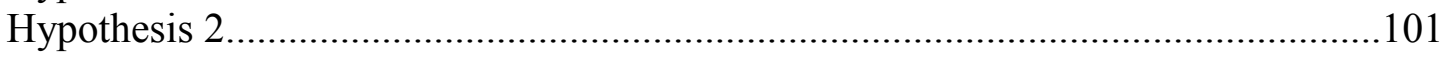

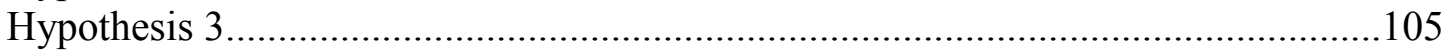

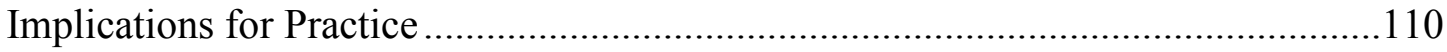

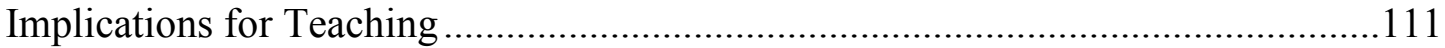

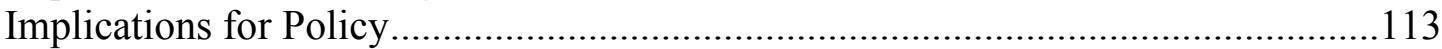

Implications for Future Research........................................................................117

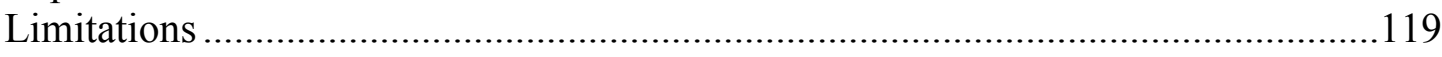

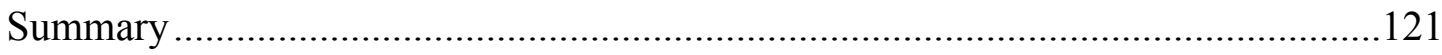

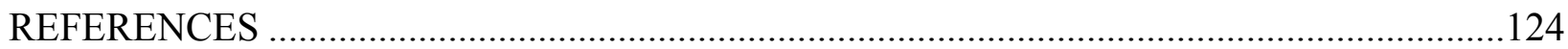

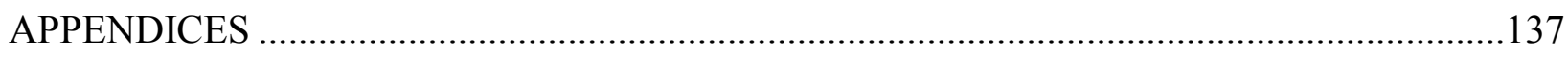

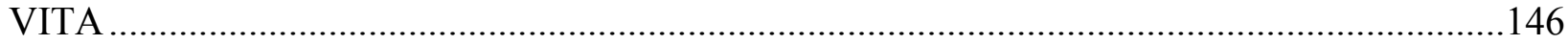




\section{LIST OF TABLES}

TABLE

PAGE

1. Demographic Characteristics of Study Participants by Group .....................78

2. Observed Pre-Test, Post-Test, and Difference Score Means for Physical Fitness Variables by Group

3. Observed Pre-Test, Post-Test and Difference Score Means for Nutrition, Knowledge, VPA (External \& Internal Barriers) and FVPA Variables by Group.....82

4. Adjusted Means for Physical Fitness Changes from Pre to Post by Group Controlling for Pre-Test, Gender, and Ethnicity

5. Adjusted Means for Nutritional Habits, Knowledge and VPA Changes from Pre to Post by Group Controlling for Pre-Test, Gender and Ethnicity. 


\section{CHAPTER I}

\section{INTRODUCTION}

The state of fitness and wellness in the population of the United States in the $21^{\text {st }}$ century is deplorable. According to the United States Center for Disease Control (CDC, 2006), the prevalence of obesity, which is measured by having a Body Mass Index (BMI) of greater than $30(\mathrm{BMI}>30)$ is a health concern for children, adolescents and adults. BMI is an indicator of body fatness.

The latest statistics are alarming, indicating that approximately $66 \%$ of Americans were overweight in 2005-2006 with $33.3 \%$ of men and $35.3 \%$ of women being obese (CDC, 2008). Physical inactivity and poor nutrition are major contributors of obesity and of chronic diseases such as diabetes, cardiovascular disease, stroke and cancer among others. In fact, chronic diseases related to obesity contributed to five out of six leading causes of death in 2002 (CDC, 2008). In reference to children and adolescents, the trend of obesity continues to increase. Current CDC statistics show that approximately $16 \%$ of children and adolescents are overweight accounting for about 9 million individuals. These numbers tripled the statistics provided for 1980. Adams (2007) reported that the United States Surgeon General suggested that unhealthy dietary habits and sedentary living are responsible for approximately 300,000 deaths annually and that illnesses occurring from obesity may be comparable to poverty, smoking or alcoholism. Clearly there is a need to educate the populace of the United States about making positive changes in lifestyle, nutrition and an increase in physical activity to curtail the detrimental effects of being overweight and obese. Lifetime habits are often established prior to young adulthood. College students are equally at risk of suffering 
from health complications at a later age if they do not engage in regular physical activity and follow healthy lifestyle practices. The college setting may be the last opportunity to educate a large segment of the population of young adults to be physically active and establish a healthy lifestyle for their lifetime.

Physical education departments have been identified as critical for combating physical inactivity and obesity because they are one of few academic units in higher education that focuses on educating students with the knowledge and skills of physical activity (Corbin, 2002; CDC-USDHHS, 1996). However since the 1970s, there has been a decrease in the physical education requirement in most colleges throughout the nation within the general education curriculum. Reports of the American College Health Association (ACHA) and National College Health Association (NCHA) concurred with Adams (2007) in stating that over $35 \%$ of all college students are either overweight or obese (ACHA, 2007). In essence, the previously mentioned studies indicated that a large number of college students are above the expected body weight for their height.

Institutions of higher education need to develop ways to educate students to promote a lifetime of healthy practices.

\section{Purpose of the Study}

The recent increase in childhood and adolescent obesity has been referred to as an epidemic by the Center for Disease Control, especially among minorities. Studies have included Whites, African-Americans, and Latinos (CDC, 2008). The Latino population has been targeted as a major concern given (a) the increase in childbirths among the Latino population in the United States, (b) an alarming rate of obesity among the children 
of Latino parents, and (c) the consequent social, medical, physical, and psychological impact of being overweight and/or obese while not unique to Hispanics (CDC, 2008).

Hispanics are the largest, fastest-growing minority in the United States. During the decade of 2000 to 2010, the Hispanic population increased by $43 \%$ which was four times the growth of the total population at $10 \%$ (U.S. Census Bureau, 2010). The Mexican origin population represented the largest Hispanic group in 40 states. They resided mostly in the South, West and Midwest regions of the country, and most research on Hispanics has been conducted in these regions. However, South Florida is unique in that even though it has a large number of college students of Hispanic descent, they represent the diversity among Hispanic Americans. The State of Florida has the third largest Hispanic origin population after California and Texas. Of those, Cubans account for the largest Hispanic population in Florida (U.S. Census Bureau, 2010).

The purpose of the study was to investigate and report the physiological and psychological benefits provided by a self-selected wellness and physical activity course on a multi-ethnic 2 -year college population from a large metropolitan city in the Southeastern United States. This study has the potential to be significant because it samples one of the most multicultural educational institutions in the United States with a large Latino student population. It seemed appropriate to conduct the study in a multiethnic setting because of the increasing ethnic diversification in college campuses and general society, as well as the scarcity of information on this topic particularly with minority populations. Concurrently, there is a lack of research on the topic of physical activity performance, attitudes and behaviors in reference to racial and ethnic diversity within college students. 
The current study provides data for the implementation of future health and wellness programs and provides information on how a sample of a college population with one of the largest Hispanic student enrollments in the United States significantly benefited from a self-selected health and wellness course. The benefits of such a class may be very significant from a health and wellness viewpoint since statistics show that in $2007,45.6 \%$ of Hispanic men over the age of 18 who resided in the U.S. were overweight and $34.6 \%$ of Hispanic women were overweight (CDC, 2009). In addition, this study demonstrates the value of a two or three credit required health and wellness course at the collegiate level throughout the State of Florida or other institutions. It provides evidence for educational policy decisions on behalf of a physical activity course for all college students.

\section{Background}

Studies show that participation in physical activity declines in a large segment of first-year students in college during the transition from high school to college. Bray and Born (2004) examined the incidence of vigorous physical activity of incoming high school students in college. Self-reported measures of exercise behavior indicated that there was a marked decline in physical activity among students transitioning from the last 2 months of high school to the first 2 months of college.

A meta-analysis of the behavior of college students in reference to physical activity reported that the number of students on college campuses who are physically inactive was $40 \%$ or higher (Guan et al., 2005). Results of the study also indicated that the present interventions being created for students by health and physical activity professionals in most institutions of higher education are not producing the desired results 
of increasing healthy behaviors among students. Colleges and universities are not including physical activity in their general education requirements. If they were, it could conceivably increase knowledge of positive lifestyle behaviors and provide more opportunities for students to engage in physical activities. Researchers also indicated that there is a lack of research on the topic of physical activity levels of college students (Guan et al., 2005).

Previous studies have tried to answer questions about the value of health and wellness courses for college students. Are physical activity courses an answer to the continued decline in physical activity by college students in the U.S.? How beneficial are these classes when offered or required at colleges and universities? Adams and Bryntenson (1995) investigated the effects of conceptually based classes on the attitudes and exercise behaviors of college alumni. The results indicated that those students who participated in a required two credit course which included lectures on various health related topics and an exercise component placed significantly greater value on the physical education program they attended and remained more physically active after they graduated from college than those students who chose a class from a category of requirements that included art, music, speech and physical education.

In contrast, other studies have reported different results. DeLong (2006) examined college students' motivation to be physically active as well as the effects of a required physical activity course on their level of physical activity. The results indicated that there was no significant evidence to support the notion that a required physical activity course increases the physical activity patterns of students. It was also established that participating in a required physical activity class did not influence the students to 
continue to exercise after the class was completed. However, a limitation of their study was that it was conducted in a small, predominantly White liberal arts college with a religious affiliation from a small city in a Southeastern state (DeLong, 2006). Cardinal et al. (2002) also found similar non-significant results in their study involving a required physical fitness course conducted with a mostly Caucasian student population. Students taking the required lifetime fitness for health course showed minimal improvement in behavior change toward exercise outside of class when compared with the comparison group made up of psychology students. The discrepancy exists in these studies about the value of fitness courses, as well as the lack of data reflecting how Hispanic college students from various countries of origin and Black college students are affected by a health and wellness course.

\section{Theoretical Framework}

The theoretical framework for assessing the physiological and psychological results of college students enrolled in a health and wellness class was based on Bandura's Theory of self-efficacy, which contends that self-efficacy beliefs provide the foundation for human motivation, well-being and personal accomplishment (Pajares, 2002). The stronger the perceived self-efficacy, the greater the effort placed by individuals to execute a behavior that may be considered difficult to attain (Bandura, 1986). Students with a strong sense of selfefficacy are intrinsically motivated and will usually overcome barriers better when presented with difficult tasks. Students with high self-efficacy will make a strong commitment to accomplishing their educational objectives and attribute failure to things which they can control. In reference to exercise participation, self-efficacy beliefs are extremely important since self-efficacy beliefs will greatly impact the amount of effort individuals spend on an 
activity, how long they will continue to perform that activity in spite of the obstacles presented and how resilient they will be when faced with adversity (Pajares, 2002). Research has shown that there is a strong correlation between self-efficacy and exercise behavior (Sullum et al., 2000). Those individuals who continued to exercise despite having to face external or internal impediments such as time constraints and health problems; scored higher on exercise self-efficacy assessments than those participants with lower scores (Buckworth, Granello, \& Belmore, 2002). These results might be indicative that having the confidence in the ability to perform exercise consistently and successfully may be an important antecedent to one's future fitness-promoting behaviors.

\section{Research Questions}

The latest health statistics in the United States referring to the lack of physical activity by most individuals and the current obesity epidemic indicate that serious steps need to be taken to educate the general public about the benefits of physical activity and engaging in healthy behaviors (Flegal et al., 2010). Because college age is when we see the decline in physical activity, college is an exemplary institution for these principles of healthy living to be taught. Some institutions have a physical fitness course requirement that can be satisfied by activity classes in a particular sport, classroom-only education in nutrition, or other health related topic. Some, but not all colleges and universities require a two or three credit wellness and physical activity course. In the fitness course, students engage at least for one semester in a physical activity course where they are required to perform conditioning exercises that include aerobic activities and strength training, and are lectured on health related topics. Even though, physical activity and proper nutrition are public health objectives for Americans, colleges and universities are requiring fewer physical activity 
courses as part of the curriculum than in years past. Additionally, the majority of large universities and colleges with multi-cultural populations do not include a health and wellness course in their general education curriculum (Sparling, 2003 as cited in Sullivan et al., 2008) and previous research on participation in a required health and wellness course has been done mostly on small, private college populations. Prior research (Adams \& Bryntenson, 1995; Ermler \& Kovar, 1993) suggests one of the best health and wellness course structures includes providing knowledge to students on the benefits of exercise and actual participation in exercise. The various forms of that exercise and the actual combination of learning and doing have not been tested with a diverse population.

Three research questions guided this study: (a) What is the effectiveness of a selfselected, conceptually based health and wellness courses in developing the health related factors of cardio-respiratory endurance, body fat composition, muscular strength, muscular endurance and flexibility among a racially and ethnically diverse student population? (b) How does such a course impact the exercise self-efficacy level of racially and ethnically diverse students enrolled in the course? (c) How does a self-selected health and wellness course impact the knowledge of racially and ethnically diverse students on health issues and physical activity participation?

\section{Terminology}

Fitness: The ability to perform moderate to vigorous levels of physical activity for 20 minutes or more without undue fatigue.

Wellness: Optimal health and vitality, encompassing the six dimensions of well-being: physical, emotional, intellectual, interpersonal, spiritual and environmental.

Physical inactivity: Sedentary, literally "sitting" during most of the day. 
Physical activity: Any movement of the body produced by skeletal muscles that result in energy expenditure, especially through movement of large muscle groups, for example, carrying groceries, playing a sport at least once or twice a week.

Healthy lifestyle practices: The performance of healthy choices such as the consumption of nutritionally dense foods, stress management and avoidance of unhealthy habits such as alcohol, smoking and drug abuse.

Exercise: A type of physical activity that requires planned, structured and repetitive bodily movement with the intent of improving or maintaining one or more components of physical fitness, (e.g., step-aerobic class, strength training, Pilates class) on a consistent basis.

Self-efficacy: Refers to the belief in one's ability to successfully take action and perform a specific task. In reference to exercise, it is the belief that one will perform exercise consistently regardless of any impediments or obstacles.

Health-related fitness program: Fitness programs that are prescribed to improve the individual's overall health such as cardiorespiratory endurance and muscular strength and endurance.

Intensity: In cardiorespiratory exercise, how much effort is put forth during exercise to improve or maintain fitness. This combination of activities is based on the amount (intensity $\mathrm{x}$ duration) of activity performed during the week and uses the concept of METs (metabolic equivalents) to assign an intensity value to a specific activity.

Moderate physical activity: Cardiorespiratory exercise that requires an intensity at $60 \%$ of maximal capacity. Physical activity performed 5 days per week. 
Vigorous physical activity: An exercise that requires a MET (metabolic equivalent) level equal to or greater than 6 METs $(21 \mathrm{mkl} / \mathrm{kg} / \mathrm{min})$. 1 MET is the energy expenditure at rest, $3.5 \mathrm{ml} / \mathrm{kg} / \mathrm{min}$. METS are defined as multiples of the resting metabolic rate. Examples of activities that require 6 METS are aerobics and cycling at a minimum of 10 to $12 \mathrm{mph}$. Cardiorespiratory exercise that requires an intensity level above 60 percent of maximal capacity.

\section{Delimitations}

The study was conducted at a 2-year college composed primarily of White and Black Hispanic students as well as many Black students mostly of African-American descent and Haitians with a small number of students from other ethnicities. This is a multi-cultural community with a large enrollment of students in a metropolitan area in South Florida. The results may not be generalizable to two-year colleges that do not have a large diverse enrollment or to 4-year universities. Yet, the student diversity paralleled the enrollment growth in higher education and population growth in society and reflected the future population of higher education (NCES, 2007). This sample included majority (Caucasian) and minority students, therefore moving the research forward. A large sample of men and women who were enrolled in several health and wellness courses were recruited for the study as the experimental group. A comparison group was composed of students enrolled in a Student Life Skills course who were willing to participate in the study. In addition, surveys and questionnaires were used. These are self-reported instruments where it is assumed that participants will respond honestly and accurately to all questions. 


\section{Chapter II}

\section{LITERATURE REVIEW}

The literature review will be discussed under the following categories: Status of wellness programs in colleges and universities in the United States, relationship between fitness self-efficacy and fitness behavior, relationship between knowledge of fitness and fitness behavior of college students, research on impact of fitness classes on fitness behaviors of individuals, impact of required fitness classes on the behavior of college students and physical activity patterns of racial and ethnic minorities with an emphasis on college students.

\section{Status of Wellness Programs in Colleges and Universities in the United States.}

The college years are an important time for young adults to be positively influenced regarding lifetime physical activity. During this period of time, young adults are moving through a transition in their lives, as for most of them it is the first time they live away from home. Engaging in physical activity can result in many physical and psychological benefits for all college students and particularly to all college freshmen (Grubbs, \& Carter, 2002). In short, physical activity can help in reducing stress and create an overall sense of well-being.

The university curriculum offers an excellent forum to raise the level of awareness and knowledge of health related fitness and provides opportunities for students to develop positive lifestyles in terms of wellness behaviors. Physical activity courses are extremely important and often counter balance the negative lifestyle associated with the traditional college lifestyle, such as sleepless nights due to studying, poor dietary consumption, along with high levels of academic stress. Well-structured fitness and activity programs can address all of these factors. A study conducted by Sparling and Snow (2002) indicated that 
alumni that engaged in physical activity during their senior year in college, had greater motivation for continued exercise participation beyond the college years.

The importance of influencing this population cannot be overstated, especially since research has shown that a large number of college students throughout the nation are demonstrating patterns of behavior that are very harmful to their health (NASPE, 2007). The prevalence of physical inactivity among college students calls for immediate action. Healthy Campus 2010 identifies physical inactivity as one of the six priority health risk behaviors for college populations. Guan, Keating, Pinero and Bridges (2005) conducted a meta-analysis to investigate the behavior of college students in reference to physical activity. This was done because few studies had been conducted on physical activity in higher education. The researchers found that most studies focus on the percentage of physically inactive students and on physical activity preferences. According to various surveys, it was found that the students' overall physical activity levels were not higher than the general population and some studies even stated that approximately 40 to $50 \%$ of the students were not physically active.

Guan, et al. (2005) followed the physical activity patterns of students to identify those who were in need of immediate interventions to increase their physical activity levels due to their sedentary lifestyle, and also to be able to predict students who were more likely to be physically inactive later in life. It was found that the majority of students who exercised regularly during their senior year in college, continued to do so 5 to 10 years later. Guan et al. (2005) examined age, gender, ethnicity, physical activity history, and health status of the participants, and the results indicated that age was a determining factor in physical activity. Students younger than 30 years of age were more likely to engage in more vigorous physical 
activities than those who were over 30 . Gender was also a determinant of physical activity since it was found that men were inclined to participate in weight lifting and team sports while women chose aerobics, dance and yoga. Men also participated for longer periods of time than women.

Health issues that specifically concern college students such as the excess intake of alcohol could be addressed in a required wellness and physical activity course. The Surgeon General of the United States has established reducing binge drinking among college students as a major health goal for the nation (Healthy People, 2010). Binge drinking is referred to the consumption of at least five continuous drinks for men and four continuous drinks for women during a 2-week period. It has been reported that approximately 2 in 5 college students engage in binge drinking (Wechsler, Lee, Nelson \& Kuo, 2002). This style of drinking among college students is associated with serious negative consequences, including academic difficulties, antisocial behavior, physiological and psychosocial problems, high risk sexual behavior as well as drinking and driving which is responsible for many deaths and injuries (Presley, Leichliter \& Meilman, 1999; Wechsler, Kuo \& Lee, 1999). Wechsler, et al.'s 2002 study stated that underage students had a tendency to drink less frequently but were more likely to drink to excess when they drank. In spite of stricter laws prohibiting the sale of alcohol to people less than 21 years of age, college students have reported that alcohol is easily accessible. Drinking by both underage and of-age students were related to their living arrangements. When students lived off campus with parents or in substance-free dorms, the incidence of binge drinking was lower than for those who lived on campus. Most of the drinking was done in off campus bars and off campus parties. In reference to exposure to educational materials, some students reported having attended a lecture, a workshop or 
even taking a special course on alcohol. However, none of the students were required to take any health courses where the topic of alcohol and its consequences were addressed.

The American College Health Association collects data every year and produces a report named the Collegiate National Health Assessment. Forty-eight postsecondary institutions participated in the Fall 2007 report with a total of 23,044 surveys being completed by students on campuses which were located throughout the nation in rural and metropolitan areas, large and small campuses and inclusive of two and four year colleges from private and public institutions. The $A C H A-N C H A 2007$ report indicated the medical problems that most students confronted were allergy problems, back pain, sinus infection, and depression. Stress was a major contributor to academic difficulties with $32.9 \%$ reporting being stressed as a result of academic difficulties. The total reported percentage that used alcohol during one or more days within the past 30 days was $61 \%$ cigarettes $13 \%$ and marijuana 11\%. Among college students, who consumed alcohol in the last year, many reported various consequences. For example, $31.1 \%$ reported doing something they later regretted, and $26.2 \%$ reported forgetting where they were or what they had done.

In reference to nutrition and exercise a total of $53.1 \%$ of participants were exercising to reduce their weight, while $34 \%$ were dieting to lose weight. In addition, $60.8 \%$ of college students reported eating one or more fruits per day and $28 \%$ indicated not participating in vigorous exercise for 20 minutes or longer once or twice a week. However, $32.3 \%$ of the students reported exercising for more than 20 minutes once or twice a week. The percentage of overweight or obese students was reported at 36.6 percent. In the area of mental health, $64.5 \%$ reported being overwhelmed by all they had to do anywhere from one to ten times 
within a 12 month period. Additionally, $64.4 \%$ felt exhausted most of the time but not from physical activity and $63.5 \%$ felt very sad.

Limitations to this study were that $75.2 \%$ of the participants were White with $4.7 \%$ being Black and $6.9 \%$ of Hispanics or Latino origin which is not representative of the overall student population presently in colleges and universities (ACHA, 2007). This study was descriptive of students' behavior, but its purpose was not to document the effectiveness of physical activity courses to deter negative lifestyle behaviors or suggest interventions.

It is essential to recognize that for entering freshmen, college life without the limitations and restrictions of home life can be very exciting and yet very stressful. Traditional college students enter the university setting immediately after high school, approximately at the age of 18 or 19 years. They are faced with new academic workloads and social and lifestyle adjustments. This is an opportune time to provide them with adequate health and wellness information and physical activity and to teach them how to establish healthy lifestyle behaviors. However, research shows that a large number of students engage in several risky behaviors including alcohol use, tobacco use, physical inactivity and unhealthy dietary practices (Von Ah et al., 2004). It is estimated that approximately $25 \%$ of all college students smoke and $75 \%$ of those continue to smoke into later adulthood placing them at risk for cardiovascular diseases, which is the number one cause of death presently in the U.S. (Flay, 1993). According to the Center for Disease Control and the U.S. Health and Human Services (1999), the highest rate of decline in physical activity occurs in early adulthood period between the ages of 18 and 24 years which is in most cases when students complete high school and begin their college years. Therefore, identifying factors that 
influence health protective behaviors in college students and developing health promotion and prevention of diseases warrants further attention.

The barriers and benefits of engaging in physical activity for college students have been studied in several forums. Some of the perceptions obtained from students in reference to the benefits of exercise include an increase in their level of fitness, improvement of body image and muscle tone and that exercise gave them a sense of accomplishment (Grubbs \& Carter, 2002). Barrier statements fluctuated from "exercise is tiring", "it is hard work" and "it is fatiguing", to "exercise takes too much time".

Gyurcsik et al. (2006) conducted an ecologically based examination of barriers to physical activity with students from seventh grade through the first year at the university. The barriers were classified in five groups, intrapersonal, interpersonal, institutional, community, and public and physical environment barriers. The findings revealed that as student school years increased so did the barriers to exercise. More significantly were the data demonstrating that college students named health issues such as injury or illness and lack of sleep as intrapersonal barriers. The most significant interpersonal barrier to exercise was social invitations during workout time and for institutional barriers it was school workload was too much to allow time for physical activity. They also named lack of sports team and lack of transportation to facilities as the community barriers. In reference to physical environmental barriers, the weather being too cold or getting dark too early was the main complaint. From a practical perspective, if college students are required to take a physical activity course to graduate, then some of these barriers would be eliminated because exercise would become part of their required class work since the physical activity class would be part of the curriculum and therefore, become the structure upon which the 
foundation of physical activity would be created, rather than leaving physical activity participation for leisure time.

Several national reports such as the Surgeon General's report of Physical Activity and Health of 1996, Healthy People 2000 and Healthy People 2010 have documented an increase in obesity and chronic disease in the adult population of the United States. In spite of these reports, most American colleges and universities are not requiring students to enroll in conceptual health and wellness courses that educate the body as well as the intellect. Oxendine, 1969, 1972; Oxendine \& Roberts, 1978 (as cited in Hensley, 2000) reported that until the mid-1960s, the majority of colleges and universities required some type of physical activity course from their students. However during the 1970s, this number declined steadily. At the present time, the requirement of physical activity courses is more prevalent among small and private institutions with an enrollment between 1,000 and 5,000 students (Hensley, 2000). The primary reason for the elimination of physical activity courses has been due to the reduction in the overall general education requirements in institutions of higher education. A large number of colleges and universities do offer concept-based courses that combine lecture and exercise participation but as an elective course not a requirement listed in the general education curriculum. At a time of decreasing health, institutional intervention efforts in the curriculum have also decreased.

\section{Relationship Between Fitness Self-efficacy and Exercise Adherence}

According to Albert Bandura (1997), self-efficacy is the confidence that one can accomplish a goal or activity in spite of obstacles or barriers that may arise. Self-efficacy is created from the combination of four principal sources of information, which are enactive mastery experiences, vicarious experiences, otherwise known as modeling, physiological 
factors and social persuasions. Enactive mastery experiences are the most influential of the four sources of efficacy because they provide evidence of whether a person can overcome barriers in order to succeed. The more successful a person is in accomplishing a task or event, the greater his/her efficacy will be when confronted with obstacles or barriers that he can indeed complete the event. However, failures can cause the complete opposite, that is, the more failure a person experiences the more likely he/she is to withdraw from completing or engaging in an event because of discouragement due to failure.

Modeling or vicarious experiences serve as an effective tool for promoting a sense of self-efficacy. When a person perceives someone else of same or similar abilities being successful, this raises his her self-confidence to the belief that helshe can also succeed in mastering an activity. Similarly, if someone who is competent fails at a task in spite of giving maximum effort, it can lower the self-confidence of those trying to model that person. People will have a tendency to model others when they have not had enough knowledge or personal experiences to rely on their own capabilities. People can always raise their self-efficacy by measuring their own successes versus their failures. However, modeling that delivers effective coping strategies can increase person self-efficacy of individuals. Modeling can be a very powerful influence especially when individuals are unsure of themselves.

Physiological and emotional states can provide individuals with a sense of vulnerability and ineptitude when faced with elevated levels of stress or when high demands are place on the body from activities involving strength, or stamina (Bandura, 1997). When individuals feel fatigued after participation in an activity, it usually leads to 
a sense of vulnerability and diminishes efficacy. Affective states can also play a major role on efficacy. People will interpret the physiological results of physical activity according to their somatic states. Some may push themselves to the limit to improve their physical capabilities. Others will interpret the increased heart rate, perspiration and increased respiration as an overwhelming feeling that is intolerable. This interpretation of physical activity leads to lower efficacy and the desire to perform at lower levels of intensity or none at all to avoid the fatigue and aches related with increasing levels of physical activity. Thus, it is the person's belief in the implications of their physiological response that alters their self-efficacy, rather than the sheer power of the response.

Verbal persuasion refers to encouragements or discouragements given by significant people. Individuals that are persuaded verbally about their capabilities to perform a task or event will be highly motivated and increase their efficacy to complete such task. A sense of personal efficacy can be sustained much easier when people are assured by those they respect that they have the abilities to overcome obstacles and master the event. People will have a tendency to believe in their capabilities if the verbal encouragement stems from individuals who are highly competent in the same activity or are very knowledgeable based on years of experience in the activity.

The benefits of pursuing healthy habits and engaging in physical activities for lifetime benefits have been documented in the literature extensively (CDC, 2006, Healthy People, 2010). However, "the perceived inefficacy barrier to preventive health is all too familiar in people's resignation about health risks, such as smoking or obesity, over which they can exercise control" (Bandura, 1997). Assumed self-regulatory efficacy has 
been found to be a predictor of whether people adhere to an exercise or physical activity program or not. Those with a low sense of self-efficacy will be the first ones to drop out and those with very little self-doubt will most likely stay to complete the program. Exercise efficacy can then be measured by the commitment of individuals to perform exercise regularly in spite of the obstacles and barriers they may confront from a social, situational or personal perspective.

The social cognitive theory (SCT) is a psychological theory that advocates that human behavior is dictated by the interrelationship of three factors: behavior, environmental and personal. According to SCT, learning is acquired when these three factors converge to guide and inform the individual how to proceed. Efficacy beliefs affect each of these phases of personal change. Since the SCT is based on understanding an individual's reality construct, it is very useful in the field of behavior identification and health promotion. Most research performed in the field of physical activity interventions uses SCT as the theoretical foundation for many of their intervention efforts. The theoretical constructs of SCT most widely targeted have been social situation and self-efficacy (Hortz, 2005).

Petosa, Suminski and Hortz (2003) measured the constructs of Social Cognitive Theory (SCT) in predicting the future behavior of college students towards vigorous physical activity. They focused on social support, self-regulation, self-efficacy, outcome expectancy, exercise role identity and positive exercise experience as predictors of vigorous physical activity among college students. The results indicated a very low percentage of students engaging in programmed physical activities at high intensities. 
Approximately 45 percent of the students in the study did not perform any type of vigorous physical activity at all, and only $2.3 \%$ averaged five days or more of vigorous physical activity. Statistical data from a multiple regression analysis indicated that each of the SCT variables were contributors to the prediction of vigorous physical activity by the subjects and useful in the study of exercise patterns of behavior among college students. Low SCT constructs resulted in low self-efficacy to overcome perceived barriers to exercise.

The study was valuable in providing suggestions to academic programs in health and physical education on how to increase the development of self-regulation skills for college students through instructional programs and actual life experiences. For example, students can be encouraged to join student clubs and participate in intramural sports. For those individuals who are not competitive, moderate-intensity activities with student appeal can be offered such as Zumba (combination of various dances) Pilates (core exercises), step aerobics and kick boxing to mention a few. The overall goal would be to develop activities that appeal to the entire student body regardless of their activity pattern. This in turn, may develop self-efficacy to exercise, as students become more efficient overcoming barriers to exercise if interventions are created to increase self-regulation skills. It was also suggested that educational programs in health and wellness courses should develop exercise adherence strategies by providing realistic expectations from exercise programs and enhancing positive experiences that may contribute to the increase of physical activity patterns in college students. 
Doerksen et al. (2009) examined social cognitive predictors of moderate and vigorous physical activity in college freshmen. Students from a variety of majors, non-athletes were recruited for the study. Participants were asked to wear an accelerometer that measures movement for seven days at the end of the semester. Their exercise self-efficacy was assessed with an 18-item exercise self-efficacy scale. In addition, participants were asked to identify their physical activity goals for the semester in terms of how much exercise they expected to perform throughout the semester and the outcome expected from exercise adherence. To determine the contribution of the social cognitive variables to exercise performance, several multiple regression analyses were performed. Moderate physical activity and vigorous physical activity were the dependent variables. The results indicated a correlation of the social cognitive variables with each other. However, none of the social cognitive variables were significant predictors of moderate physical activity. BMI was a significant predictor of physical activity at moderate intensities but not at high or vigorous intensities. The results also showed no correlation of outcome expectations to either moderate or vigorous physical activity. Only self-efficacy and physical activity goals were found to be significant independent predictors of vigorous activity. Interventions that increase these constructs, particularly self-efficacy and goal-setting strategies may increase physical activity participation of college students who are in a stage of life where healthy lifestyles can be learned and adopted. A strength of this study is that physical activity was measured objectively with an accelerometer and not from a survey which decreases the certainty of results.

As previously mentioned, Guan, Keating, Pinero and Bridges (2005) investigated many cognitive determinants in relationship to physical activity and special attention was given to 
self-efficacy. High self-efficacy usually resulted in a high physical activity participation level. In fact, it was the most significant contributor for positive changes toward exercise behavior among female students. They emphasized that students will not increase their physical activity simply because they are told that they should engage in exercise, and that extra efforts were needed to promote physical activity among college students. It was indicated that a possible strategy to combat physical inactivity in college students would be to change requirements of physical education in order to better educate students as to the need to engage in physical activities on a regular basis. Knowledge would create the precondition for change. It was also suggested that conducting health and fitness appraisals along with monitoring services might assist students in establishing consistent physical activity patterns. Additionally, a health and wellness course inclusive of exercise programs with enjoyable and suitable activities would involve students into a weekly pattern of physical activity that may predict enduring changes in lifestyle habits.

Results from a study conducted by Dishman et al. (2005) indicated that adolescents who have confidence in their ability to perform physical activities will be less influenced by barriers to exercise, and engage and enjoy a variety of physical activities. Adolescent girls from $6^{\text {th }}$ and 8 th grade were recruited from various regions across the nation. The measures used for examining whether self-management strategies facilitated the relationship between self-efficacy and self-reported physical activities were four cognitive and four behavioral strategies. Self-management strategies, such as time management techniques and selfefficacy about physical activity were measured with an eight-item questionnaire that included statements such as "I can be physically active during my free time on most days no matter how busy my day is.” (p.12). Perceived barriers and outcome expectancy about 
physical activity, and physical activity were also measured. The statistical analysis provided support for self-efficacy and self-management strategies as having direct effects on physical activity. Outcomes of the sixth grade model indicated that self-efficacy had a direct effect on all of the variables. However, this was not the case with eighth grade girls as no direct association between self-efficacy and physical activity was observed among the eighth grade participants. The study supported the perspective that interventions on self-efficacy, as tools to overcome barriers may be an important objective for teachers to provide adolescents in the physical education environment. These interventions included scheduling the physical education classes towards the end of the school day to alleviate the barrier of "feeling conscious about their looks" due to perspiration from physical exertion. In addition, providing a selection of physical activities from low intensity, e.g., pantomime, mirror image, balloon activities and popular dances to more intense games and sports such as tag games, step aerobics, basketball and volleyball among others, may be helpful in alleviating the decline in physical activity in adolescent girls. The use of self-management strategies may equally increase self-efficacy in young girls. Yet, the lack of significance for eighth graders suggests more research is needed on self-efficacy interventions to increase participation in physical activity.

Stimpson (2000) used the Transtheoretical Model of Change to evaluate the level of physical activity among the populace in various counties of Virginia. This model of change stipulates that people go through changes in their lives via five stages namely precontemplation, contemplation, preparation, action and maintenance. This model of change has been used extensively for the incorporation of healthy behaviors such as smoking cessation and the initiation and continuation of physical activity. The study was performed 
on mostly White females from the age group of $40-59$ who were members of a program created in Virginia to ensure that the people of Virginia would have healthy communities, emphasizing nutrition, wellness and family and child development.

The main purpose of the study was to determine barriers to exercise, stages of exercise and preferences for activities for participants. Various surveys were administered to the participants including one for self-efficacy indicating areas of negative effect, possible relapses and inclusion of physical activity in their daily plans. Results of the self-efficacy measures showed that those individuals that had the highest self-efficacy scores were in the action or maintenance stage of exercise participation. In addition, those participants that were in the pre-contemplation or contemplation stage had lower self-efficacy scores than those in the action and maintenance stage. Even those that were in the contemplation stage had lower scores than those in the action stage. In essence, self-efficacy was significantly related to the stage of exercise among all of the participants.

The results of the study clearly indicated that those in the action and maintenance stage had a high level of confidence that they would continue to exercise even in the presence of barriers such as time constraints or tiredness. It clearly demonstrates support for Bandura's theory that the confidence that people have about performing a certain behavior will seriously affect the performance of such behavior and the importance of fitness self-efficacy in adults.

In another study, college students were recruited for a research project where the Transtheoretical Model of Change was implemented as a means to promoting muscular fitness behaviors. This study was the first to examine the processes of change, behavioral and cognitive as well as self-efficacy in relation to muscular fitness-promoting behaviors. 
Two direct discriminant function (DDF) analyses were performed with self-efficacy, and using the behavioral and cognitive processes of change as the independent variables (Cardinal \& Kosma, 2004). The structure coefficients which analyzed the correlation between each predictor and the first discriminant function indicated that the behavioral processes of change; the process by which a person navigates through stages from not changing at all, to contemplating change, action and so on until the behavior is actually changed; were the most important followed by self-efficacy. The second DDF analysis indicated that almost all of the predictors increased across the stages of change with the exception of stimulus control. In essence, the results of the study sustained that the behavioral and cognitive processes of change as well as self-efficacy contributed to predicting the stages of change for muscular fitness-promoting behaviors. This information is valuable for fitness professionals interested in developing interventions for college students that are concerned with initiating, maintaining or increasing muscular fitness. For example, behavioral contracts may be used to incite students to take personal responsibility for their muscular fitness as well as developing and monitoring their improvement periodically. Another strategy could be focusing on the benefits of muscular fitness, providing easy access to equipment, and teaching techniques on exercise performance.

However, the study had several limitations such as identifying costs versus benefits of participation in an exercise program; the development of a sound psychometric design to measure the pros and cons linked to muscular fitness-promoting behaviors and most important of all, the sample of students was from a fairly homogeneous group of active college participants. It was indicated that further studies should be performed among groups of various ethnic backgrounds, functional levels and age groups. Several studies have 
supported the premise that self-efficacy can be a predictor of moderate and/or vigorous activity in adolescents and college students and merits further study with more diverse populations.

A study was conducted to investigate the relationship between exercise self-efficacy and wellness in a college population. Sidman et al. (2009) tried to determine wellness perceptions related to beliefs about physical activity and exercise self-efficacy. As previously mentioned, exercise self-efficacy has been found to be a reliable predictor of physical activity behavior. However, Sidman's study tried to find a correlation between exercise self-efficacy and the six dimensions of wellness which are physical, psychological, social, spiritual, intellectual and emotional. A large number of students from a mid-Atlantic university who were enrolled in a physical activity and wellness course were recruited for the project. They were given a Perceived Wellness Survey (PWS) and a self-efficacy and exercise habits survey to assess the psychological concept of self-efficacy in the physical activity context. The questionnaire measured the participants' confidence to participate in physical activities for at least a period of six months.

Several statistical analyses were used to interpret the results of the data including a bivariate analysis and standard multiple regression analysis. The results indicated that exercise self-efficacy was significantly related to overall wellness and to all of the dimensions of wellness except for social wellness in the bivariate correlations. The regression results indicated that exercise self-efficacy was a significant predictor of physical, spiritual, intellectual, psychological and emotional wellness. Additionally, the participants indicated a greater ability to adhere to a program of physical activity even when they lacked time. Students with higher self-efficacy were more likely to continue exercising after eight 
weeks than those with lower self-efficacy. Perhaps social wellness was not associated with exercise self-efficacy because it is best addressed in terms of social support and should be assessed separately from exercise self-efficacy (Sidman et al., 2009). Limitations to this study were the use of self-reported surveys with no other adjunctive data and also the lack of randomization since only students in the physical activity and wellness class were recruited for the study. The population of participants in the study was obtained from a mostly white, female sample. The replication of this study with ethnically and racially diverse populations is well advised.

\section{Relationship Between Knowledge of Fitness and Behavior for Fitness of College}

\section{Students}

Is there a relationship between knowledge of fitness and actual behavior and performance of physical activity? If knowledge predicts behavior, then significant knowledge might be gained through a required health and wellness course, particularly one that focuses on healthy living and lifelong activity skills. Perception of health-related knowledge may contribute to students choosing to engage in healthier lifestyle habits with an increment in physical activities upon completion of a wellness course. There are several studies that examined these assumptions.

Bryntenson \& Adams (1993) conducted a comparative analysis of alumni from four colleges where the participants had been required to complete conceptually based physical education courses in three out of the four colleges and with each college having different participation requirements. Group A was required to take a wellness course every semester, group B was required to take four courses of wellness, group C was required to take four semesters of wellness but combined with personal health courses and group D only had to 
take one course from a list of various general education courses such as art, music, speech or wellness. The results indicated that those students in group A, students required to take a wellness course every semester, not only improved their knowledge of health related topics but also placed greater value toward fitness and increased their exercise habits. Those students in groups B and C also placed a greater value on exercise and exercised more days per week than those in group D. The alumni from groups A, B, and C exercised more frequently, were more knowledgeable about fitness and maintained a more positive attitude towards exercise and fitness than those alumni in group D which supports the theory that student participation in a health and wellness course will lead to more knowledgeable students in the topics related to health and wellness and will also lead to more physically active students.

Research conducted by McCormick and Lockwood (2006) on the perception and knowledge among college students enrolled in a lifetime wellness course revealed valuable results. Pre and post perception and knowledge questionnaires were given to participants. The hypothesis was that both perception of physical education classes and knowledge of fitness and healthy behaviors would increase as a result of the lifetime wellness course. Prior research conducted by McCormick and Lockwood (2006) led them to the assumption that health promotion courses are sometimes perceived as easy courses, and as such, students believe their self-knowledge of fitness is accurate and as a result, physical activity courses appear to be simplistic and unnecessary. However, students may not have a thorough understanding of wellness and its various components. In this study, the students' knowledge was particularly low on the topics of cardiorespiratory endurance, muscular strength and endurance, flexibility, nutrition and cardiovascular health out of a total of 14 
topics taught in the class. The pre-test results on knowledge increased from a total of $34 \%$ to $72 \%$. Results of the study revealed that students enrolled in the lifetime wellness course improved their knowledge and perception of fitness significantly. In addition, students learned important information on cardiorespiratory endurance, nutrition and cancer among other topics. Similar results were obtained by Avans (2003) in her study of kinesiology majors and non-majors in reference to knowledge of basic fitness principles. It was found that for the non-majors the responses were incorrect on $37 \%$ of the questions from over $75 \%$ of the participants. For the majors, the results were higher with over $54 \%$ answering the questions correctly. The results of the post-test indicated an increase in the correct responses from all participants of both groups. Both of these studies only looked at knowledge and did not assess changes in actual physical fitness.

Research was conducted by Adams et al. (2004) on the topic of transfer of knowledge to physical activity participation by students who had taken a conceptual Health Related Fitness Course (HRF) and the retention of knowledge after 16 weeks of course completion. The findings indicated that the experimental group retained knowledge learned in HRF courses at an acceptable level and although there was no statistical significance in the activity reports, there were significant gains in the students attitude toward physical fitness and the value placed on the wellness course. The results of this study provided strong support for conceptually-based fitness courses in colleges and universities in order to educate a population of mostly young adults currently enrolled in these institutions.

A secondary analysis conducted by Adams, Graves and Adams (2006) which included alumni that had never taken a physical activity course compared to those that were currently taking it and to various groups that were classified from 1 to 52 weeks after having taken the 
course to those that had taken the course over 157 weeks prior. The overall findings were that students do retain knowledge of fitness for a minimum of four years when enrolled in a conceptually -based health related course. Their studies revealed that a college wellness course can increase students health related knowledge in the short and long term. However, the previously mentioned studies were mostly conducted with a population of college students from small, private colleges. The present research compiled a sample of students from a large metropolitan public college with a large percentage of minorities, mostly Hispanics and Blacks.

Yet, the question remains: will the knowledge obtained in the classroom transfer to actual behavior modification? Studies conducted by Park, 1988; Taggart et al; (as cited in Hildebrand, 1995) have shown that knowledge of health related topics and the benefits of physical activities do not necessarily transfer to actual participation of physical activities. Apparently, teaching health concepts to students does not necessarily imply that they will transfer the knowledge into a lifestyle of exercise and participation. Other studies have resulted in similar conclusions, Cardinal, Jacques and Levy (2002) assessed the efficacy of a university course which was aimed at promoting exercise behavior. This was a universityrequired knowledge and activity course lasting 10 weeks. The objective was to assess the effect of a wellness course on the students' leisure time exercise behavior. The researchers conducted a quasi-experimental study with three groups, one of them composed of students enrolled in a required wellness course, a second group which was previously enrolled in a wellness class and currently taking a psychology class and a third group that had never taken a wellness course and was enrolled in a psychology class. 
Exercise behavior was measured with a questionnaire on the leisure time of participants. The Transtheoretical Model of behavior change was used for measuring the stages of change of participants. The required wellness course taught material contained in a fitness book and students had to attend lectures twice a week for 50 minutes and complete a 2 hours activity based lab once a week. The statistical analysis was performed using a repeated measures ANCOVA with age as the covariate. The analysis resulted in three main effects, for group, stage of change and time. There were also four interaction effects for group: stage of change, group by time, stage of change by time, and group by stage of change by time. The alpha was set at $\mathrm{p}<.05$. In general, the improvement in stage of change for exercise behavior was as follows: $17.8 \%$ of those in the wellness course group improved, $28.1 \%$ in the prior wellness course group improved and 30\% of the participants in the group without a wellness course improved. Since those students who are already in the maintenance stage cannot improve, a secondary analysis was done for those who were in the pre-contemplation stage through to the action stage. Again, significant differences were found among the groups, those in the wellness class improved $35 \%$, those in the prior wellness class improved $49.1 \%$ and students in no wellness class improved $41.7 \%$. In essence, the subjects in the wellness class increased their exercise participation by a minimal level over those in the two other experimental groups. The results indicated a minimum improvement by the students enrolled in the wellness class which may indicate that the wellness class was not effective in influencing behavior change for exercise in the participants (Cardinal, Jacques and Levy, 2002). The results suggested that the participants in the prior wellness class or no wellness class may have learned behavior skill development from the psychology course and that wellness courses needed to have more behavioral skill development so that 
students learned and maintained healthy behaviors. Results from these studies seem to indicate that there is a need to revise curriculums in the wellness courses to increase interventions that will increase behavioral skill development rather than merely providing information and knowledge on the benefits of exercise participation. For example, providing activities that will increase or build upon the awareness of the participants' health status and physical activity patterns. In addition, the use of goal oriented activities for specific purposes such as weight loss, gaining muscles mass, etc. and addressing obstacles and impediments that would preclude the participants from engaging in physical activities on a regular basis (Cardinal \& Spaziani, 2007). Yet again, this study used a predominantly White population.

\section{Research on Impact of Fitness Classes on Fitness Behaviors of Individuals}

The facts reported by the surgeon general of the United States cannot be overstated. Nearly half of American youths whose age range is from 12 to 21 years of age are not participating in vigorous physical activity (CDC, 1999) and participation in physical activity declines as the age or grade in school increases. Are required physical activity courses an answer to the continued decline in physical activity by college students in the U.S.? How beneficial are these classes when offered or required at colleges and universities? Adams and Bryntenson (1995) investigated the effects of conceptually based classes on the attitudes and exercise behaviors of college alumni. Data was gathered from alumni of two private conservative Christian colleges. The schools were quite similar in their philosophies and physical education facilities. However, college A was teaching a physical activity class as a conceptually-based physical education (CPE) class with lecture component and exercise participation, while college B was teaching an activity-based physical education (APE). The 
researchers wanted to find out the differences between alumni in knowledge obtained, exercise habits learned and attitude toward fitness. College A required a two credit course which included lectures on cardio-respiratory fitness, body composition and other health related subjects. In addition, the students participated in exercise sessions during class and took a cardiovascular test such as jogging or cycling to measure improvement in performance throughout the semester. The sample consisted of 413 alumni who graduated from 1982 to 1987. College B had a physical education program that did not require a physical education class but it could be selected from a category of requirements that included art, music, speech and physical education. No health tests were given or fitness concepts taught in this class, it was an APE one credit course. The sample of 567 alumni included those who graduated between the years of 1978 to 1984 .

The instrument used for measurement was a modified survey, previously used by the researchers in 1992 and 1993 while conducting other studies. The questionnaire asked demographic data as well as perceived value that the subjects placed on physical activity and their current exercise behaviors. The questionnaires were mailed by the physical education department chairpersons to a random list of alumni. The researchers wanted to find out if there were differences among the alumni based on the type of required class that was taken. The results of a one way MANOVA with five dependent variables indicated statistical significant differences between the participants of college A and college B. A Post-hoc independent $\mathrm{t}$-test showed that alumni that participated in a required CPE valued their learning experience and their college's physical education program more than those that participated in the APE courses. Alumni from college A placed more value in their physical education department because of the contributions it made toward their knowledge of fitness 
and exercise habits. The alumni from college A remained more physically active after they graduated from college than those from college B. The researchers concluded that the alumni that participated in the CPE program placed significantly greater value on the physical education program they attended in comparison to those from college B who received only APE courses.

The strengths of the study were that the researchers had conducted previous investigations on this topic in same or similar colleges. They were using a survey instrument that had content validity established by experts and the comparison groups were homogeneous in that these were two private, conservative Christian colleges. The student populations had similar ratios in gender and ethnicity as well as mean age of incoming freshman and academic scores. However, the limitations indicated by the researchers were that the study only measured the perceived knowledge the alumni had, not the actual knowledge and that the statistical effect size for each group was low, which may indicate that the "real" difference between the groups could be relatively small. As a result, they suggested further studies to be conducted on the topic. Another limitation found in the study was that the alumni from college A were younger than those in college B because of the different years in the data collection and this could account for them being more physically active than their counterparts in college B. The study was done in two small private Christian colleges with a large number of Caucasian students which would indicate that the results can only be applied to the same predominantly White populations of students.

In contrast, the present study was conducted in a Hispanic Serving Institution (HIS), which is also populated, by a large number of non-Hispanic Blacks and Caucasian students. The rate of overweight and obesity in Hispanics and non-Hispanic Blacks has doubled in the 
last decade according to the CDC, 2009. One factor may be due to the differences in dietary patterns of Hispanics and Blacks over Whites. Studies have shown that Blacks and Hispanics are more likely to consume foods that are fried and high in fat while Caucasians are more likely to use lower-fat alternatives and modify foods to make them lower in fat (Gans, et al., 2003). In addition, Hispanics read less nutrition labels than any other group and Blacks consume less fat from milk or cheese than Whites while consuming more fat from meats (Kristal, Shattuck \& Patterson, 1999). Well-designed health and wellness programs with more effective interventions for diverse populations may be beneficial to improving the health status of Blacks and Hispanics.

Research indicates that there are many determinants associated with physical activity participation in adults. Factors associated with physical activity have been categorized as demographic and biological (age, education, gender, etc.) among others. It has been found that men engage in physical activities more than women, and people of lower income levels have lower rates of physical activity than those with higher income. Even after adjusting for socio economic factors, Blacks and Hispanics perform less physical activities than Whites (Popkin, Duffey \& Gordon, 2005). There are also environmental factors such as access to facilities, climate, and cost of program that can be related to physical activity participation. Some variables from the psychological, behavioral and social categories can also present a support or hindrance for participation in physical activities as in the case of self-efficacy, perceived barriers and benefits, social support and intention to exercise. Finally the type of activity offered, intensity and perceived effort are also determinants of physical activity (Sallis \& Owen, 1999). 
Colleges and universities are excellent settings to promote physical activity participation in students. The priorities listed by Healthy People and Healthy Campus 2010 list physical activity as the leading health indicator for college students (ACHA, 2010). The majority of college students are between the ages of 18 and 24 with 57\% being females. The lack of participation in physical activities by women has been reported by the 1996 Surgeon's General Report on Physical Activity as well as other sources (Buckworth, 2001).

Buckworth and Nigg (2004) focused their research on physical activity, exercise, and sedentary behavior in college students at a large Midwestern university who were taking elective conditioning activities. Questionnaires were used to measure exercise behavior, physical activity history and sedentary behaviors. The results indicated significant differences between men and women on variables on sedentary behaviors and physical activity. Men reported higher levels of exercise but also more hours of computer use or watching television than women. The use of computers by men was negatively associated with the time they spent exercising or doing strength training and frequency of exercise participation. For women, watching television was negatively related with physical activity participation as well as typical exercise frequency and moderate and vigorous physical activity during the past year. However, studying was positively correlated with the duration of exercise and strength training.

Significant relationships were also found between age and physical activity. The older students performed less physical activity and used computers for longer periods of time whereas younger students spent more time doing vigorous activities and also reported performing physical activities during the previous 12 months more so than older students. Results of the study seem to indicate that participation in exercise needs to be targeted by 
health promotion programs in colleges and universities to combat sedentary behaviors of students during their free time.

Motivational factors for physical activity in college students may be to improve skills already obtained in sports related activities, others may want to use physical activities to improve fitness or for weight control but as a general consensus, they seem to want to participate in physical activities for enjoyment and because they have had positive experiences in previous physical education or physical activity classes (Hildebrand \& Johnson, 2001). Therefore, colleges and universities may benefit from modifying their physical activity interventions to draw the attention of students and increase participation in exercise activities.

In addition, the method of instruction used by the institution can make a difference on the effectiveness of the course to provide knowledge and fitness to the students. Ermler \& Kovar (1993) were interested in determining the effect of three different lifetime fitness classes on various parameters. College students were enrolled in three fitness classes that met twice a week for 14 weeks. One class had a lecture and an activity lab per week. A second class had three lectures and one activity lab during a period of two weeks and the third class had 20 minutes of lectures and 20 minutes of activity during every class meeting. The instructor was the same for all three groups, the course objectives and the type of activities given to all three groups were the same. It was hypothesized that all of the groups would improve from pretest to posttest on recovery heart rate, intent to exercise and attitude toward exercise. Physiological data such as the step test for cardiovascular endurance and flexibility testing were collected and psychological measures were equally evaluated with questionnaires. 
Results indicated a significant improvement of all groups from pretest to posttest. Statistical results indicated varying significant levels for the dependent measure among the groups. All three class structures were effective in improving intention to exercise and flexibility. However, group three had the highest improvement in recovery heart rate of all the groups. In essence, the study indicated that the way in which the curriculum is structured in physical activity courses will produce different outcomes and at least in this research the class with a combination of lecture and exercise participation, improved the cardiorespiratory endurance level of students more effectively than those in the other two groups.

In other physical activity intervention studies, behavioral intention to exercise and increases in physical activity performance were not found to be significant. Project GRAD conducted by Calfas et al.(2000) provided physical activity interventions to college students not only to investigate the benefits of such courses but also to evaluate long term maintenance of physical activity behaviors learned during participation in the interventions. Students participated in 50 minute lectures for 15 weeks and also participated in supervised physical activity labs once a week lasting longer than one hour. A comparison group attended 2 hour lectures during 15 weeks and covered health related topics.

An 18 month follow up intervention was conducted via mailed literature on various fitness topics with follow up phone calls by peer health facilitators. The effects of the intervention were analyzed and at the 2-year follow up period there were no significant group differences for both men and women. The conclusions ascertained from the study were that the intervention of the health course enrollment was not effective in promoting the continuation of physical activity participation among the subjects and even though women 
improved in total physical activity after the intervention, it was not maintained during the follow-up period. The intervention and comparison groups did increase their levels of physical activity but only during the class, then they gradually decreased to the baseline after two years. These results once again present serious challenges to curriculum designers of health and fitness courses and to physical activity instructors.

There is a need to develop practical and effective approaches during the creation and implementation of health and fitness courses. Interventions need to steer away from teaching exercise participation simply because it is beneficial to the students' health and instead attempt a motivational approach that will elicit more of an intrinsic motivation, one which brings forth students that want to participate in physical activity because it is enjoyable, fun and it creates a feeling of satisfaction. This would be the main objective of a wellness course. However, this does not occur in most cases due to numerous variables such as teaching format, class setting and grading constraints among others.

\section{Impact of Fitness Classes on the Behavior of College Students}

Some universities and colleges do require students to complete a physical activity course as part of the academic curriculum needed for graduation. Several studies have been conducted to investigate the impact of required physical activity courses on physiological and psychological related factors of physical activity. Thomas M. Adams II, a Professor at Arkansas State University has collaborated with various researchers in studying the effect of required fitness courses on the attitudes and behaviors of alumni and the possibility of lifetime changes occurring as a result of completing physical activity courses or a combination of conceptual physical activity courses with physical activity labs. In 1990, Bryntenson, Adams and Schollmeier studied the physical activity behavior of alumni at Oral 
Roberts University (ORU). This is a private, Christian institution that requires full time students to complete a health and physical education course every semester. Previous studies at the same university conducted by Bryntenson (1985) had indicated significant improvement in fitness, knowledge and attitudes of students and that the concept of fitness was being implemented effectively at this institution. However, the post graduate physical activity behaviors had not been measured extensively. ORU alumni were compared to another private Christian college which required only one semester of a health and physical education (HPE) course and did not require field tests or enrollment in conceptual classes of physical education. A large random sample was obtained from students that had graduated from 1977 to 1988 from both institutions and the participants completed questionnaires. The findings indicated that the alumni from ORU had been positively affected by the HPE courses, their knowledge and physical activities had increased, and they were more active than students from the institution in comparison. Results seemed to indicate that the continuous engagement of students in a physical activity course may create a physically active lifestyle not only during their enrollment at the institution but also after graduation.

Similar studies were performed by Adams and Bryntenson in 1992 when they compared four colleges that provided physical education courses with varying degrees of physical activities. In essence, the greater the requirement, the more valuable it became for the students and the greater their exercise participation after graduating from college. Programs that require students to know the value of exercise, the how, why and when of physical activity as well as their physiological and psychological benefits appear to be more successful in terms of the performance and knowledge of physical activity by alumni. When four programs of physical education were compared in reference to knowledge and attitudes 
of alumni, it was found that those programs which included academic information on healthrelated topics as well as the component of physical activity as requirements, resulted in students with a more positive outlook and better understanding of physical activity than the program which offered physical activity alone (Bryntenson \& Adams, 1993). Similar results were obtained when Adams and Bryntenson (1995) conducted a study of alumni who took a required activity course in comparison to more recent graduates that were taught a conceptual physical activity course after modifications were made to the physical education curriculum. The alumni that had been enrolled in the conceptual courses placed greater value on the physical education course and were more physically active than the group that was only required to take physical activity courses while in college. A possible explanation for the increase in cardiovascular participation of the group enrolled in the conceptual course over the physical activity course group could have been the age difference. However, statistical tests were conducted to analyze the differences and the possibility of the younger group being more active due to age was rejected. A major limitation of all of these studies is that they were conducted in private conservative colleges with a lack of diversity in ethnicity and race.

In a similar study Pearlman et al. (1997) surveyed 2,000 college alumni to find out if a required physical education course had improved their knowledge of fitness and influenced their lifestyle habits. The majority of the participants were Caucasian with 3\% African Americans. Both genders were surveyed with the women being overrepresented 57\% over $43 \%$ of men. Questionnaires on knowledge, attitudes and behaviors were sent to the participants. Two private colleges were chosen for the study, college A had alumni that were required to take a fitness course and college B students that had not taken any fitness 
course. Students from college A were knowledgeable about their blood pressure and cholesterol levels. College A alumni felt that the required course had a positive effect in their lifestyle habits and it was demonstrated by their exercise habits and lifestyle habits. College A alumni participated in more sports activities and were more likely to run or jog than those from college B. They also smoked less, and were likely to consume less dietary fat and less sodium in their diets.

Although some universities, mostly private, require their students to complete a course on health and wellness prior to graduation; only a limited number of studies have assessed the efficacy of these courses. Data from this literature review has shown that the health and wellness courses have the potential to positively influence the heath behaviors of college students as well as their physical activity performance (Cardinal, Jacques, \& Levy, 2002). To that effect, Blaser (2005) conducted a study at Brigham Young University to assess the impact of three types of physical education courses from which students could choose to meet the health and wellness general education requirement. One course was taught in the face-to-face format with a conceptually based course that covered all aspects of health and fitness including nutrition, cardiovascular health and human sexuality among other topics. Another course was taught online and a third method was based on physical activity participation that focused on sport skill development without any lecture format. Three instruments were used to assess the changes in health behaviors; a health and wellness inventory derived from the Center for Disease Control's Behavioral Risk Factor Surveillance System Survey Questionnaire, a health attitudinal scale and a demographic inventory. Data analysis of between and within the groups was conducted for each nutrition and physical activity behavior. Results indicated that the online course had the smallest 
impact on students' nutrition and physical activity participation. The physical activity class had a clear impact on the students' physical activity behavior but not much on the nutrition aspect and the conceptually-based class (face-to-face format) had the largest impact on both the nutrition aspect and physical activity behavior improvements.

The principal limitation of the study was the use of self-reported surveys. No actual physical fitness tests were given to the students. In addition, the study was conducted with mostly Caucasian students in a private university with a religious affiliation. This population may not have been representative of the present U.S. college student population. However, the end result of the study was that a conceptually-based class provided in a face to face format was most effective in improving the nutrition and physical activity behaviors of college students and the suggestion that long term studies be conducted by other researchers.

Physiological testing of students to investigate the benefits obtained from school required activity was the focus of Hazelwood's study (2007). She recruited three groups of students with different physical activity behaviors: athletes, students enrolled in a required physical activity class and a comparison group of "monitor only". Fitness measures and surveys were given at 4 different times throughout the research. Very sophisticated evaluative equipment was used to determine the fitness levels of the participants; they were tested on blood pressure, and changes in blood pressure while training. Other physiological

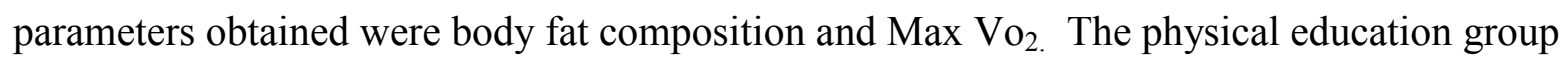
achieved the lower of the blood pressure measurements of all three groups. Overall, the majority of the participants from all three groups obtained positive benefits from the experience such as changes in behavioral habits, more sleep, consuming less junk food and 
exercising more per week. The major barrier was school work and exams which prevented them from exercising more often. The fitness profiles indicated positive results for the physical activity intervention group and the athletes and unfavorable fitness profiles for the "monitor only" group. In addition, over 50\% of those in the physical education group and the athletes stated that they felt more motivated to continue exercising due to having a structured program of exercise.

The results clearly indicated physical activity courses can be effective methods of promoting fitness and reducing the risk of diseases later on in life. However, there are several limitations of the study. It was conducted in an institute of technology, with an enrollment less than 3,000 students. The male to female enrollment ratio in this university was higher for males which is opposite to the national trend with $71.5 \%$ female high school graduates enrolling in college to $65.9 \%$ males (U.S. Bureau of Labor Stats, 2008) and the study was conducted with 54 students. As a result, it can be assumed that this study can be not be generalized until it is conducted in a setting where there is a better proportion of the overall student population represented inclusive of multiple ethnic representations and larger data.

A study was conducted in Canada with students enrolled in a health and wellness college class. Over 800 students completed a survey rating themselves on ten wellness practices at the beginning of the semester and towards the end of the semester. In the pretest, the highest scores were on safety and sexuality with very low scores for physical activity and nutrition. However, upon completion of the course, post-test results revealed improvement in seven wellness scores. After analyzing students' assignments it was found that their knowledge and affect had increased at the completion of the wellness course 
(Wharf-Higgins et al., 2010). The results support the perspective that a well-designed health and wellness course may increase knowledge of health related topics and overall student wellness.

\section{Physical Activity Patterns of Racial and Ethnic Minorities with an Emphasis on College Students}

Research shows that historically, Hispanics and Blacks are less active than Whites (Kriska \& Rexroad, 1998) which may be a contributing factor to a large number of Hispanics and Blacks suffering from chronic diseases. Since Blacks and Hispanics are less involved in physical activities than Whites, they may benefit from exercise interventions that would increase their activity levels. Even though data showed that Hispanics have a higher incidence of hypertension, obesity and heart disease when compared to non-Hispanic Whites (Mitchell et al., 1990), research on Hispanics' behavior in relation to physical activity was very scarce as was research on interventions to increase exercise levels during leisure time that considered diverse ethnic populations.

This pattern of sedentary living by the Hispanic population seems to affect even youngsters of school age. A study conducted by Butte, et.al, (2007) investigated the patterns of physical activity in overweight and non-overweight Hispanic children. Results indicated that the types and levels of physical activity that children engage in are correlated to their gender, age and body mass index (indicator of cardiovascular risk factor). The youngsters in the study were less active as age increased, boys performed more high intensity activities than girls and overweight children were more sedentary than non-overweight children. Overweight children were found to engage in sedentary activities such as watching TV, playing computer and video games and talking on the phone. A comparison of the National 
Health and Nutrition Examination Survey (NHANES) III of 1988-1994 with the most recent NHANES of 2003-2006 indicated an increase in obesity for Mexican American boys aged 12-19 from 14.1\% to 22.1\% and in Mexican American girls aged 12-19 an increase in obesity from $9.2 \%$ to $19.9 \%$. The statistics are alarming, and if interventions are not created for adolescents to become more involved in physical activities, the already high obesity rate and its associated illnesses will continue to demise the Hispanic population.

Marquez et al. (2004) compiled studies from 1991 to 2003 with a total of 20 studies that were of a qualitative nature and mostly completed by women. Self-efficacy was reported as the most common reported psychological outcome in women being highly motivated to participate in exercise; as the self-efficacy levels increased so did their participation in physical activities. This was found to be particularly true in Mexican American females of all ages. Social support was also a correlate of physical activity. Those individuals that had a greater level of social support to exercise were more likely to engage in physical activities or sports. The barriers that were present for most urban Latino women were lack of time and energy as well as having child care responsibilities and being self-conscious about their appearance. For those women who actually engaged in some type of activity whether it was joining a walking club or some other type of self-paced activity, a decrease in the perceived barriers was reported. Yet, other studies reported fear of injury and illness as major obstacles to physical activity. In reference to attitudes and beliefs, the results of various studies suggested that Hispanics had a more negative attitude toward exercise and less healthy eating habits than non-Hispanic Whites. They were more resistant to change which warranted interventions to educate them on the benefits of healthy nutritional habits and physical activity. 
Limitations of the studies were extensive; there is a need to conduct research to determine what interventions will influence exercise adherence, not just report on the lack of activity of Hispanics. It is also imperative to conduct studies that will include factors such as socio-economic status, race and gender to develop interventions. The literature used in this review had several cross-sectional studies with very few programs offered for Latinos to increase physical activity. In addition, it is important to be sensitive to the various cultures when creating interventions for exercise. The studies were conducted on either Mexican Americans or a combination of minorities without conducting studies on a specific race or ethnic group other than Mexican Americans. The examination of correlates by race and ethnicity is very important in creating programs that are culturally sensitivity to those populations. The levels of acculturation of various groups were not taken into consideration in some of the studies. This is an important factor since it has been reported that Mexican Americans that are acculturated to the U.S. have a tendency to use more tobacco products and consume less healthy diets than those who are still attached to their Mexican values and dietary habits. However, Crespo et al. (2001) cited that people who are more accustomed to the American way of life also engage in more physical activities during the leisure time. Providing physical activity interventions for Hispanics that are culturally appropriate may increase their engagement in exercise and fitness which will ultimately facilitate an improvement in their quality of life.

The Educational Resources Information Center in its report of 2001- 2002 indicated that the representation of Hispanics/Latinos in college increased over 200 percent from 1976 to 1996 (Snyder, 2003). However, this statistic is relative to those Hispanics who completed high school and the high school graduation rate of Hispanics is low with $57 \%$ in comparison 
to non-Hispanic Whites with $88 \%$ high school graduation rate (U.S.Census, 2003). A favorable aspect of Latinos graduating from high school is that they enroll in college immediately after completing high school at $66 \%$ which is comparable to other groups such as Whites $68 \%$ and African Americans at $60 \%$. A more recent report from the National Center for Education Statistics (NCES, 2007), indicated that Hispanic college enrollment has had a $372 \%$ increase while Black student enrollment has gone up 103\%. These statistics are indicative of the type of student population that will be enrolling in the near future in U.S. colleges and universities. Hispanics in the United States originate from 19 countries, each with its own cultural background and distinctive ethnic peculiarities. It has been found that there are significant differences in leisure-time physical activity in the various Hispanic subgroups (Neighbors, Marquez \& Marcus, 2008). Interventions need to address the various cultural factors and diversity among these Hispanic subgroups to help them adopt and maintain a program of physical activity and targeted efforts should be given to the various racial and ethnic groups that are increasingly enrolling in our colleges and universities.

Overall, the enrollment of minority groups including Asian, Pacific Islanders and Indian/Alaskan Natives has risen at a faster rate than that of Whites. However, most Hispanics enroll in two-year colleges and usually they are Hispanic-serving institutions(HSI). Even though Hispanic enrollment has increased in the last two decades, most studies conducted on Hispanic populations have been primarily on MexicanAmericans. The present study was conducted in a college which is a two-year, Hispanicserving institution but whose population is mainly composed of Cubans, Colombians and Nicaraguan-Americans, and descendants of Hispanic countries in addition to Mexico. The study investigated the impact, positive, negative or none at all, that a self-selected physical 
activity course had on health-related fitness results, knowledge and exercise self-efficacy in a diverse population of students predominantly of Hispanic and Black descent.

McMahan, Cathorall \& Romero (2007) performed research in a Hispanic Serving Institution to find out if Hispanic college students were knowledgeable on health related issues such as cardiovascular diseases (CVD). Diseases of the heart are the number one cause of death among Hispanics and most everyone; therefore, establishing appropriate health related behaviors is very important in the prevention of heart disease. They concluded that Hispanic college students had inaccurate information on the number one cause of death in the United States and limited knowledge on the risk factors of heart disease. It is crucial that Hispanic college students are educated on health related issues given that the Hispanic population is affected by several CVD risk factors such as obesity and Type II diabetes (National Diabetes Information Clearinghouse, 2004 as cited by McMahan, Cathorall \& Romero, 2007.)

Due to results from research indicating that minority college students have a low profile of physical activity performance during leisure time, Hall, Kuga \& Jones (2002), conducted a study using data from five universities in Pennsylvania to establish the exercise determinants that contributed to exercise performance in minority groups from various colleges. Participants were 62\% African Americans, 9\% Hispanics and 29\% Asian. A battery of questionnaires was used to measure physical activity performance, exercise benefits versus barriers, reasons for exercise, and stage-of-exercise adoption measures. Results from gender and race indicated that males are more likely than females to engage in sports of high intensity levels, whereas women will engage in aerobic activities more than sports with moderate to low levels of intensity. In addition, African American and Hispanic 
women have been found to be less active than their male counterparts in physical activity in general. Young men, regardless of race, were more physically involved in activities and participated for enjoyment and greater fitness whereas weight control was the determinant factor for women to engage in exercise participation. Correspondingly, other studies reflected similar patterns of exercise behavior among minority populations (Ainsworth et al., 1992; Kelly, 1994, 1995).

Sullivan et al. (2008) conducted a study on minority community college students and compared the leisure time-exercise spent by students enrolled in a physical education course or some other health course to a group of students who were enrolled in other courses at the college. Those in the physical education course were required to meet twice a week for approximately 1.5 hour performing physical activities such as aerobic exercise and resistance training. Anthropometric data were collected on waist and hip circumferences, blood pressure and height and weight. In addition, the experimental and comparison groups were given questionnaires on leisure-time activities. Age, gender and race were used as independent variables. Approximately $64 \%$ of the students were Mexican-American, $31 \%$ were African-American and 13\% were Asian-American. The results indicated that almost $66 \%$ of the participants were either overweight or obese and $45 \%$ were categorized as prehypertension that means that they are at high risk factors for heart disease. No significant difference was found by the demographic variables of age, race and gender. A weekly Leisure-Time Exercise Questionnaire was used to record the physical activity data of the participants

Participants who were taking physical education courses reported having a higher leisure-time exercise patterns than students not enrolled in physical activity courses. 
However, data result indicated that blood pressure and waist circumference were not significantly better in those taking the physical education courses. The researchers indicated that there is a need to perform in-depth studies on minority college students and the risks for cardiovascular diseases, and cancer among this population, which is steadily increasing in colleges and universities throughout the United States.

The results of the study suggests that students of different ethnicities and race are at high risk for lifestyle related illnesses such as cardiovascular disease, diabetes and cancer among others and would greatly benefit from a required health and wellness course at colleges and universities.

A limitation of this study and most others conducted on Hispanic populations is that they were conducted on Mexican-Americans and then the results were generalized as the "Latino population." However, Hispanics are people who have a Spanish ancestry but within this ancestry there are many ethnic variations such as religious beliefs, cultural norms, nutritional factors, and gender role expectations which fluctuate from one Spanish descending population to another. Giardina et al. (2008) argued that grouping Hispanics without consideration for social, historical, cultural, health, and socioeconomic distinctions impedes our understanding of lifestyle differences impacting behavior. Results of her study indicated that only $20 \%$ of Caribbean Hispanics had an active level of daily activity compared with $31 \%$ of Mexicans. In addition, lack of activity in Caribbean Hispanic women was greater (89\%) than among non-Hispanic White women (79.7\%) or Mexican American women $(61.5 \%)$.

Each country has its own cultural beliefs and educational attainment, which suggests that even though many times people of Spanish ancestry are grouped under one heading of 
Latinos/Hispanics, there is much diversity among these groups and special consideration should be given at the collegiate level to address the various issues affecting these college students; one of these issues being poor nutritional habits and lack of physical activity.

For example, the nutritional habits of Mexicans and other Central American countries are corn (maize) and beans (mostly black or pinto beans). Mexicans in particular will consume corn tortillas from which they create several stuffed foods such as tacos, flautas and enchiladas, accompanied usually with very spicy sauces. Conversely, Salvadorians use the corn to produce a different type of tortilla or small cake (pupusas) filled with meat, cheese or beans. The consumption of animal products is scarce for low-income families due to its cost, and the tendency is to consume sausage and pork fried rinds which are less expensive but higher in fat content (Kitler \& Sucher, 2001).

Beef is a foundation in the diet of most South Americans from Argentina, Uruguay and Brazil. Traditionally, siders of beef, pork and goat are grilled slowly for hours. Rice is a staple food in Brazil which accompanies the national dish called feijoada, a combination of black beans cooked slowly with smoked meats and sausages and served with toasted cassava meal. The kidney, brain and tripe are considered delicacies for many South Americans ( Kiple \& Ornelas, 2000).However, Peruvians and Ecuadorians prefer a diet of fish and seafood in the coastal regions with its popular dish ceviche, a citrus-marinated seafood, and in the mountains a diet consisting mostly of potatoes with many varieties found in the mountainous regions. In the Caribbean, islanders prefer rice and beans as a staple in their diets with a combination of cassava or plantains and entrees often being fried in lard. The Spanish influence can be seen in the foods cooked in Colombia and Venezuela with the use of olive oil in many of their meals in addition to cheese, garlic and onions. In reference to 
beverages, coffee is very popular in Brazil and other South American countries such as Colombia, and Ecuador, while Yerba mate, a tea-like beverage ingested for its medicinal properties, is consumed mainly in Argentina, Uruguay and Paraguay. The traditional Hispanic diet is low in vegetables, especially green vegetables and relies heavily on grains and beans, but within the Hispanic subgroups there are many regional differences in terms of the composition of the diet, its preparation and the accompanying beverages based on traditions and historical background.

As previously stated, South Florida has an extensive number of immigrants from Cuba, Colombia, Nicaragua along with Mexicans and other Hispanic groups (U.S. Census Bureau, 2009). These variations may create differences in research results, and as such, ethnic differences were incorporated as independent variables for this study. For example, from a socio-economic standpoint, students from Central America are less likely to complete a college education. In the year 2000, Cubans had the highest percentage of high school graduates who continued to enroll in undergraduate higher education with $41.7 \%$ while Central and South American high school graduates had a 37.2\% of students who enrolled in undergraduate higher education (not including Mexicans who had the lowest graduation rates) (Fry, 2002 as cited in Torres, 2004).

The different educational status of various Hispanic groups may be significant in determining physical activity participation. S. J .Marshall (2007) led a team of investigators to study the effect of race and social class on the prevalence of physical inactivity. They analyzed data collected using the National Physical Activity and Weight Loss Survey (NPAWLS). The findings indicated that Hispanics who did not complete high school were the most inactive with $32.3 \%$ and Black men with a college education had the highest rate of 
physical activity with 96\%. Prevalence of leisure time inactivity was highest for those with lower incomes within each racial and ethnic group. Social strata were even more prevalent among women.

Siu (2003) conducted a study to examine the influence of self-efficacy and social connection on physical activity participation for different ethnic groups. A life style survey was administered to a sample of the U.S. population in 1999 and analyzed with various statistical models. The variables used were age, income, gender and education. In addition, social connections, e.g. social gatherings, hosting a party; self-efficacy and physical activity were measured. The results indicated that White women who have better social connections and higher self-efficacy engage in more physical activity. Among blacks, there was a linear relationship between self-efficacy, income level and physical activity; a higher income level ensued higher self-efficacy and thus greater participation in physical activity. In the case of Hispanics, neither self- efficacy nor social connections had any effect on the connection of age and physical activity. Higher income was influential in creating better social connections which in turn lead to more participation in physical activity for both Whites and Hispanics. African Americans engaged in more physical activity when they had a greater sense of self-efficacy and more social connections, especially males. The study showed that gender, age, income and education were significant determinants of physical activity.

Overall, the more education a person had, the more physically active the person was. However, there were differences in what influenced certain ethnic groups to participate in physical activity. The findings recommended that different methods of instruction and interventions be used depending on the population represented at the college or university. Curriculums should reinforce strongly the development of self-confidence and efficacy and 
create social networks via clubs and intramural competitions for students to develop social connections and engage in physical activity.

African Americans have a high risk for illnesses associated with sedentary living such as hypertension and heart disease (Chepyator-Thomson, Russell \& Culp, 2007). A number of studies have identified low levels of physical activity in African American adults, especially in women. Research from Ainsworth, Berry, Schnyder and Vickers (1992), as well as LaPorte, Haile and Huller 1986 (as cited in Kelley \& Kelly, 1994), have reported that African Americans of college-age perform physical activity at approximately less than 2,000 kcal per week which is rated as a low level of physical activity. Kelly and Kelly (1994) researched the physical activity patterns of a sample of college students from a historically African-American university. All students were enrolled in a required physical activity class for freshmen. The study collected data on various measures of physical activity levels. A physical activity history questionnaire was given along with the Lipids Research Clinics Physical Activity Questionnaire (LRCPAQ) to measure physical activity patterns of the participants. Other computed statistics were based on gender, age, height and weight to determine body mass index and class standing. The results of the study indicated that a large percentage of the young African American college freshmen did not participate vigorously in physical activity on a daily basis, specifically females. Even though the limitations of the study indicated that the research was conducted with a small and limited sample size, the results clearly showed African American college students not participating in moderate to intense physical activities (30 to 60 minutes of physical activity) and males being more physically active than females. 
Suminsky, et al. (2002) compared the physical activity patterns of various minority groups (including Asian, African-American, Caucasian and Hispanic) of college students. Using self-reported measures of physical activity and collecting data on height and weight, results indicated that African American females had the second highest rates of no participation in physical activity after Asian females, and Hispanic men had the highest rates of no participation in physical activities in comparison to the other male ethnic groups. Many explanations have been proposed to account for the low levels of physical activity in African American adults. It has been suggested that it is due to insufficient education or the lack of a culturally responsive curriculum that will encourage students to be physically active from an early age. For example, women may be less informed about the importance of physical activity because since an early age they may have been taught to take care of household related activities and possible lacked a role model that would influence them to the benefits of regular physical activity. In some Hispanic cultures, girls are chastised if they participate in games and physical activities that boys participate in a regular basis. These taboos can be tempered by a culturally responsive curriculum that will teach girls the benefits of being physically active throughout their lifetime.

The prevalence of physical inactivity in African American females is much higher when compared to other minority groups. For example, McArthur \& Raedeke (2009), reported in their study of race and sex differences in college students that Black female students were the most overweight and the least active which increases their risk for chronic illnesses.

This pattern of physical inactivity was the topic of a qualitative study conducted with African American college females enrolled in a southern university. Researchers investigated the experiences these women had in their physical education programs from 
elementary school through high school and how this affected their participation in physical activity in college. Several themes emerged from the interviews and reflections from the women, such as the significance of physical education in schools. Most of the participants revealed a declining interest in physical activity as they moved on from elementary, to middle and high school. As elementary school students, most of them participated in physical activity during school hours and enjoyed after school activities such as kickball and basketball, but as they became adolescents they were less involved in athletics and more enthusiastic about academic work and social life. The pattern that emerged from their reflections was that the curriculum for physical education classes did not stress the relationship between physical activity and health. As the women grew older, they were required to take less physical education classes and very few of them actually participated in high school sports. It was also found that the women that did participate in varsity sports engaged only in track and field and basketball that were sports they felt competent in performing. Basketball and track and field are sports which have a large representation of well-known black athletes, and as such many African Americans engage in these two sports. These women were using these athletes as models to give them a sense of self-efficacy. They believed that they could perform well in basketball and track and field because many other black athletes had also been successful in these sports. However, unlike basketball and track and field, there are many other sports that can be performed throughout a lifetime such as golf, tennis, swimming and bowling (Chepyator-Thomson, Russell \& Culp, 2007). The authors suggest one rationale for youngsters not participating in these sports is due to the lack of African American role models. 
Cultural sensitivity and lifetime participation should be key factors in the development of physical education programs at all levels of the educational pyramid. McArthur \& Raedeke (2009) cited several studies that indicated that habits learned and performed during the college years might evolve into lifetime habits. Yet, several studies reviewed earlier showed mixed and no impact on long-term behavior from some courses. Continued efforts to increase exercise participation among college students are very much needed, particularly among minority students. Education is a critical factor in relation to participation of physical activity by all races and ethnic groups. Fitness programs need to address the various cultural and racial differences of college students in order to promote a physically active lifestyle. Exposing college students to recent creative interventions in physical fitness such as Pilates, spinning, Zumba dancing and kick-boxing could incite their desire to be physically active on a regular basis while incorporating a healthy and perpetual behavior in their lives.

Basically, the research presented in chapter two supported that most students of college age do not engage in physical activity at a healthy level and are not setting lifetime habits. The students enrolled in colleges that required them to partake in physical education courses benefited them health-wise, and they were more likely to continue to perform physical activities beyond the college years. The limitations of most of the studies were reflected in the fact that most institutions where the studies were conducted were private, small colleges with less than 10,000 students and with a homogeneous population of White students. The representation of minority students was extremely limited and, when minorities were present, they were mostly Mexican Americans and African Americans. There was a lack of ethnic diversity in the majority of the studies. 
The general purpose of the current study was to determine how students representing a variety of Hispanic and Black ethnic groups: Hispanic Caribbean, Hispanic South Americans, Hispanic Central Americans, Hispanic Americans, Black Caribbean, African Americans and other Black ethnic groups are influenced by a self-selected physical activity course. Research on predominantly White students has suggested that coursework which combining an educational component with an activity component may be most effective but merits further investigation. This study compared course content formats and their benefits for an ethnically diverse sample. The relationship between knowledge about the benefits of activity and the probability that students engaged in activity is well established only with White students. Therefore, it merits further investigation with minority students who may have different beliefs and barriers about exercise. This study was undertaken to determine if self-selected health and wellness courses impacted exercise performance, knowledge of health related topics and, exercise self-efficacy among racially and ethnically diverse students. 


\section{CHAPTER III}

\section{METHODS}

The purpose of this study was to investigate and report the physiological and psychological benefits provided by a self-selected wellness and physical activity course on a multi-cultural 2-year college population in a large metropolitan area. Three research questions guided this study: (a) What is the effectiveness of a self-selected, conceptually based, health and wellness courses in developing the health related factors of cardiorespiratory endurance, body fat composition, muscular strength, muscular endurance and flexibility among a racially and ethnically diverse student population? (b) How does such a course impact the exercise self-efficacy level of racially and ethnically diverse students enrolled in the course? (c) How does a self-selected health and wellness course impact the knowledge of racially and ethnically diverse students on health issues and physical activity participation?

\section{Research Hypothesis 1}

Participants in a 16-week program of health and wellness will decrease their body fat, increase their cardiorespiratory endurance, muscular strength, muscular endurance and flexibility at the conclusion of the semester in relation to the comparison group.

\section{Research Hypothesis 2}

Participants in a 16-week program of health and wellness will increase their confidence in participating in fitness activities more than the comparison group. 


\section{Research Hypothesis 3}

Participants in a 16-week program of health and wellness will become more knowledgeable in health related topics by the completion of the semester, than the comparison group.

\section{Treatment}

The study focused on a self-selected health and wellness course with an emphasis on the various health related components. The course was taught with primary and secondary objectives using the same content material based on two health and wellness textbooks. The primary objectives dealt with health related factors and the secondary objectives placed emphasis on the six dimensions of wellness: physical, intellectual, emotional, interpersonal/social, environmental and spiritual wellness. The classes met either twice a week for a period of 75 minutes or three times a week for a period of 50 minutes each session. Two health and wellness instructors who emphasized the six interrelated dimensions of wellness taught the course.

The health and wellness course teaches students the roles of exercise, physical activity, diet, and stress management in achieving optimal wellness. Students learned to assess their fitness and nutritional status and participated in exercise sessions most times the class met. The exercise sessions combined aerobic conditioning with strength training. Based on the syllabi provided by the instructors, at the end of the semester students were expected to have knowledge of: (a) the major health problems of the United States, (b) the elements of the six dimensions of wellness, (c) his/her current health and fitness status by completing the assessment techniques and comparing the results with optimal health standards, (d) how to develop a personal fitness program, (e) the steps needed to create a 
behavior management plan to change a wellness-related behavior (f) the heart and circulatory system, respiratory system, muscular system, nutrition and weight control along with principals of training and stress as they relate to the goal of attaining optimal health, (g) the correct method for developing strength, flexibility and cardiovascular fitness, (h) the determinants of exercise self-efficacy and methods to enhance exercise self-efficacy, (i) health consequences of obesity and selected terminology pertinent to exercise programs and lecture materials.

A comparison group also participated in the study. Students from a Student Life Skills course were given the same battery of tests as the students in the health and wellness course without receiving the instruction and exercise sessions of the experimental group. Comparisons of the pre-post tests were performed with the experimental group (health and wellness classes) and the comparison group (SLS classes) and data were compiled and statistically analyzed for significant differences.

\section{Institutional Review Board}

Permission to conduct the study was obtained from the Institutional Review Board from Florida International University who was overseeing this project and the college involved in the project. Informed consent was obtained of all participants for all of the fitness tests as well as written data. Subjects underwent pre and post fitness evaluations with five components measured. 1) cardiovascular endurance, 2) body fat composition, 3) muscular strength, 4) muscular endurance as well as 5) flexibility. They also completed a pre-post health and fitness knowledge test and an exercise self-efficacy questionnaire. 


\section{Participants}

Students from a large metropolitan two- year college with a diverse multi-ethnic population participated in the study. The student enrollment at this institution is approximately 130,000 students with a distribution of $60 \%$ female and $40 \%$ male. The breakdown according to race/ethnicity is $8 \%$ White, $69 \%$ Hispanic, $19 \%$ Black of African American descent and 4\% of other ethnic backgrounds. This institution does not require students to enroll in a credited course on health and wellness. The self-selected health and wellness course met twice a week for 1 hour and 15 minutes or three times a week for 50 minutes per session. It was composed of a physical activity participation component and a lecture component. Each class had approximately 25 students enrolled. A total of 6 sections of health and wellness classes participated in the study, totalling with 185 students. All student participation in the research was voluntary with no consequences to their grades if they chose not to participate. Convenience sampling was necessary in order to incorporate students who were enrolled in the self-selected health and wellness courses. Participants' demographic information was obtained as well as an informed consent form from each participant. A comparison group was obtained from students enrolled in a Student Life Skills course who agreed to participate in the project. Three sections of students from this course were enrolled for the study. Each class had approximately 25 students. The comparison group was given the pretest and posttest measurements but did not receive any lectures on fitness and wellness nor participated in required or instructor led exercise sessions throughout the semester. 


\section{Instrumentation}

A measure of self-efficacy for participation in vigorous physical activity created by Dwyer, Allison and Makin (1998) for their research on self-efficacy in high school students was given to students at the beginning of the semester and toward the end of the semester (See Appendix A). The inventory was then analyzed using an ANCOVA to identify the results of completing a self-selected personal wellness course on exercise self-efficacy of physical activity. The exercise self-efficacy instrument was partly derived from other instruments that had good psychometric properties such as the Reynolds et al. (1990) and McAuley (1993) physical activity self-efficacy scales. Dwyer, Allison and Makin's instrument is composed of 20 items that assess the degree of confidence on a 5-point Likert scale, ranging from (1) not at all confident, to (5), very confident to participate in vigorous physical activity if specific perceived barriers to physical activity are present (e.g., lack of time due to school work; lack of support from family; do not have fun). Their analysis of the data provided two factors, namely, selfefficacy to overcome external barriers and self-efficacy to overcome internal barriers. In addition, a global self-efficacy item was added questioning the degree of confidence that the students had to participate in vigorous physical activity at least three times a week. The 12-item external barriers subscale had a coefficient alpha of 0.88 and the 8 -item internal barriers subscale had a coefficient alpha of 0.87 (Dwyer et al. 1998). The subscales significantly correlated with the frequency of participation in vigorous physical activity. The instrument was also examined for reliability and validity. The external and internal barriers subscales that contained multiple items to represent the two specific domains appropriately had high internal consistency reliability. In order to establish 
validity of self-efficacy measure, Pearson correlations (two tailed) between the physical activity self-efficacy subscales and other measures were calculated. Both internal and external barriers subscale were significantly related to the global measure of self-efficacy. The correlation was as follows; global self-efficacy correlated $.40(p<0.0001)$ with the external barriers subscale and $0.28(p<0.0001)$ with the internal barriers sub-scale. Results of the Pearson correlations indicated the external barriers subscale correlating significantly and positively with frequency of participation in vigorous physical activity in physical education class $(r=0.10, p<0.01)$, in other school settings $(r=0.22, p<$ $0.0001)$, and outside of school $(r=0.28, p<0.0001)$. The internal barriers subscale correlated significantly and negatively with frequency of participation in vigorous physical activity in physical education $(r=-0.11, p<0.001)$, in other school settings ( $r=$ $-0.17, p<0.0001)$, and outside of school $(r-0.24, p<0.0001)$. These results demonstrated that the self-efficacy measure predicts participation in vigorous physical activity, which is an indication of criterion validity. In essence, the study showed support for internal consistency, criterion validity and discriminant validity of the self-efficacy measure.

Frequency of participation in vigorous physical activity was measured by asking students to report how many days in an average week they normally participated in vigorous physical activity, at the present time, in (a) physical activity class, (b) other settings (e.g., intramurals,), and (c) outside of school (e.g., fitness center; Dwyer et al, 1998).

A knowledge based examination on health related topics covered by two Health and wellness books Fit \& Well by Fahey, Insel, and Roth (2008) and In Pursuit of Fitness by Stokes, Rothstein, and Schultz (2009) was given to the participants at the beginning of 
the semester and then at the end of the 16 week course (See Appendix B). The health related topics included the dimensions of wellness: physical, emotional, intellectual, interpersonal, spiritual and environmental. In addition, the lectures covered nutrition, cardiorespiratory endurance, cardiovascular health, body composition, weight management, muscular strength and endurance, flexibility, stress and environmental issues. All wellness courses utilized the Fahey et al. (2008) textbook or the Stokes and colleagues (2009) book to teach the above-mentioned topics and exercise labs.

Instruments to evaluate physiological measurements were: cardiorespiratory endurance (CRE) was measured via 1.0 mile walk and 1.5 mile run, body fat composition was measured with the Omron Body Fat Analyzer, a bioelectrical impedance analysis (BIA) which measures impedance of the body to a small electric current. Muscular endurance was measured using the curl -up test and the push-up test to exhaustion, with women performing the modified push-up test. Muscular strength was evaluated using the grip strength Dynamometer and the Sit-and-Reach Test was used for flexibility. The fitness assessments are already a part of the course requirements and do not represent an additional burden for students enrolled in the experimental group.

\section{Body Fat Composition}

The participants were tested for body fat composition using the Omron Body Fat Analyzer. This is an instrument that measures body fat by using bioelectrical impedance which sends a mild electrical current through the participant's body to measure body fat versus lean body mass. BIA measures the impedance or resistance to the signal as it travels through the water that is found in muscle and fat. The more muscle a person has, the more water their body can hold. The greater the amount of water in a person's body, 
the easier it is for the current to pass through it. Basically, the lower the resistance, the greater the lean body mass and the more fat in a person, the more resistance to the electrical current going through the body (Fahey et al., 2009). The unit requires information on gender, age, weight and height. It calculated the participant's body mass index (BMI), another measure of body composition; and body fat percentage in less than 30 seconds. Bioelectrical impedance analysis has approximately 4 to 5 percent of error rate. Therefore, it is very important to follow the instructions given by the manufacturer and the same instrument should be used for all measurements taken. Acceptable body fat percentages in women are 25 to 30 percent and 18 to 25 percent in men.

\section{Cardiorespiratory Endurance}

Participants were also measured for aerobic endurance by completing a 1.0 mile walk for sedentary and overweight individuals and a 1.5 mile run for active individuals. Those participants that suffered from any type of injury or disease that did not allow them to participate in the 1.5 mile run, or those who were very inactive ( 0 to 1 day of PA per week), or had over $30 \%$ body fat were given the 1.0 mile walk. These cardiorespiratory endurance (CRE) tests are used frequently to predict $\mathrm{VO}_{2}$ max that is the volume of oxygen estimated to be consumed while exercising at maximum capacity $\left(\mathrm{VO}_{2}\right.$ max is the maximum amount of oxygen in milliliters used in 1 minute per kilogram of body weight.) One of the simplest and most accurate assessments of cardiorespiratory fitness is the 1.5 mile run. The objective of this test is to complete a 1.5-mile run in the shortest possible time. Individuals who exercise regularly and people with active lifestyles can usually complete the 1.5-mile distance jogging or running. Because this test requires individuals to complete the course as fast as possible, it is not the best option for sedentary people 
over age 30, for people who have a very low fitness level due to medical reasons, for individuals with joint problems, or for obese individuals. For those individuals with impediments, the 1.0 mile walk is better suited. The 1-mile walk test is another common field test to estimate cardiorespiratory fitness. The walk test is based on the same idea as the 1.5-mile run test: that people who have higher cardiorespiratory fitness will be able to complete the test faster than those with low cardiorespiratory fitness. This test is particularly good for sedentary and overweight individuals. The equipment required to complete a 1.5 mile run as well as the 1.0 mile walk is an oval track or a measured course and a stop watch (Powers \& Dodd, 2009).

\section{Muscular Strength}

Muscular strength by definition is the ability to lift a maximum resistance once. The hand grip dynamometer can be used to provide a rough estimate of strength and was the instrument used for this study due to the large sample size. The participant was instructed to place his/her elbow at 90 degrees and a few inches from the body. The dynamometer was gripped as hard as possible for a few seconds without making any other bodily movement. The dynamometer provided a reading in kilograms. Out of three trials given to participants, the highest score was recorded (Hoeger \& Hoeger, 2007).

\section{Muscular Endurance}

Muscular endurance is the ability to lift sub-maximal resistance during an extended period of time. The standard push-up test was given to men and the modified push-up test for women because they tend to have relative less upper body strength than men. The position for the standard push up test is in a prone position on the floor with the hands at shoulder width apart, arms extended and the body in a straight line with 
weight on toes. A push up is completed when the individual lowers his body to within two inches from the ground and raises himself back up keeping the body in a straight line. The subjects performed as many repetitions as possible without pausing. Women followed the same procedure but they placed their knees on the floor with feet crossed. The depth of push up for women is when the shoulders are at the same height as the elbows. When the participants were exhausted and could not perform a well-executed push up, the test ended.

Another assessment for muscular endurance is the curl-up test. This test was performed by lying down on the back with arms alongside of the body on a mat with a strip of tape barely touching the fingertips and a second strip located approximately 10 centimeters away from the first strip. Legs were bent so that the knees were at approximately 90 degrees angle with the feet planted securely on the floor. The participant raised his/her neck and spine until the fingers touched the second strip, and then lowered himself until the shoulders and head touched the mat. This procedure was repeated slowly until the participant became exhausted and could not perform any more curl-ups. A partner was counting the number of consecutive curl-ups performed by the participant. The curl-up differs from the sit-up in that the trunk is not raised more than 30 to 40 degrees above the floor and only the abdominal muscles are involved in this exercise (Powers \& Dodd, 2009).

\section{Flexibility}

Flexibility refers to the ability of an individual to move through a full range of motion without causing injury. It encompasses joints, ligaments and tendons (Hoeger \& Hoeger, 2007). Flexibility assessment was conducted by using the sit-and-reach method. 
To perform the test, a Sit-and-Reach Flexibility Tester was used. The participant was instructed to warm up and stretch out prior to the first trial. The subject sat on the floor with the hips, back and head against a wall, the legs were fully extended and shoes were taken off. The feet were placed firmly against the flexibility tester. The participant placed one hand on top of the other and moved the indicator on the flexibility tester forward trying to reach as far as possible. The final position was held in place at least for 2 seconds, while knees remained flat on the floor. Three trials were given and the highest score was recorded.

\section{Nutrition}

Nutrition and weight status along with an increase in exercise participation are objectives of the Healthy People 2020 national program that has been implemented for 3 decades by the U.S. Department of Health and Human Services (2011) in order to identify health disparities, increase public awareness on topics of health and wellness, and improve the health of Americans. A nutritional habits questionnaire (Powers \& Dodd, 2009) was integrated in the study to investigate how participants from diverse cultures, and a vastly Hispanic population, made their dietary choices. The questionnaire consisted of scenarios where the participants were given a healthy nutritional choice and a less healthy nutritional choice with a total of 10 questions.

\section{Data Collection}

This section outlines procedures of data collection and analysis. An analysis of variance (ANOVA) with repeated measures was the statistical scheme. In addition, an ANCOVA or analysis of covariance was included in the study in order to explain variation in the dependent variable. Students enrolled in nine classes with approximately 
25 students per class were recruited for the study. An experimental group consisted of six classes of students enrolled in a health and wellness course, and a comparison group consisted of three classes from a non-health related course. The students were recruited from three of the eight campuses for this institution. Out of a possible total of 225 students, the study sample consisted of 185 participants due to missing data from pre-test to post-test. For each of the dependent variables, slightly different sample sizes (166 to 185) were analyzed due to different patterns of missing values from pre-test to post-test. During the pretest analysis, the comparison group consisted of 55 students and the experimental group had 130 participants. Due to extended absences and students dropping out of the class for various reasons, the posttest participants consisted of 43 participants from the comparison group and 101 students from the experimental group.

Students who participated in the health and wellness courses followed the lecture and participation format for a 16 weeks period during the fall semester. During the last week of the semester the participants were tested once again using the anthropometric tests with the same instrumentation. The health related knowledge test and exercise selfefficacy inventory were also given to participants during the last week of classes and they reported their physical activity behaviors.

A pretest and posttest comparison was made to investigate if the participants improved in aerobic capacity by performing the 1.5 mile run or 1.0 mile walk with a faster completion time than during the pretest and if body fat composition decreased in comparison to the pretest given at the beginning of the semester. The strength dynamometer test as well as curl-ups, push-ups and the sit-and-reach examinations were performed to evaluate the performance of the participants at the beginning of the course and at the conclusion of the 
class. The exercise self-efficacy inventory was given to the students at the end of the semester for course completion as well as a knowledge-based exam on the health related topics covered throughout the course.

A comparison group was attained from students enrolled in a Student Life Skills course that agreed to participate in the project. They were given the pretest and posttest measurements but did not receive any lectures on fitness and wellness nor did they participate in instructor led exercise sessions throughout the semester.

\section{Data Analysis}

The data were analyzed using an analysis of variance (ANOVA). The use of multiple $t$-tests would not be advisable because as the number of $t$ tests increase so does the probability of a Type I error. A Type I error is an error in hypothesis testing, in this case it is when a true null hypothesis is rejected. An ANOVA was applied using the CRE test, body fat composition, muscular strength measurements, muscular endurance and flexibility as dependent variables. The exercise self-efficacy inventory and the knowledge exam were also included as dependent variables in a pre and posttest analysis with gender and race/ethnicity as independent variables. The CRE test was the dependent variable with gender and race/ethnicity as he independent variables. The same procedure was conducted with body fat composition, muscular strength, muscular endurance, flexibility, exercise selfefficacy inventory and knowledge exam scores. The hypothesis was tested at the alpha $\alpha=$ .05 level of significance. Students enrolled in the experimental group and comparison group received a pretest and posttest for each of the independent variables previously mentioned.

Factorial designs are good statistical instruments to use when one is interested in examining treatment variations, effective and useful in examining interaction effects. As a 
result, a 2 X 2 (two by two) factorial design was used for the health and wellness course, the comparison group and gender (male, female). In addition, a 2 X 3 factorial design was implemented with the health and wellness course and comparison group and the independent variable race and ethnicity (Blacks, Whites, African-Americans and Hispanics). A computer assisted statistical analysis program named SPSS (Statistical Package for the Social Sciences) was used to perform bivariate statistics. The dependent measure was the difference between the pretest and the posttest by course (treatment or comparison group), gender, and race/ethnicity.

In addition to the ANOVA, an ANCOVA or analysis of covariance was used in the study. An ANCOVA can assist in the interpretation of data, to control error and increase precision, to adjust treatment means of the dependent variable for differences in values of the corresponding independent variable and to estimate missing data. The covariate in this study was the pretest score and the dependent variable was the difference score. In essence, the purpose of the covariate was to find out if the difference in the mean scores of the two treatment groups on the posttest are significantly different independent of the pretest scores. The analysis of covariance will increase statistical power and reduce error variance as long as the assumptions underlying an ANCOVA are met. The analysis of covariance (ANCOVA) is done by using linear regression. This means that ANCOVA assumes that the relationship between the independent variable and the dependent variable must be linear in nature (Hinkle, Wiersma \& Jurs, 2003).

\section{Limitations}

A weakness of this study was that the pre and posttest data was collected over a 16-week period, a relatively short period of time. A longitudinal study would be helpful 
to establish trends in the student population in reference to their exercise habits sometime after the class is completed but was not possible in the present study. In addition, due to the convenience sampling methodology, the random selection of students when choosing the representatives of the sample was not implemented in this study. Lastly, the role of acculturation was not examined in this study but should be a topic for future research since studies have shown that acculturation has positive and negative effects on health behaviors (Despues \& Friedman, 2007). Students who are bicultural may adopt some of the lifestyle behaviors of the mainstream culture while also maintaining some of the traditions from their own culture such as nutritional habits. 


\section{CHAPTER IV}

\section{RESULTS}

The purpose of this investigation was to analyze the effectiveness of a conceptually based health and wellness course in developing various physical fitness factors, self-efficacy of exercise and knowledge of health related topics. The results obtained from the participants in the health and wellness courses were compared to the results obtained from the participants enrolled in a non-health related course used as the comparison group. The three research questions that guided this study were:

1.What is the effectiveness of a self-selected conceptually based health and wellness course in developing the health related factors of cardio-respiratory endurance, body fat composition, muscular strength, muscular endurance and flexibility among a racially and ethnically diverse student population?

2. How does such a course impact the exercise self-efficacy level of racially and ethnically diverse students enrolled in the course?

3. How does a self-selected health and wellness course impact the knowledge of racially and ethnically diverse students on health issues and physical activity participation?

\section{Demographics}

Students enrolled in nine classes with approximately 25 students per class were recruited for the study. An experimental group consisted of six classes of students enrolled in a health and wellness course, and a comparison group consisted of three classes from a non-health related course. The students were recruited from three of the eight campuses for this institution. Out of a possible total of 225 students, the study 
sample consisted of 185 participants due to missing data from pre-test to post-test. For each of the dependent variables, slightly different sample sizes (166 to 185) were analyzed due to different patterns of missing values from pre-test to post-test. During the pre-test analysis, the comparison group consisted of 55 students and the experimental group had 130 participants. Due to extended absences and students dropping out of classes for various reasons, the post-test participants consisted of 43 participants from the comparison group and 101 students from the experimental.

To illustrate the demographic characteristics for the study participants by group, a frequency distribution table was generated for gender, age, race/ethnicity, birthplace, parents' birthplace, hours worked per week, and income (see Table 1). There were no significant differences between experimental and comparison groups by gender, age, birthplace, parents' birthplace, hours worked per week, or income, $p>.05$. Fifty-two percent $(n=67)$ of the experimental group and 55\% $(n=30)$ of the comparison group were male. Fifty-two percent $(n=67)$ of the experimental group and 58\% $(n=32)$ of the comparison group were between 18 and 20 years old.

There was a significant difference in ethnicity by group, $\chi^{2}(1, n=184)=6.02, p$ $<.014$. Although $71 \%$ of students in the experimental group was Hispanic $(n=92)$, only $52 \%$ of the comparison group was Hispanic $(n=28)$. The majority of the experimental and comparison group participants described themselves as Hispanic. However, most of the students in the sample were born in the United States with $70 \%$ of the experimental group $(n=91)$ and $67 \%$ of the comparison group $(n=37)$ born in the U.S. For the question on parents' birthplace, the majority of the students reported that at least one 
parent was born outside the United States with $80 \%(n=103)$ experimental group and $75 \%(n=41)$ of the comparison group having a parent born outside of the U.S.

Table 1

Demographic Characteristics of Study Participants by Group.

\begin{tabular}{|c|c|c|c|c|}
\hline \multirow[b]{2}{*}{ Characteristics } & \multicolumn{2}{|c|}{ Experimental $(n=130)$} & \multicolumn{2}{|c|}{ Comparison $(n=55)$} \\
\hline & Frequency & $\%$ & Frequency & $\%$ \\
\hline \multicolumn{5}{|l|}{ Gender } \\
\hline Male & 67 & 51.50 & 30 & 54.50 \\
\hline Female & 63 & 48.50 & 25 & 45.50 \\
\hline \multicolumn{5}{|l|}{ Age } \\
\hline$<18$ & 14 & 10.80 & 5 & 9.10 \\
\hline $18-20$ & 67 & 51.50 & 32 & 58.20 \\
\hline $21-29$ & 42 & 32.30 & 16 & 29.10 \\
\hline$>=30$ & 7 & 5.40 & 2 & 3.60 \\
\hline \multicolumn{5}{|l|}{ Race/Ethnicity* } \\
\hline Hispanic & 92 & 70.80 & 28 & 51.90 \\
\hline Black, non-Hispanic & 27 & 20.80 & 20 & 37.00 \\
\hline White non-Hispanic & 8 & 6.20 & 2 & 3.70 \\
\hline Other & 3 & 2.30 & 4 & 7.40 \\
\hline \multicolumn{5}{|l|}{ Birthplace } \\
\hline United States & 91 & 70.00 & 37 & 67.30 \\
\hline Caribbean & 25 & 19.20 & 10 & 18.20 \\
\hline Central America & 5 & 3.80 & 4 & 7.30 \\
\hline South America & 7 & 5.40 & 2 & 3.60 \\
\hline Other & 2 & 1.50 & 2 & 3.60 \\
\hline \multicolumn{5}{|l|}{ Parents' birthplace } \\
\hline United States & 26 & 20.20 & 14 & 25.00 \\
\hline Caribbean & 64 & 49.60 & 20 & 36.40 \\
\hline Central America & 15 & 11.60 & 11 & 20.00 \\
\hline South America & 20 & 15.50 & 6 & 10.90 \\
\hline Other & 4 & 3.10 & 4 & 7.30 \\
\hline \multicolumn{5}{|l|}{ Weekly work hours } \\
\hline 0 & 51 & 39.50 & 29 & 52.70 \\
\hline $1-20$ & 39 & 30.20 & 13 & 23.60 \\
\hline $21-30$ & 22 & 17.10 & 3 & 5.50 \\
\hline $31-40$ & 12 & 9.30 & 8 & 14.50 \\
\hline$>40$ & 5 & 3.90 & 2 & 3.60 \\
\hline \multicolumn{5}{|l|}{ Employment income } \\
\hline Less than $\$ 10,000$ & 88 & 71.50 & 35 & 76.10 \\
\hline$\$ 10,000-\$ 20,000$ & 28 & 22.80 & 10 & 21.70 \\
\hline$\$ 21,000-\$ 30,000$ & 2 & 1.60 & 1 & 2.20 \\
\hline$>\$ 30,000$ & 5 & 4.10 & 0 & 0.00 \\
\hline
\end{tabular}


In reference to work status, $40 \%(n=51)$ of the experimental group and $53 \%$ $(n=29)$ of the comparison group were not employed. Additionally, the largest number of students with employment worked 20 hours or less in both the experimental $(30 \%, n$ $=39)$ and comparison groups $(24 \%, n=13)$.

Students were asked about the income earned from employment alone. The results indicated that $72 \%(n=88)$ of the experimental group and $76 \%(n=35)$ of the comparison group earned less than $\$ 10,000$ per year.

This quasi-experimental study used a pre-posttest design with a comparison group. It was implemented to evaluate the effectiveness of the health and wellness courses via the implementation of fitness tests on cardiorespiratory endurance, body fat composition, muscular endurance, muscular strength, and flexibility. In addition a knowledge test on health related topics (Fahey et al., 2008), an exercise self-efficacy scale (Dwyer et al., 1998) was included in the project for both the experimental and comparison group. The physiological measurements were analyzed as follows: cardiorespiratory endurance measured via the 1.5 mile run test (Powers \& Dodd, 2009); body fat composition measured with the Omron Bioelectrical Impedance (Fahey et al., 2009); muscular endurance measured using the sit-up test and the push-up test to exhaustion (women measured using the modified push-up test) (Powers \& Dodd, 2009); muscular strength evaluated using the grip strength dynamometer (Hoeger \& Hoeger, 2007); and flexibility measured by the Sit-and-Reach Test (Hoeger \& Hoeger, 2007).

Table 2 provides the observed means for pre-test, post-test, their difference scores, and standard error of the mean for the physical fitness variables: body fat, 1.5 mile run, sit-ups, strength of dominant and non-dominant hands, push-ups, and flexibility. 
The experimental and comparison groups were tested at pre-test for differences using ttests. No significant differences were found on any pretest of the physical variables except for sit-ups, $p<.001$. The experimental group completed significantly more situps $(M=60.1)$ compared to the comparison group $(M=31.4)$ at pretest.

Table 2

Observed Pre-Test, Post-Test, and Difference Score Means for Physical Fitness Variables by Group

\begin{tabular}{|c|c|c|c|c|c|}
\hline Variable & Group & $n$ & $\begin{array}{c}\text { Pre-test } \\
M \\
(S E) \\
\end{array}$ & $\begin{array}{c}\text { Post-test } \\
M \\
(S E) \\
\end{array}$ & $\begin{array}{c}\text { Difference } \\
M \\
(S E) \\
\end{array}$ \\
\hline \multicolumn{6}{|l|}{ Body fat $(\%)$} \\
\hline & Experimental & 129 & $\begin{array}{l}21.90 \\
(0.79)\end{array}$ & $\begin{array}{l}20.44 \\
(0.78)\end{array}$ & $\begin{array}{l}-1.46 \\
(0.28)\end{array}$ \\
\hline & Comparison & 53 & $\begin{array}{l}21.47 \\
(1.18)\end{array}$ & $\begin{array}{l}20.29 \\
(1.20)\end{array}$ & $\begin{array}{l}-1.18 \\
(0.39)\end{array}$ \\
\hline 1.5 mile run (minutes) & Experimental & 123 & $\begin{array}{l}14.84 \\
(0.16)\end{array}$ & $\begin{array}{l}14.35 \\
(0.17)\end{array}$ & $\begin{array}{l}-0.49 \\
(0.13)\end{array}$ \\
\hline & Comparison & 41 & $\begin{array}{l}15.29 \\
(0.33)\end{array}$ & $\begin{array}{l}17.00 \\
(0.52)\end{array}$ & $\begin{array}{l}1.70 \\
(0.49)\end{array}$ \\
\hline Sit-ups (\#) & Experimental & 130 & $\begin{array}{l}60.05 \\
(3.27)\end{array}$ & $\begin{array}{l}75.35 \\
(5.45)\end{array}$ & $\begin{array}{l}15.29 \\
(4.51)\end{array}$ \\
\hline & Comparison & 48 & $\begin{array}{l}31.40 \\
(1.59)\end{array}$ & $\begin{array}{r}30.38 \\
(1.89)\end{array}$ & $\begin{array}{l}-1.02 \\
(1.06)\end{array}$ \\
\hline Strength (dominant hand) (kg) & Experimental & 130 & $\begin{array}{l}40.28 \\
(1.12)\end{array}$ & $\begin{array}{l}41.1 \\
(1.12)\end{array}$ & $\begin{array}{c}0.82 \\
(0.39)\end{array}$ \\
\hline & Comparison & 54 & $\begin{array}{l}37.50 \\
(1.73)\end{array}$ & $\begin{array}{l}37.12 \\
(1.76)\end{array}$ & $\begin{array}{c}-0.38 \\
(0.88)\end{array}$ \\
\hline Strength (non-dominant hand)(kg) & Experimental & 130 & $\begin{array}{l}36.15 \\
(1.10)\end{array}$ & $\begin{array}{l}37.36 \\
(1.15)\end{array}$ & $\begin{array}{l}1.20 \\
(0.47)\end{array}$ \\
\hline & Comparison & 54 & $\begin{array}{l}36.54 \\
(1.83)\end{array}$ & $\begin{array}{l}35.64 \\
(1.71)\end{array}$ & $\begin{array}{l}-0.90 \\
(0.90)\end{array}$ \\
\hline Push-ups (\#) & Experimental & 129 & $\begin{array}{l}30.81 \\
(1.50)\end{array}$ & $\begin{array}{r}37.63 \\
(1.64)\end{array}$ & $\begin{array}{c}6.81 \\
(0.98)\end{array}$ \\
\hline & Comparison & 48 & $\begin{array}{c}29.83 \\
(1.84)\end{array}$ & $\begin{array}{l}29.77 \\
(2.28)\end{array}$ & $\begin{array}{l}-0.0625 \\
(1.19)\end{array}$ \\
\hline Flexibility (inches) & Experimental & 128 & $\begin{array}{c}7.95 \\
(0.49)\end{array}$ & $\begin{array}{c}8.86 \\
(0.47)\end{array}$ & $\begin{array}{c}0.91 \\
(0.22)\end{array}$ \\
\hline & Comparison & 48 & $\begin{array}{l}13.17 \\
(0.49)\end{array}$ & $\begin{array}{r}13.47 \\
(0.49)\end{array}$ & $\begin{array}{l}0.30 \\
(0.33)\end{array}$ \\
\hline
\end{tabular}


Table 3 displays the same comparison of means and difference in means for nutrition, knowledge test, self-efficacy scale (external and internal barriers), global selfefficacy, and frequency of vigorous participation activities (FVPA) while students are attending a physical activity class, in other settings such as in intramural competitions, and when not attending school. No significant differences were found on pre-test means for nutrition, self-efficacy scale (external and internal barriers), global self-efficacy, and FVPA. However, there was a significant difference between groups on knowledge test, $p$ $<.001$, with the experimental group $(M=57.0)$ scoring higher than the comparison group $(M=42.6)$. Thus the groups scored similarly on most pre-test measures. Although differences occurred for sit-ups and knowledge on pretests the ANCOVA analysis adjusts for all pre-test variability.

ANCOVAs were conducted on the pre to post change scores for all dependent variables. The covariate for each analysis was the pre-test of the dependent variable being tested. The factors were group, gender, and ethnicity. The test of means between groups, controls for differences in the pretest value as well as differences by gender and ethnicity. The pre to post change score was chosen as the dependent variable instead of the posttest score in order to additionally test for changes from pre to post within groups controlling for pretest, gender, and ethnicity. For each ANCOVA, homogeneity of slopes was tested between the pretest and group, gender and ethnicity and none were found to be significant. Therefore for each dependent variable, the ANCOVA model included pretest, group, gender, ethnicity, and interactions of group with gender, and group with ethnicity. 
Table 3

Observed Pre-Test, Post-Test and Difference Score Means for Nutrition, Knowledge, VPA (External \& Internal Barriers) and FVPA Variables by Group

\begin{tabular}{|c|c|c|c|c|c|}
\hline Variable & Group & $n$ & $\begin{array}{c}\text { Pre-test } \\
M \\
(S E)\end{array}$ & $\begin{array}{c}\text { Post-test } \\
M \\
(S E)\end{array}$ & $\begin{array}{c}\text { Difference } \\
M \\
(S E)\end{array}$ \\
\hline \multicolumn{6}{|l|}{ Nutritional habits $(0-100)$} \\
\hline & Experimental & 126 & $\begin{array}{l}51.18 \\
(1.79)\end{array}$ & $\begin{array}{l}73.22 \\
(1.92)\end{array}$ & $\begin{array}{l}22.03 \\
(2.07)\end{array}$ \\
\hline & Comparison & 51 & $\begin{array}{l}56.14 \\
(3.23)\end{array}$ & $\begin{array}{l}64.84 \\
(3.1)\end{array}$ & $\begin{array}{l}8.69 \\
(3.25)\end{array}$ \\
\hline \multicolumn{6}{|l|}{ Health Knowledge Test $(0-100)^{\mathrm{a}}$} \\
\hline & Experimental & 122 & $\begin{array}{l}56.97 \\
(1.20)\end{array}$ & $\begin{array}{l}58.81 \\
(1.40)\end{array}$ & $\begin{array}{l}1.84 \\
(1.55)\end{array}$ \\
\hline & Comparison & 53 & $\begin{array}{r}42.64 \\
(1.55)\end{array}$ & $\begin{array}{l}44.53 \\
(1.85)\end{array}$ & $\begin{array}{l}1.89 \\
(2.01)\end{array}$ \\
\hline \multicolumn{6}{|l|}{$\begin{array}{l}\text { VPA(self-efficacy scale) } \\
\text { external barriers }{ }^{b}\end{array}$} \\
\hline & Experimental & 126 & $\begin{array}{l}3.40 \\
(0.09)\end{array}$ & $\begin{array}{l}3.46 \\
(0.08)\end{array}$ & $\begin{array}{l}0.052 \\
(0.08)\end{array}$ \\
\hline & Comparison & 47 & $\begin{array}{l}3.35 \\
(0.12)\end{array}$ & $\begin{array}{l}2.10 \\
(0.13)\end{array}$ & $\begin{array}{l}-0.35 \\
(0.16)\end{array}$ \\
\hline \multicolumn{6}{|l|}{$\begin{array}{l}\text { VPA (self-efficacy scale) } \\
\text { internal barriers }\end{array}$} \\
\hline & Experimental & 126 & $\begin{array}{l}3.35 \\
(0.09)\end{array}$ & $\begin{array}{c}3.22 \\
(0.09)\end{array}$ & $\begin{array}{l}-0.12 \\
(0.09)\end{array}$ \\
\hline & Comparison & 45 & $\begin{array}{l}3.13 \\
(0.17)\end{array}$ & $\begin{array}{l}2.87 \\
(0.14)\end{array}$ & $\begin{array}{l}-0.26 \\
(0.19)\end{array}$ \\
\hline \multicolumn{6}{|l|}{$\begin{array}{l}\text { VPA self-report of behavior } \\
\text { particip. at least } 3 \times \text { a week }\end{array}$} \\
\hline & Experimental & 127 & $\begin{array}{l}3.91 \\
(0.11)\end{array}$ & $\begin{array}{c}4.17 \\
(0.09)\end{array}$ & $\begin{array}{l}0.26 \\
(0.09)\end{array}$ \\
\hline & Comparison & 47 & $\begin{array}{l}3.66 \\
(0.17)\end{array}$ & $\begin{array}{l}3.64 \\
(0.16)\end{array}$ & $\begin{array}{l}-0.02 \\
(0.19)\end{array}$ \\
\hline
\end{tabular}

${ }^{a_{\%}} \%=$ percentage of correct answers from a 20 item written exam on health related topic, with 20 indicating proficient knowledge of wellness topics.

${ }^{b}$ Vigorous participation activity self-efficacy scale; 12 items questionnaire on external barriers for participation in VPA., $1=$ not at all confident, $2=$ not confident, $3=$ somewhat confident, $4=$ confident, 5

$=$ very confident, scores range from 1 to 5 with high score indicating self-efficacy of exercise.

${ }^{\mathrm{c}}$ Vigorous participation activity self-efficacy scale; 8 items questionnaire on external barriers for participation in VPA., $1=$ not at all confident, $2=$ not confident, $3=$ somewhat confident, $4=$ confident, 5 $=$ very confident, scores range from 1 to 5 , with high score indicating self-efficacy of exercise.

${ }^{\mathrm{d}}$ Global self-efficacy: One item on global self efficacy for participation in VPA at least 3 times per week. $\mathrm{b,c,d} 1=$ not at all confident, $2=$ not confident, $3=$ somewhat confident, $4=$ confident, $5=$ very confident. 
Table 3 (continued)

Observed Pre-Test, Post-Test and Difference Score Means for Nutrition, Knowledge, VPA (External \& Internal Barriers) and FVPA Variables by Group.

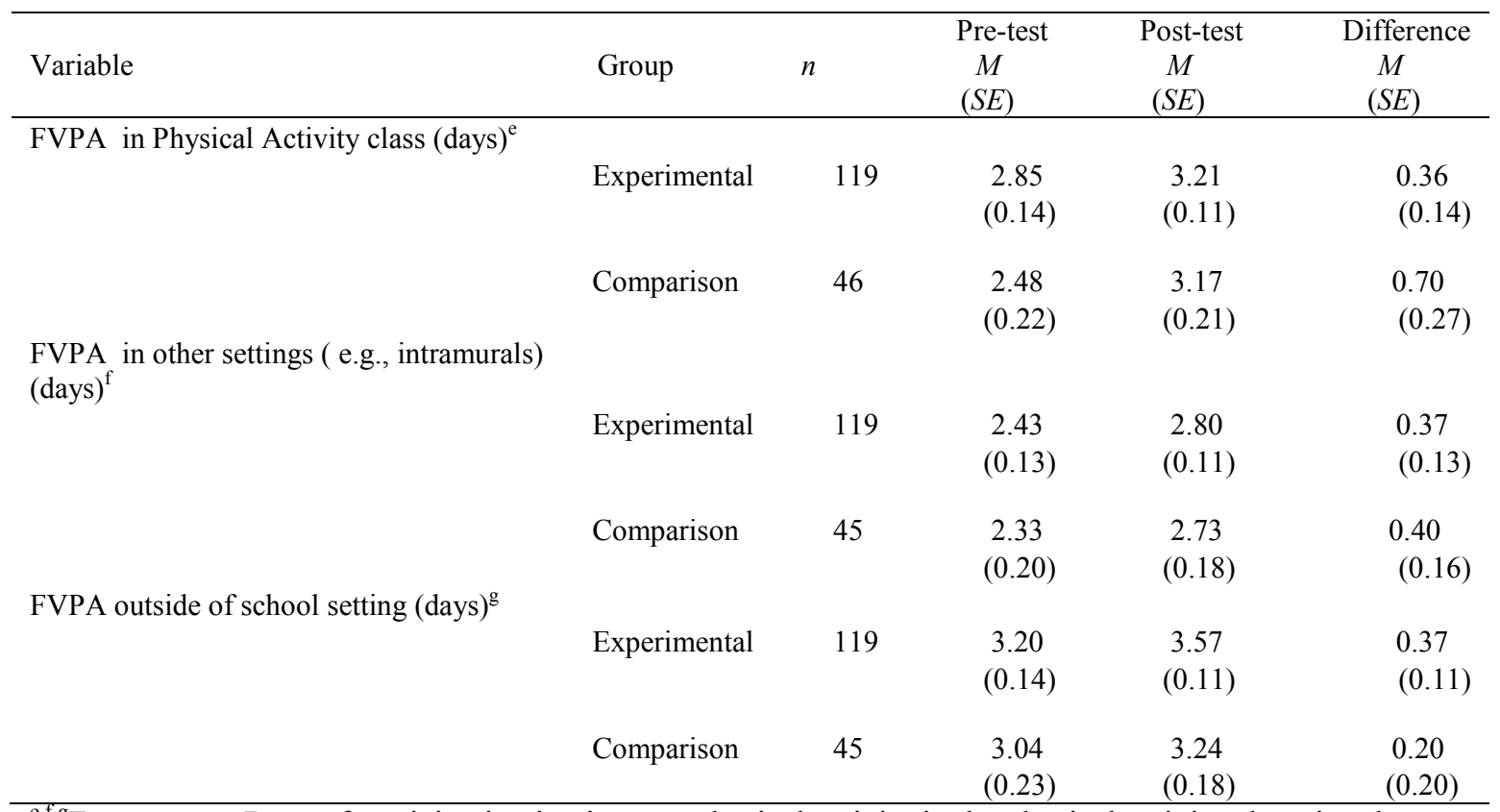

${ }^{\mathrm{e}, \mathrm{f}, \mathrm{g}}$ Frequency $=$ Days of participation in vigorous physical activity in the physical activity class, in other settings, or outside of school setting. $1=0$ times, $2=$ once per week, $3=$ twice per week, $4=$ three times per week, $5=$ more than 3 times per week, scores range from 1 to 5 , where 5 indicates maximum performance of physical activities.

\section{Physical Fitness Measure Analyses}

There was no difference between treatment and comparison groups in body fat loss, $F(1,175)=0.00, p=.951$, controlling for pre-body fat, gender, and ethnicity (see Table 4). Both groups lost significant body fat from pre- to post-test, $p<.05$. However, there was a significant group difference by ethnic interaction, $F(1,175)=4.43, p=.037$. For individuals with a mean pre-test body fat of $21.8 \%$, the adjusted means change scores were -1.89 for the experimental Hispanic, -0.21 for the experimental non-Hispanic, -0.90 for the comparison Hispanic, and -1.27 for the comparison non-Hispanic groups. In the experimental group, Hispanics lost more body fat percentage at the end of the 16 weeks semester $(M=-.189)$ than non-Hispanics $(M=-0.21)$. In addition, the experimental 
Hispanic group lost significant body fat from pre to post, $p<.05$. Finally, males lost more body fat than females, $p<.001$ regardless of treatment or comparison group.

For walk/run time, a significant difference was found between groups from pretest to post-test, $F(1,157)=45.13, p<.001$, controlling for pre-walk run time, gender, and ethnicity. The experimental group participants improved their run time by half a minute (adj $M=.49$ ) compared to the comparison group whose run time increased (adj $M$ $=1.92$ ). Both groups changed significantly from pre to post, however in opposite directions, $p<.05$. No differences were found by gender or ethnicity.

For sit-ups, a significant difference was found between groups from pre- to posttest, $F(1,169)=6.15, p=.014$, controlling for pre-sit-ups, gender, and ethnicity. The experimental group participants improved the number of sit-ups performed to exhaustion (adj $M=10.8$ ) compared to the comparison groups $(\operatorname{adj} M=3.82)$. Additionally, the experimental group's increase in sit-ups was significant, $p<.05,95 \%$ CI $[4.64,16.91]$. There were no significant differences found for gender or ethnicity. The strength test was divided in dominant and non-dominant hand. For the purpose of this study, the hand that a participant was more dexterous with was called the dominant hand and the hand with lesser skills, the non-dominant hand. The ANCOVA results for strength of the dominant hand indicated a significant difference between groups from pre- to posttest, $F(1,177)=3.98, p=.047$, controlling for pre-dominant hand score, gender, and ethnicity. The experimental group improved in strength of dominant hand by almost $1 \mathrm{~kg}(M=0.86)$, which was significantly greater than the comparison group who actually lost strength $(M=-.84)$. However, within each group, experimental and comparison, there was no statistical significance found from pre- to 
posttest, $p<.05$. A significant difference was found by ethnicity, $F(1,177)=4.21, p=$ .042. The Hispanic participants increased their dominant hand strength by almost $1 \mathrm{~kg}$ $(M=.086)$, which was significantly greater than the non-Hispanic group who decreased in strength $(M=-.084)$. Nevertheless, within each ethnic group, Hispanic non-Hispanic, there was no significant difference from pre to posttest, $p<.05$.

The ANCOVA results for non-dominant hand strength showed a significant difference between groups from pre to posttest, $F(1,177)=7.17, p=.008$, controlling for pre-non-dominant hand score, gender, and ethnicity. The experimental group participants improved their strength by more than $1 \mathrm{~kg}(M=1.33)$ compared to the comparison groups whose strength decreased by more than $1 \mathrm{~kg}(M=-1.10)$. Both groups changed significantly from pre to post, however, in opposite directions, $p<.05$. The experimental group enrolled in the 16-week health and wellness course had an improvement in strength of .30 to $2.36 \mathrm{~kg}(95 \% \mathrm{CI})$. In addition, there was a significant difference by gender, $F$ $(1,177)=9.59, p=.002$. Males significantly improved their non-dominant hand strength $(M=2.22)$, while the females significantly decreased their non-dominant hand strength $(M=-1.99)$. Both genders changed significantly from pre to posttest, however in opposite directions, $p<.05$.

Significant differences were also found for the interaction of group and ethnicity, $F(1,177)=46.02, p=.015$. In non-Hispanics, the experimental group significantly increased in non-dominant hand strength more $(M=1.77)$ than the comparison group, $(M$ $=-2.88$ ). Furthermore, in the non-Hispanic group, the experimental participants 
Table 4

Adjusted Means for Physical Fitness Changes from Pre to Post by Group Controlling for Pre-Test, Gender, and Ethnicity.

\begin{tabular}{|c|c|c|c|c|}
\hline Fitness variable & $\begin{array}{c}\text { Experimental } \\
A d j . M \\
(S E)\end{array}$ & $\begin{array}{c}\text { Comparison } \\
A d j . M \\
(S E)\end{array}$ & $p$ & $\eta^{2}$ \\
\hline Body Fat (\%) & $\begin{array}{l}-1.05 \\
(0.28)\end{array}$ & $\begin{array}{l}-1.08 \\
(0.40)\end{array}$ & 0.951 & 0.00 \\
\hline Group by Ethnicity & & & 0.037 & 0.03 \\
\hline Hispanic & $\begin{array}{l}-1.89 * a \\
(0.30)\end{array}$ & $\begin{array}{l}-0.90 \mathrm{a} \\
(0.56)\end{array}$ & - & - \\
\hline Non-Hispanic & $\begin{array}{l}-0.21 b \\
(0.47)\end{array}$ & $\begin{array}{l}-1.27 \mathrm{a} \\
(0.56)\end{array}$ & - & - \\
\hline 1.5 Walk (min) & $\begin{array}{l}-0.49 * \\
(0.19)\end{array}$ & $\begin{array}{l}1.92 * \\
(0.50)\end{array}$ & $0.001 * *$ & 0.22 \\
\hline Sit-ups (\#) & $\begin{array}{l}10.78 * * \\
(3.11)\end{array}$ & $\begin{array}{l}-3.82 \\
(4.84)\end{array}$ & $0.014 *$ & 0.030 \\
\hline $\begin{array}{l}\text { Strength } \\
\text { (Dom.Hand) }(\mathrm{kg})\end{array}$ & $\begin{array}{l}0.86 \\
(0.48)\end{array}$ & $\begin{array}{l}-0.84 \\
(0.69)\end{array}$ & $0.047 *$ & 0.020 \\
\hline $\begin{array}{l}\text { Strength } \\
\text { (Non-Dom.Hand)(kg) }\end{array}$ & $\begin{array}{l}1.33 * * \\
(0.52)\end{array}$ & $\begin{array}{l}-1.10 \\
(0.74)\end{array}$ & $0.008 * *$ & 0.040 \\
\hline Group by Ethnicity & & & 0.015 & 0.030 \\
\hline Hispanic & $\begin{array}{l}0.89 \\
(0.56)\end{array}$ & $\begin{array}{c}0.69 \\
(1.04)\end{array}$ & - & - \\
\hline Non-Hispanic & $\begin{array}{l}1.77 \\
(0.88)\end{array}$ & $\begin{array}{l}-2.88 \\
(1.06)\end{array}$ & - & - \\
\hline Push-ups (\#) & $\begin{array}{l}5.88^{* *} \\
(1.00)\end{array}$ & $\begin{array}{l}-0.27 \\
(1.49)\end{array}$ & $0.01 * *$ & 0.06 \\
\hline Flexibility (inches) & $\begin{array}{l}0.78 * * \\
(0.23)\end{array}$ & $\begin{array}{l}0.94 * * \\
(0.36)\end{array}$ & 0.71 & 0.01 \\
\hline
\end{tabular}

$* \mathrm{p}<.05 * * \mathrm{p}<.01$

Note. ${ }^{*}$ on an adjusted mean indicates a significant change from pre to post within group.

Note. Sample sizes for experimental group ranged from 123- 130, comparison group from 41-54.

Note. Ethnic means in a column/row with different superscripts are significantly different using Holm's sequential Bonferroni, $\mathrm{p}<0.05$

increased their non-dominant hand strength from pre to post, $p<.05$, while the non

Hispanic comparison group decreased in non-dominant hand strength from pre to post at 
$p<.05$. Hispanics from the comparison group had significantly higher change in nondominant hand strength $(M=.69)$ than non-Hispanics $(M=-2.88), p=.018$.

The results obtained for the push-ups category revealed a significant difference between groups from pre to posttest, $F(1,177)=11.70, p=.001$, controlling for pre push-ups score, gender, and ethnicity. The experimental group's improvement in pushups $(M=5.88)$ was considerably greater than the comparison group $(M=-.27)$. There was also a significant difference by gender, $F(1,177)=3.92, p=.049$. Males' increase in push-ups $(M=4.81)$ was significantly greater than that of females $(M=.080), p<.05$, $95 \%$ CI $[2.20,7.41]$. No differences were found by ethnicity.

There was no difference between groups in flexibility, $F(1,176)=0.001, p=$ .713 , controlling for pre-flexibility score, gender, and ethnicity. Both the experimental $(M=.78)$ and the comparison group $(M=.94)$ significantly increased in flexibility, $p<.05$. No significant differences were found by gender or ethnicities.

\section{Nutrition, Knowledge, and Exercise Self-Efficacy Analyses}

Participants received a nutritional instrument that questioned them on dietary habits (See Appendix C). Ten questions were presented to the participants asking them to choose between a healthy and a less healthy menu item, such as, "What would you order in an Italian restaurant: spaghetti with red sauce or five cheese lasagna?" Each healthy choice received 1 point; each non-healthy choice received 0 points. Participants who completed at least $80 \%$ of the instrument were included in the analysis. The experimental group was lectured on nutrition and weight control throughout the semester as part of the class curriculum while the comparison group received no information on the topic. The results of the ANCOVA showed a significance difference in nutritional 
habits between groups from pre to posttest, $F(1,170)=6.77, p<.010$, controlling for pre-nutrition score, gender, and ethnicity (see Table 5). The experimental group participants improved their nutritional habits $(M=20.23)$ significantly more than the comparison group $(M=11.22)$. In addition, both groups significantly improved from pre to posttest, $p<.05$. No significant differences were found by gender or ethnicity. This suggests that Hispanics and non-Hispanics improved from the nutrition curriculum.

The results for the health and wellness knowledge test indicated a significant difference between groups from pre to posttest, $F(1,168)=10.80, p<.001$, controlling for pre-knowledge score, gender and ethnicity. The experimental group participants improved their knowledge of health and wellness $(M=4.17)$, while the comparison group decreased in knowledge $(M=-4.77)$. Both groups changed significantly from pre to posttest but in different directions, $p<.05$. No differences were found by gender or ethnicity.

The self-efficacy scale was evaluated by separating it in three sections: (a) external barriers or obstacles that keep and individual from performing vigorous physical activity (VPA) due to external reasons such as bad weather, (b) internal barriers such as feeling tired or sick, and (c) self-report of behavior or times a person exercises in various settings. The results from the self-efficacy external barriers section indicated a significant difference between groups from pretest to posttest, $F(1,166)=6.38, p<.012$, controlling for pre-VPA external barriers score, gender, and ethnicity. The experimental group showed no improvement $(M=.01)$, but the comparison group decreased significantly $(M=-.36), p<.05$. In addition, there was a significant group difference by ethnic interaction, $F(1,166)=7.37, p=.007$. For Hispanics, the experimental group 
changes in VPA external barriers $(M=0.13)$ were significantly larger than the comparison group changes $(M=-0.63)$. The decrease was significant for the Hispanic comparison group $p<.05$; however, the increase for the Hispanic experimental group was not. In the comparison group, the non-Hispanic group changes in VPA external barriers $(M=-.09)$ was significantly larger than Hispanic group changes, $p<.05$.

There was no difference between groups in VPA internal barriers from pretest to posttest $F,(1,164)=.726, p=.395$, controlling for pre-VPA internal barriers score, gender, and ethnicity. However, it was moderated by an interaction with ethnicity, $F$ $(1,164)=9.25, p=.003$. For Hispanics, the experimental group changes in VPA internal barriers $(M=0.02)$ were significantly larger than the comparison group changes $(M=$ 0.60). This difference did not occur because the experimental group improved, but because the results in the comparison group decreased significantly.

The VPA self-report of behavior showed a significant difference between groups from pretest to posttest, $F(1,167)=7.65, p=.006$, controlling for pre self-report of behavior score, gender, and ethnicity. The experimental group increased significantly in their exercise participation $(M=.28)$ in relation to the comparison group $(M=-.17)$ from pre to posttest. In addition, the experimental group increased significantly from pre to posttest, $p<.05$. No differences were found by gender or ethnicity. 
Table 5

Adjusted Means for Nutritional Habits, Knowledge and VPA Changes from Pre to Post by Group Controlling for Pre-test, Gender and Ethnicity.

\begin{tabular}{|c|c|c|c|c|}
\hline Variable & $\begin{array}{c}\text { Experimental } \\
A d j . M \\
(S E) \\
\end{array}$ & $\begin{array}{c}\text { Comparison } \\
A d j . M \\
(S E) \\
\end{array}$ & $p$ & $\eta^{2}$ \\
\hline Nutritional habits (\%) & $\begin{array}{l}20.23 * * \\
(1.96)\end{array}$ & $\begin{array}{l}11.22 \\
(2.84)\end{array}$ & $0.01 * *$ & 0.038 \\
\hline Knowledge (\%) & $\begin{array}{l}4.17 * * \\
(1.44)\end{array}$ & $\begin{array}{l}-4.77 \\
(2.17)\end{array}$ & $0.001 * *$ & 0.060 \\
\hline $\begin{array}{l}\text { VPA External } \\
\text { (confidence to } \\
\text { participate) }\end{array}$ & $\begin{array}{l}0.01 \\
(0.08)\end{array}$ & $\begin{array}{l}-0.36 \\
(0.12)\end{array}$ & $0.012 *$ & 0.037 \\
\hline Group by Ethnicity & & & $0.007 * *$ & 0.043 \\
\hline Hispanic & $\begin{array}{l}0.13 b \\
(0.09)\end{array}$ & $\begin{array}{c}-0.63 * a \\
(0.16)\end{array}$ & - & - \\
\hline Non-Hispanic & $\begin{array}{r}0.12 b \\
(0.14)\end{array}$ & $\begin{array}{l}-0.09 \mathrm{ab} \\
(0.18)\end{array}$ & - & - \\
\hline $\begin{array}{l}\text { VPA Internal } \\
\text { (confidence } \\
\text { to participate) }\end{array}$ & $\begin{array}{l}-0.17 \\
(0.09)\end{array}$ & $\begin{array}{l}-0.30 \\
(0.13)\end{array}$ & 0.395 & 0.004 \\
\hline Group by Ethnicity & & & $0.003 * *$ & 0.053 \\
\hline Hispanic & $\begin{array}{l}0.02 \mathrm{~b} \\
(0.09)\end{array}$ & $\begin{array}{l}-0.60 * a \\
(0.17)\end{array}$ & - & - \\
\hline Non-Hispanic & $\begin{array}{r}-0.35 b \\
(0.15)\end{array}$ & $\begin{array}{l}-0.01 \mathrm{ab} \\
(0.21)\end{array}$ & - & - \\
\hline $\begin{array}{l}\text { VPA (self-report of } \\
\text { behavior) }\end{array}$ & $\begin{array}{l}0.28 * * \\
(0.09)\end{array}$ & $\begin{array}{l}-0.17 \\
(0.14)\end{array}$ & $0.006 * *$ & 0.044 \\
\hline
\end{tabular}


Table 5 (Continued)

Adjusted Means for Nutritional Habits, Knowledge and VPA Changes from Pre to Post by Group Controlling for Pre-test, Gender and Ethnicity.

\begin{tabular}{|c|c|c|c|c|}
\hline Variable & $\begin{array}{l}\text { Experimental } \\
\text { Adj. } M \\
(S E) \\
\end{array}$ & $\begin{array}{c}\text { Comparison } \\
\text { Adj. } M \\
(S E) \\
\end{array}$ & $p$ & $\eta^{2}$ \\
\hline FVPA in school & $\begin{array}{l}0.310^{*} \\
(0.123)\end{array}$ & $\begin{array}{l}0.46^{*} \\
(0.17)\end{array}$ & 0.49 & 0.003 \\
\hline $\begin{array}{l}\text { FPVA in other } \\
\text { settings }\end{array}$ & $\begin{array}{l}0.32^{*} \\
(0.11)\end{array}$ & $\begin{array}{l}0.35^{*} \\
(0.16)\end{array}$ & 0.88 & 0.000 \\
\hline $\begin{array}{l}\text { FVPA outside of } \\
\text { School }\end{array}$ & $\begin{array}{r}0.26^{*} \\
(0.10)\end{array}$ & $\begin{array}{l}0.09 \\
(0.14)\end{array}$ & 0.32 & 0.006 \\
\hline
\end{tabular}

$* \mathrm{p}<.05 * * \mathrm{p}<.01$

Note. *on an adjusted mean indicates a significant change from pre to post within group.

Note. Sample sizes for experimental group ranged from 123-130, comparison group from 41-54.

Note. Ethnic means in a column/row with different superscripts are significantly different using Holm's sequential Bonferroni, $\mathrm{p}<0.05$.

\section{Research Question 1}

Research question 1 asked, What is the effectiveness of a self-selected conceptually based health and wellness course in developing the health related factors of cardio-respiratory endurance, body fat composition, muscular strength, muscular endurance and flexibility among a racially and ethnically diverse student population? The research question was designed to assess the effectiveness of a self-selected health and wellness course on fitness parameters among its participants, in contrast to a comparison group who did not receive any formal instruction on health and wellness or an exercise component for a period of 16 weeks. The participants' fitness factors were assessed at the beginning and at the conclusion of the semester. An ANCOVA was conducted on each fitness parameter across the assessment periods. 


\section{Research Hypothesis 1}

Participants in a 16-week program of health and wellness will increase their body fat loss, cardiorespiratory endurance, muscular strength, muscular endurance and flexibility at the conclusion of the semester in relation to the comparison group. The ANCOVA results indicated no statistical difference between the groups in body fat loss. However, there was significant group difference by ethnic interaction with Hispanics in the experimental group losing more body fat than non-Hispanics. Hispanics in the experimental group lost a significant amount of body fat by the end of the semester. Men from both groups, experimental and comparison, lost more body fat than women by the end of the 16 weeks.

For the cardiorespiratory endurance test, the experimental group improved their running time, $p<.001$, whereas the comparison group decreased their running time scores at the end of the semester with no differences found by gender or ethnicity. In situps, a statistical difference was found between groups with the experimental group improving significantly, over the comparison group, $p<.05$. In dominant hand strength, the experimental group participants also increased their strength after the 16-week period when paralleled to the comparison group, $p<.05$. Hispanics increased their dominant hand strength significantly greater than the non-Hispanics. Nonetheless, within each group of Hispanics or non-Hispanics there was significant difference from pre to posttest.

Results of the non-dominant hand strength test revealed a significant difference between the groups, with the experimental group improving while the comparison group decreased in strength, $p<.01$. There was also a significant difference by gender, with men improving significantly while women's non-dominant hand strength decreased 
significantly. A significant interaction between group and ethnicity was found, with nonHispanics from the experimental group increasing strength more than non-Hispanics from the comparison group. In non-Hispanics, the experimental participants improved their non-dominant hand strength. In the comparison group, Hispanics had greater change than non-Hispanics. However, this was due to the non-Hispanics decreasing in strength in the posttest analysis.

In push-ups, the experimental group improved over the comparison group by the final assessment, $p<.01$, and men significantly improved in their results of push-ups over the results of women. Flexibility results showed no significant difference between groups, by gender or ethnicity.

To summarize, from seven fitness tests given to the participants of both groups, the experimental group significantly improved in five tests over the comparison group, $p$ $<.05$. Although there was no significant difference by group in body fat loss, there was a significant interaction of group by ethnicity because the Hispanic experimental group lost more body fat than the experimental non-Hispanics from pre to posttest. There was no significant difference by group in flexibility. The semester was only 16 weeks, and the results of five different measures were significant; therefore, this study suggests that across ethnic and gender groups a health and wellness class is valuable for physical health.

\section{Research Question 2}

Research question 2 asked, How does such a course impact the exercise selfefficacy level of racially and ethnically diverse students enrolled in the course? The research question was designed to assess the effectiveness of a self-selected health and 
wellness course among participants on fitness self-efficacy, in contrast to a comparison group that received neither formal instruction on health and wellness nor an exercise component for a period of 16 weeks. The participants' fitness self-efficacy was assessed at the start and at the end of the semester. The self-efficacy scale was divided in three sections: external barriers, internal barriers, and self-report of behavior.

\section{Research Hypothesis 2}

Participants in a 16-week program of health and wellness will increase their confidence in participating in fitness activities more than the comparison group. The research findings revealed a significant difference between groups in confidence to deal with external barriers to exercise, $p<.05$, no significance between groups in internal barriers to exercise, and significance between groups in self-reported efficacy, $p<.01$ with participants in the experimental group reporting more self-efficacy. Two of the three sections indicated the experimental group increased significantly in confidence to participate in physical activities in spite of obstacles.

\section{Research Question 3}

Research question 3 asked, How does a self-selected health and wellness course impact the knowledge of racially and ethnically diverse students concerning health issues and physical activity participation? The research question was designed to assess the effectiveness of a self-selected health and wellness course among participants on knowledge of health related topics, in contrast to a comparison group with no formal instruction on health and wellness and no exercise component for a period of 16 weeks. The participants' knowledge of health and wellness related topics were assessed at the start and at the end of the semester. 


\section{Research Hypothesis 3}

Participants in a 16-week program of health and wellness will become more knowledgeable in health related topics by the completion of the semester, more than the comparison group. The ANCOVA demonstrated that the experimental group improved significantly over the comparison group. In fact, although the experimental group improved in health related knowledge, the comparison group decreased their knowledge score results.

In addition to the fitness tests, self-efficacy scale, and knowledge exam, the participants received a nutrition questionnaire to assess their nutritional habits. The results indicated both groups, experimental and comparison, improved their scores from the initial assessment to the end of the semester but the experimental increased their score more.

In summary, the ANCOVA results indicated participation in the health and wellness courses improved some individual fitness factors, self-efficacy of exercise, knowledge of health related topics, and nutritional habits. While the comparison group had been given similar feedback on their state of fitness at the beginning of the semester, they did not make the same lifestyle changes without the support of the course. 


\section{CHAPTER V}

\section{DISCUSSION}

This chapter summarizes the study and discusses the findings. The chapter includes the implications for practice, teaching, policy, and research and concludes with limitations of the study.

\section{Summary of the Study}

The fitness levels of college students are declining or failing to improve, and the greatest reduction in physical activity occurs to those between the ages of 18 and 24 (CDC, 2006). Current studies have documented the lack of physical activity and the increase of body fat composition in the college student population (CDC, 2006; Leslie, Sparling \& Owen, 2001; Sparling, 2007). Pribis, Burtnack, McKenzie, and Thayer (2010) reported in their study of physical fitness in relation to BMI and body fat composition among university students from 1996 to 2008 a significant decline in the fitness level and an increase in body fat composition. Pribis et al. (2010) study results challenge the Health and Human Services (2008) Physical Activity Guidelines for Americans on the amount of physical activity needed to obtain health benefits. The recommendation for children and adolescents is to perform 60 minutes or more of physical activity, one that includes all of the major muscle groups, per day and additional strength training three times a week. For most adults a minimum of 150 minutes of moderate-intensity aerobic activity should be performed weekly with 2 days of strength training.

Johnston et al. (2010) concluded that college students decline their physical activity performance levels as they increase their years of study from freshman to seniors. 
However, if college students are given interventions where they are instructed to perform physical activities throughout the semester, they become more physically active (Claxton \& Wells, 2009), which enhances their overall health and assists in maintaining proper body weight.

Health related courses inclusive of active participation in physical activities are not required in most colleges and universities throughout the United States, which may be a contributing factor to the increase of body fat in many college students and the decline of physical activity participation. Minority college students in particular do not participate in physical activities while attending college, so physical activity interventions aimed at this population are critical (Suminski et al., 2002). The purpose of this study was to assess the effectiveness of a conceptually based health and wellness course in developing physical fitness factors, self-efficacy of exercise, and knowledge of health related topics to ethnically and racially diverse college students participating in a selfselected 16-week semester class.

\section{Hypothesis 1}

The first hypothesis stated that there would be a positive relationship between participation in a health and wellness course and fitness scores. The results from the ANCOVA indicated a significant positive relationship between enrollment in a health and wellness class and improvement of cardiorespiratory endurance and muscular endurance and strength. However, based on the findings of the ANCOVA results, there was no significant difference between the experimental and the comparison group in body fat loss and flexibility. 


\section{Cardiorespiratory Endurance}

The results of the ANCOVA procedure supported hypothesis 1 after statistically controlling for pre-walk run time, gender, and ethnicity. It is important to control for covariates because they could conceivably affect the dependent variable. In this manner, the relationship between the treatment and the outcome can be assessed accurately (Creswell, 2008). The experimental group's decrease in running time was significant, $p<$ .05 with a $95 \%$ confidence interval $[-0.86,-0.11]$, and the comparison group actually increased in time during the walk-run, $p<.05,95 \%$ CI $[1.32,2.52]$, which indicated cardiovascular improvement for participants of the experimental group. The benefits of physical activity as a contributor to cardiorespiratory endurance have been documented (Fahey et al., 2011; Hoeger \& Hoeger, 2007; Powers \& Dodd, 2009; Stokes et al., 2009). The present study concurred with the literature review and provided support for the benefits for this ethnically diverse sample.

\section{Sit-Ups, Push-Ups}

The first hypothesis was equally supported by the results of the ANCOVA. The findings indicated that the participants in the experimental group performed significantly better in sit-ups and push-ups than the participants in the comparison group. It is suggested that as the participants in the health and wellness course engaged in weekly exercise sessions, their muscular endurance increased while the comparison group presumably maintained a more sedentary lifestyle. In fact, the result obtained in the push-ups test was significantly better for the experimental group at $p<.001$. In addition, men performed significantly better in push-ups than women both at the beginning and at the end of the semester. These outcomes are to be expected because physiologically men 
have a greater number of muscle fibers and sex-specific male hormones that allow for greater muscle hypertrophy and thus a greater ability to perform push-ups than women (Fahey et al., 2011).

\section{Strength}

The strength test indicated that the experimental group increased their strength by almost $1 \mathrm{~kg}$ in their dominant hand and over $1 \mathrm{~kg}$ in the non-dominant hand. The comparison group, however, lost strength rather than improved from the pre-test results. There was also a significant difference between men and women with men increasing their strength significantly. A significant ethnic interaction was also found. For the nondominant hand, the non-Hispanics in the experimental group increased their strength over the comparison group non-Hispanics and also increased their strength from pretest to posttest at $p<.05$. However for the dominant hand, the Hispanics increased in strength over the non-Hispanic group even though neither of the ethnic groups increased significantly in strength from pre to posttest. Strength, unlike cardiorespiratory endurance, is a health factor that requires long-term training periods in order to display positive results. Because the study was conducted during a training period, which lasted 16 weeks, it was not expected for the participants in the experimental group to have improved muscular strength considerably. Therefore, any significant difference is important.

\section{Body Fat Composition}

Hazelwood (2007) found that those participants who were athletes or were enrolled in a physical activity program significantly decreased their body fat composition over the comparison group. However in the present study, there was not a significant 
difference by group. The results indicated a significant difference by ethnic interaction so that those Hispanic participants in the experimental group lost more body fat than the non-Hispanics in that group by the end of the semester. It is suggested that Hispanics in the experimental group may have lost more body fat due to their increase in physical activity after a period of inactivity or leading a sedentary lifestyle. In addition, there was a significant difference by gender with males losing more body fat than females, $p<.001$. Additionally, the men's weight loss was significant from pretest to posttest, $p<.05$, but women did not lose weight at a significant level. These findings are in agreement with a study that indicated the prevalence of physical inactivity being higher for females and minorities compared to other subgroups (McArthur \& Raedeke, 2009). In a similar study, Hall et al. (2002) listed gender as the variable with the strongest relationship to physical activity in college students. Regardless of race, men engaged in higher levels of physical activity and at greater intensity than women, even though minority women revealed very low levels of physical activity. They also found a relationship between physical activity level and reasons for men and women wanting to engage in physical activity, mainly that men participate in exercise programs for enjoyment and fitness whereas women are more interested in weight control. All of these factors may be attributed to the higher amount of fat and weight loss in men over women. Considering the time frame was only 16 weeks and was focused on long term health rather than rapid weight loss, the findings here are not surprising.

\section{Flexibility}

Flexibility among college students participating in the experimental group and in the comparison group was not significantly different. Although both groups reported 
improvement, the experimental group did not improve significantly more than the comparison group. Flexibility is related to range of motion in a joint and requires the lengthening of soft tissues surrounding the joint to allow for a greater range of motion. However, there are various anatomical factors that can limit movement, such as the shape of bones, connective tissue, tendons, stiff muscles, and scars from previous injuries that cause tight skin (Powers \& Dodd, 2009). Unless the individuals involved in physical activity perform a series of stretching exercises to enhance the flexibility of the joints, the participants can gain strength and other benefits of exercise and not gain any flexibility. It is important to reiterate that flexibility is joint specific and if stretching exercises are not performed on a continuous basis, the desired flexibility will not be obtained. In addition, the sit and reach test is a measurement of lower back and hamstring flexibility, an area of the body that is very sensitive for many individuals due to its association with low-back pain (Fahey et al., 2011). The lack of improvement in flexibility at a significant level between groups may have been influenced by some of the factors mentioned above. The course was taught following a format of lectures and exercise sessions on topics related to health and wellness such as importance of cardiovascular endurance, selfefficacy, resistance training and flexibility guidelines, nutritional requirements and daily food choices, stress management and weight management among others. However, based on the results, it is suggested that the faculty may need to revise the curriculum and consider placing more emphasis on flexibility if so desired.

\section{Hypothesis 2}

Hypothesis 2 stated that students participating in the experimental group would report higher levels of exercise self-efficacy over the comparison group due to their 
active participation in physical activities and their beneficial effects, as well as from the knowledge gained in class on health and wellness issues throughout the 16 week semester. Exercise self-efficacy is a reliable predictor of physical activity behavior (Kim, 2007; Sidman et al. ,2009; Sullum et al. , 2000). Among adults there is a strong relationship between exercise self-efficacy and higher physical activity participation (Hu, Motl, McAuley, \& Konopack, 2007). Exercise self-efficacy and enjoyment of physical activity in college-aged women are determinants of physical activity behavior (Hu et al., 2007). However, the current study was trying to determine if continuous physical activity, being a component of a health and wellness course, would actually increase the participants' exercise self-efficacy throughout the semester as they learned and experienced the benefits of physical activities performance.

Regulatory self-efficacy for physical activity has been commonly measured with items asking about one's belief in his or her ability to be active is spite of common barriers to physical activity. The self-efficacy instrument used for the current study was divided in three sections: external barriers that keep individuals from performing vigorous physical activity (VPA), internal barriers that keep individuals from performing VPA, and self-report of behavior.

\section{External Barriers}

The results for external barriers found a significant difference between groups from pretest to posttest with the experimental group increasing the score for external barriers substantially while the comparison group's results decreased considerably ( $M=$ .01). There was also a significant interaction by ethnicity with Hispanics in the experimental group having greater exercise self-efficacy than Hispanics in the 
comparison group. However, this occurred due to decreasing results of the Hispanic comparison group, not due to a significant change in the results of the experimental Hispanic group. In addition, the non-Hispanic comparison group had significantly greater changes in external barriers $(M=-.09)$ than the Hispanic comparison group, which actually decreased $(M=-.63)$ in the results of external barriers. These results are consistent with other studies that indicated that cultural disparities may influence attitudes and beliefs about physical activity among Blacks and Hispanics, specifically in college-age females (D’Alonzo \& Fischetti, 2008).

\section{Internal Barriers}

Participants of both experimental and comparison groups did not report scores that were significantly different from pretest to posttest. The perceived barriers of illness, stress, discomfort, or lack of discipline were strong determinants for lack of participation from students of both groups. Self-efficacy beliefs provide the basis for motivation and the actualization of behavior change (Valois, Umstattd, Zulus, \& Paxton, 2008). Additionally, there are distinct differences in the cultural beliefs held by Hispanics and Blacks in reference to physical activity participation. Blacks and Hispanics have been found to be less physically active than other minorities (McAthur \& Raedeke ,2009; Suminsky, 2002) with many of the barriers being external and internal such as lack of time, lack of family support, home tasks, family issues and child care, lack of facilities, cost, feeling too embarrassed to exercise and the perception of exercise as boring (Marquez et al., 2004; Sanderson, Foushee, Bittner, Cornell, Stalker, Shelton \& Pulley, 2002). The demographics of this study indicate a large number of participants being Hispanics and Blacks, which may account for the internal barriers being such a strong 
determinant of physical activity. Even though the results of the study indicated Hispanics in the experimental group increasing over the comparison group, this only occurred due to the significant decrease of the comparison group. The results of this study suggests that physical activity interventions that are culturally appropriate should be created to increase the likelihood of participation in physical activity by minority groups. For example, research shows that social support is a positive determinant of physical activity in women ( Eyler, Wilcox, Matson-Koffman, Evenson, Sanderson, Tompson, Willbur \& Rohm-Young, 2002). Therefore, the creation of programs where the entire family can participate in recreational centers and churches may elicit an increase in physical activity participation by all family members. Members of minority organizations should be included in needs assessments and program planning with meaningful components that will empower minority groups and increase the likelihood of membership and participation in physical activities. Establishing the importance of physical activities just is not enough. Combining psychological, interpersonal and environmental components with social support may increase physical activity among Hispanics and Blacks.

\section{Self-Report of Behavior}

The experimental group increased significantly in their desire to participate in exercise when compared to the comparison group, $p<.05$. They responded positively to questions about participation in physical activity in various settings: during class, intramural activities, and independently of class in settings such as fitness centers. Similarly, in another study, students in a university-required personal wellness course reported significant improvement in attitude toward physical activity participation after completing the course (Mack \& Shaddox, 2004). These findings suggest that a health 
and wellness course may positively influence the attitudes and behavior of students toward physical activity. As a result of this course, this multiethnic group of students was more physically active at the end of the semester, a time when activity typically decreases.

\section{Hypothesis 3}

It was hypothesized that students who participated in a health and wellness course would increase their knowledge of health issues and exercise performance over those students who did not participate. The potential reach and impact of a health and wellness course in developing positive lifestyle factors can have implications for long-term health outcomes. However, the importance of physical activity has been undermined by school districts in K-12 as well as colleges and universities by eliminating many of their health and wellness requirements. Nonetheless, physical education can make important contributions in the primary prevention of inactivity-related chronic diseases and to the general education of the college student. Awareness and advocacy are needed to strengthen college wellness and fitness education programs. Knowledge of issues related to health and wellness helps students to make informed choices and understand the value of leading a physically active lifestyle. Students may think they are knowledgeable on health issues; however, research has indicated that many college students have a poor understanding of wellness and its various components prior to enrolling in a health and wellness course (McCormick \& Lockwood, 2006). Additionally, retention of knowledge on health related factors and nutrition was studied by Adams et al. (2006). It was concluded that students enrolled in a conceptually based course retained knowledge on 
health related topics for a minimum of 4 years and presented greater levels of health related knowledge over a comparison group that had never taken the course.

In the present study, the results for the health and wellness knowledge test indicated an increase in knowledge for the participants in the experimental group over the comparison group, $p<.001$. The results in the pretest for the experimental group were average with overall scores of 50 to $60 \%$ correct and the comparison group results were poor with overall scores of less than $50 \%$ correct. Not only did the comparison group not improve, they even decreased in their posttest knowledge results. It would be expected for the experimental group to increase in knowledge, but it is not known why the comparison group posttest knowledge scores decreased. One suggestion could be that because the knowledge tests were given towards the end of the semester when finals were in effect, perhaps the comparison group did not pay much attention to the questions as they had other topics to worry about, and they knew the knowledge test would not count towards a grade. Another possible factor for their lack of knowledge may have been due lack of motivation to do well or to the cultural background of the students. The study was conducted in a Hispanic-Serving Institution and Hispanics, although at high risk for heart disease and type 2 diabetes, have very limited knowledge regarding cardiovascular diseases and their risk factors (McMahan et al., 2007). However, in the present study significant differences were found between groups and Hispanics were participants in both experimental and comparison groups. This attests to the importance of the health and wellness course. 


\section{Nutrition}

Studies suggest that students gain anywhere from 10 to $15 \mathrm{lbs}$. during the first year of their college experience and this may be due to several factors, including physical inactivity, poor dietary choices, increased caloric intake, increased stress, and disturbed sleep patterns (Ferrara, 2009). Yet other studies specifically relate students' weight gain to students living independently for the first time in their lives and making the wrong nutritional choices (Levitzky, Halbmaier \& Mrdjenovic, 2004; Muth, 2008).

A nutritional questionnaire was given to both groups in the present study with questions about nutritional choices. The participants were mostly of Hispanic heritage, so their nutritional choices could be different than the Anglo American population. In general, Hispanics have a more negative attitude towards healthy eating and making changes in their current weight than Whites (Marquez et al., 2004). However, the statistical results for the present study indicated that the experimental and comparison groups improved in their choices of healthy foods over unhealthy foods. The improvement in nutritional choices occurred similarly to participants of both groups regardless of gender or ethnicity. Subjects from both groups may have increased their nutritional awareness throughout the semester due their participation in the study which may have caused motivation and concern about their health. It is suggested that the experimental group, who was lectured on nutrition and weight control, had higher scores over the comparison group but they started higher as well. These results suggest that there could have been an adjustment period for students from the beginning to the end of the semester where they learned to make better nutritional choices. However, the results of this study contradict the literature on the current trend of college men and women in 
reference to nutrition. As previously stated, studies have shown that students change their nutritional habits in an unhealthy direction during their first year in college which is responsible for weight gain in both men and women along with a decrease in physical activity (Levitsky et al., 2004; Pliner \& Saunders, 2006). However, the institution where this study took place did not provide housing for students or cafeterias with meal plans which can be a factor to students' increase in body weight. It is suggested that this component may have contributed to the positive results on healthy nutritional choices in this study in contrast with the results of other studies on college freshmen.

In summary, five of the seven physical fitness tests were statistically significant at $p<.05$ or lower with the experimental group increasing in performance over the comparison group after attending a 16-week health and wellness course. In addition, the $\eta^{2}$ (eta square) was used to determine the effect size (ES) index, which indicates the proportion of variance of the dependent variable, related to the factor, holding constant the covariate (Green \& Salkind, 2011). The effect size, which is valuable for quantifying the effectiveness of a particular intervention over a comparison group, resulted in a large effect size in one test, while other results indicated medium and small effect sizes. In terms of the $f$ values and proportion of variance (PV) accounted for, $\mathbf{f}=.10$ implies a PV of $\eta^{2}=.0099$ and it is categorized as a small effect size, an $\mathrm{f}$ value of $\mathbf{f}=.25$ implies a $\mathrm{PV}$ of $\eta^{2}=.0588$, and it is categorized as a medium effect size and an $\mathrm{f}$ value of $\mathbf{f}=.40$ implies a PV of $\eta^{2}=.1379$, as a large effect size (Cohen, 1988; Green \& Salkind, 2011). The strength of the relationship between the treatment (16 weeks of health and wellness course) and the results of the 1.5 mile run in the posttest was very strong, as assessed by partial $\eta^{2}=.22, \mathbf{f}=.50$ with participation in the health and wellness course accounting for 
over $50 \%$ of the variance of the pre to post change scores, holding constant the pre-test results of the 1.5 mile run.

From table 4, the fitness tests with significant difference between groups and categorized as having a medium effect size were strength for non-dominant hand with partial $\eta^{2}=.04$ and push-ups with partial $\eta^{2}=.06$. The physical fitness test with significant difference between groups and having small effect sizes based on the partial $\eta^{2}$ of .02 to .03 were body fat interaction by ethnicity partial $\eta^{2}=.03$, sit-ups partial $\eta^{2}=$ .03 , strength for dominant hand partial $\eta^{2}=.02$ and strength of non-dominant hand interaction with ethnicity partial $\eta^{2}=.03$.

From table 5, test results with significant difference between groups were nutritional habits, knowledge, VPA self-report of behavior and VPA external and internal with interaction by ethnicity. These measurements indicated medium effect sizes for knowledge with partial $\eta^{2}=.06$, nutritional habits with partial $\eta^{2}=.038$, VPA external with partial $\eta^{2}=.037$, VPA external group interaction by ethnicity partial $\eta^{2}=.043$, VPA internal group interaction by ethnicity partial $\eta^{2}=.053$, and VPA self-report partial $\eta^{2}=$ .044. The overall significance of the $\eta^{2}$ (eta square) results indicated a strong relationship between the 16 week health and wellness course and the pre to posttest change scores, holding constant all pretest results for most of the analyses.

It should be noted that according to Coe (2002), very few educational interventions result in medium or strong effect sizes due to the difficulties encountered in the improvement of student achievement. Additionally, the effect sizes obtained in this study demonstrated that a health and wellness course can effectively improve the performance of most individuals, positively influence their exercise self-efficacy and 
ameliorate nutritional habits in college students regardless of race or ethnicity. Even an effect size as small as .10, is still a significant improvement if the course provides students with beneficial effects. If students engage in self-selected health and wellness courses and experience some improvement in their lifestyle habits, engage in regular physical activity and make positive changes in nutritional habits, then the health and wellness classes provide a substantial and valuable benefit to college students.

\section{Implications for Practice}

The current trend in colleges and universities throughout the United States is an increase in body fat composition in students as well as a significant decline in their average fitness levels (Pribis et al., 2010; Suminsky \& Petosa, 2002). Therefore, a conceptually based health and wellness course may be the ideal setting for the adherence to exercise. The findings of the present study indicate that participation in a conceptual health and wellness course can be very beneficial for college students. The study participants in the experimental group significantly improved in most of the fitness tests, gained knowledge on health related topics, and reported an increase in their desire to participate in physical activities and exercise self-efficacy at the completion of the course. Therefore, health and wellness faculty and instructional designers should consider making health and wellness courses conceptually based, rather than exclusively physical activity or exclusively lecture.

The results of this study are also significant due to the demographics of the study. Research shows that Black and Hispanic students participate in physical fitness activities at a lower rate while having a higher risk for cardiovascular illness than White students (Blanchard et al., 2008; McMahan et al., 2007). It has also been established that levels of 
leisure-time physical activity for the general population is lower for Blacks and Hispanics when compared to Whites (He \& Baker, 2005; Nies, Vander, Schim, Artinian \& Sherrick-Escamilla 2005; Saffer, Dave \& Grossman, 2011). The number of Hispanics and Blacks currently attending colleges and universities in the U.S. has increased tremendously in the last 2 decades. In 2004, the majority of college students were women and one third were racial minorities (Eckel \& King, 2004). The current study was conducted in a Hispanic-Serving Institution with a sample of students composed of $58 \%$ females and $42 \%$ males, and $70 \%$ Hispanics, $18 \%$ Black non-Hispanics, $8 \%$ White non-Hispanics, and 4\% from other ethnicities (Miami Dade College, 2009). The majority of the students attending this college are affected by their immediate family cultural influences relative to physical activity, nutrition, and other health related behaviors. This college does not provide housing to students; therefore, most of them live at home with parents and relatives, which may create a greater influence in the students' lifestyle habits. Based on the traditional dishes consumed by Hispanics, this may not be necessarily a good thing. Yet this study demonstrated that for a majority -minority population, a health and wellness class improved fitness, beliefs about fitness activities and, knowledge of nutrition.

\section{Implications for Teaching}

This study results suggested that women might be less active than men as indicated in their fitness results. It is imperative that educators in higher education promote health and wellness courses that appeal to women, especially if these courses are not required by the institution. Health and wellness educators need to stress the difference between the style of physical education in K- 12 and at the university level. 
For example, courses such as those that are presently being taught in private wellness centers and fitness clubs: pilates, spinning, piloxing (combination of pilates and boxing), Zumba dancing, and boot camps for women seem to be very popular. These proposed activities could be discussed with students so that they are presented with options that are varied and challenging, allowing them to learn skills and offering an opportunity for socialization. In addition, these kinds of activities combined in a health and wellness course may have more appeal to female students and may start them on a path of lifetime activity.

Self-efficacy is considered a very important factor for behavior change to occur. Findings from the current study did not indicate a significant difference between the experimental and comparison groups in the external and internal barriers for exercise self-efficacy. It is imperative that educators employ interventions that will lessen the perceptions of barriers or obstacles, which prevent students from participation in physical activity such as providing guidance and feedback for students on how to vary their exercise routines to avoid boredom, identifying and finding alternatives in order to overcome barriers like lack of time, dislikes and safety issues (Nahas et al., 2003). Students should also be taught to recognize the intrinsic rewards of physical activity participation by focusing on the feeling of well being and relaxation provided by most aerobic exercises. The findings of this study agree with Naha's and colleagues' conclusions and more importantly extend them to minority students.

It is important that educators set students on a path of lifetime wellness. Physical education programs at the K-12 levels should be required throughout the entire United States with a comprehensive program inclusive of motor skills, knowledge of health 
topics, and lifetime physical activities that offer students competitive and enjoyable games. It is equally important to take into account gender and cultural differences so that physical interventions are applicable and understood by all students. At the collegiate level curriculum interventions are necessary so that health and wellness courses are created to effectively promote physical activity and healthy lifestyle habits in all college students and be a component of the general education requirements in every college and university private and public.

Most college students enroll in health and wellness courses either because they want to learn a new activity, to improve their skills in a given physical activity, or to have fun (Lenders et al., 2003). Health and wellness educators should use this information to implement strategies to engage students in the wellness center in order to promote healthy behaviors. These could be setting weekly goals, and using the buddy system where students are paired up with a classmate and they provide feedback and encouragement to each other in the attainment of goals. This system eliminates boredom and provides positive reinforcement. Additional strategies may be self-assessments through fitness testing and the evaluation of fitness factors, discussions on how to overcome extrinsic and intrinsic barriers to exercise and providing positive and fun activities to improve performance and overall fitness.

\section{Implications for Policy}

Regardless of gender or race, physical inactivity is a major problem for most college students. There is a need to implement a course of action that will engage students in daily physical activities throughout their college years. The accessibility to wellness centers that offer cardiovascular and resistance training equipment as well as 
exercise classes will appeal to some students but will not reach the entire college population. Study results indicate that currently, higher education does not support or encourage students to become physically active (Keating et al., 2005).

The positive results obtained from this study support the addition of a required conceptual health and wellness course in the general education curriculum of U.S. colleges and universities as one of the approaches to combat physical inactivity in this population. Committees responsible for educational policy and programs as well as student organizations and college presidents should seriously consider the adoption of this type of health and wellness course to educate college students on the benefits of physical activity participation and influence their lifestyle choices while in college and throughout their lives. One of the best ways to change beliefs and actions is through doing and these types of courses engage the students in doing physical activities, not just talking about it. In order to keep students active and within health standards it is suggested that all college students be required to take a battery of fitness assessments during their first and last year in college. The fitness assessments would be similar to the ones given in the present study (body fat, CRE, muscular strength, muscular endurance and flexibility) with students having to attain a minimum rating of $60 \%$ (according to age and gender) to pass the tests. Those students who passed the fitness tests successfully would be exempt from taking a health and wellness conceptually-based course. For those students who do not meet the fitness requirements upon entering college, they would need to take the health and wellness conceptually-based class during their first year in college and improve at least 10\% from their initial score assessments. All students would be reassessed at the beginning of their senior year with the same battery of fitness tests. 
They would have to pass the tests with a minimum of $60 \%$ rating or higher according to their age and gender or be required to take the health and wellness course with a minimum of $10 \%$ improvement. Fitness professionals would test students in the institution's fitness center during the first and last semester of enrollment in the institution. Such program, although potentially increasing costs for colleges and universities, will help to promote physical activity and healthy eating in college students as well as reducing the risk for obesity-related disorders in the student population.

Even at the most basic level of K-12 education, the latest trend in most of the nation's schools is to cut back on physical education classes and force students to perform more academic work during the school day. According to the National Association for Sports and Physical Education (NASPE) (2010), only 5 states require physical education in K-12 and more than half of all states permit waivers or exemptions for students to be excluded from taking physical education classes. In addition only 19 states require some form of student assessment in physical education and only 14 states require physical education grades to be included in the student's overall grade average. Ironically, if learning is what educators are looking for, then exercise is the best way to prepare the brain for cognition and understanding. Research has shown that adolescents improve academically when exposed to exercise throughout the day. Field, Diego and Sanders (2001) reported in their study of 89 suburban high school seniors that those students who engaged in high levels of exercise had better relationships with their parents, low levels of drug use, and better academic performance. Even though not all studies have found a definite benefit in academic performance from exercise, there is sufficient data on this topic, which presents a strong case in favor of physical activity as a 
contributor to enhancement in academic performance. For example, in 2002 and 2005, the California Department of Education reported the results of two studies that compared the relationship between a Fitnessgram (a battery of physical fitness tests given to students from kindergarten through $12^{\text {th }}$ grade), and achievement on academic tests. The results indicated that the higher levels of fitness were paralleled with higher levels of academic performance, especially in the area of math achievement (Tyson \& Chalmers, 2007).

Presently, First Lady Michelle Obama, who has made battling childhood obesity one of her signature causes, created "Let's Move", a competitive program designed to increase physical activity in schools and improve the health of children in the United States (Let's move!.gov, 2011). This is the type of innovative program that should be implemented if any positive changes are to be expected from children and adults in the U.S. in reference to physical activity and illness prevention. The failure to meet the goals of Healthy Campus 2010 and Healthy People 2010 by Americans is an indication that merely developing health goals is not sufficient to actually improve the health of a population.

The importance of a quality physical education program in K-12 and health and wellness program at the college level has been linked to a higher quality of life as well as academic achievement. There is sufficient research to indicate that regular physical activity in childhood and adolescence improves strength and endurance, helps build healthy bones and muscles, helps control weight, reduces anxiety and stress and increases self-esteem (NASPE, 2010; Ratey, 2008). In contrast, the U.S. Surgeon General (2001) reported that youngsters who are overweight or obese have a 70 to $80 \%$ probability that 
they will remain overweight or obese as adults. In addition, $46 \%$ of Hispanic men 18 and older are overweight or obese as well as 35\% of Hispanic women 18 and older (CDC, 2006). These statistics are not very optimistic for students entering college. The present study is indicative that a health and wellness course can positively affects the lives of most college students. More decisive and explicit methods are at times required, and the establishment of a health and wellness course at the college level may promote physical activity behaviors in college students who may otherwise adopt a sedentary lifestyle. Colleges and universities must play a major role in the prevention of unhealthy behavior in college students and the promotion of physical activity as well as a healthy lifestyle. The author suggests that the college setting may be the last chance to reach a large number of students.

\section{Implications for Future Research}

Most investigations related to healthy behavior and physical activity that have included Hispanics have been conducted on Hispanics of Mexican descent. Hailing from at least 20 countries, Hispanics compose $16 \%$ of the total population of the United States (U.S. Census Bureau, 2010). The uniqueness of this study is that most of the Hispanic participants were descendants of Cuba, Colombia, and other Latin American countries. No participant was of Mexican descent. It is important not to generalize the findings of studies conducted on Hispanic populations and to emphasize the Hispanic subcultures and their heterogeneity. Therefore, future research around healthy behavior and physical activity should include participants from various Hispanic backgrounds.

Replication of this study within the State of Florida and in various other states would be recommended. The demographics of this study is somewhat unique to South 
Florida where most of the Hispanic population resides in Miami-Dade, Broward, and Orange county (U.S. Census Bureau, 2010), and it is composed mostly of Cubans, Puerto Ricans, and Colombians. However, about 14 different nationalities make up the Hispanic population in Florida, and the study represents the spectrum of Hispanics; but future studies, particularly looking at nutrition may need to examine the sub-cultures separately. In reference to the Hispanic population in the U.S., California, Texas, and Florida have the largest number of residents and in order to validate the results of this study and establish generalizability, it is suggested that a similar study be replicated in various other states with large numbers of Hispanics. In addition, due to the large number of Hispanics in California, Texas and Florida, researchers can replicate this study with large sample sizes of each Hispanic group rather than combining them all together under the heading of Hispanic. The present study attempted to disaggregate the population by ethnic origin. However this was not possible due to the low numbers of Central and South American students participating in the study. The objective was to analyze the data from a population sample of students from the Caribbean, Central America and South America each as an independent group; but the results indicated that almost two third of the students originated from the Caribbean and very few from Central and South America. Therefore, the results were combined and reflected as Hispanic versus non-Hispanic. Presently there are 47.8 million Hispanics residing in the United States (U.S. Census Bureau, 2010), and it is predicted that in the year 2030 there will approximately 73 million Hispanics. This is a clear indication that the Hispanic population will continue to increase and very likely the number of Hispanics college students will increase too. While a wide range of risk factors and diseases affect Hispanics, nearly every health 
disparity they experience could be lessened if they were to increase their daily physical activity and follow proper nutritional guidelines. However, people do not engage in physical activity simply because it is beneficial to them. More research should be done to find out what factors are related to Hispanic students' willingness to enroll in health and wellness classes. It is imperative to investigate what motivates minority students to participate in physical activity and provide interventions that are culturally appropriate for them.

In the future, replications of this study could include a qualitative component using focus groups to investigate the attitudes, barriers, and social issues unique to Hispanics of different cultural backgrounds in relation to physical activity. For example, Chepyator-Thomson et al. (2007) interviewed African American women attending a southern university. As a result, various themes emerged that explained why many African American women do not like to engage in physical activity such as the lack of a role model or not being introduced to a culturally responsible curriculum in a health and wellness course. College campuses are important settings where the promotion of lifestyle habits can be implemented for all college students regardless of race or ethnicity. Future studies need to address the issues of healthy eating and the inclusion of physical activity in the college student population in order to decrease the current obesity trend and encourage healthy habits throughout their college years and beyond.

\section{Limitations}

One of the limitations of the study is the number of students who withdrew from the courses and therefore, the study had approximately 160 students completing the course out of a possible 225 students initially enrolled in the study. However, the sample 
population was representative of the total population of students attending this Hispanic Serving Institution, and a population sample of 160 students was adequate for a robust statistical analysis. Secondly, the study was conducted during a period of 16 weeks and changes were measured with a pre-post test quasi-experimental design. However, a longer longitudinal study would allow the researcher to observe changes over an extended period of time and determine the long term impact of the health and wellness course on physical activity participation and healthy behaviors of the participants in the experimental group after engagement in the course ends. In addition, a retention test could have been added to the study to see if healthy behavior was stable over time.

Another limitation of the study is that cluster sampling was used for the research since six classes of students enrolled in a health and wellness course were chosen for the study, and three classes from a student life skills course composed the comparison group. All of the students enrolled in these classes were invited to be in the study, they were not chosen using stratified random sampling pure random sampling. However, the sample was representative of the larger population of students attending this institution, and the use of a comparison group that did not receive the treatment increased the rigor of the study.

Even though students were given physical fitness assessments as pre and posttests, there were self-reported nutrition and exercise self-efficacy questionnaires, which were given at the beginning of the semester and during the last week of the 16 -week semester when students were undertaking final exams in their classes. For future research, it may be advisable to provide the post-test questionnaires a week prior to the completion of the semester; this may assist in the accuracy of the completion of such 
questionnaires. However, the physical fitness post-tests were given a week prior to the end of the semester.

In reference to the instruments used for testing purposes, they were originally created for military personnel, for example the 1.5 mile run was created for the U.S. Navy and assessed in White males (Powers \& Dodd, 2009). It is suggested that fitness tests be validated for specific ethnic groups such as Hispanics, African-Americans and other minorities with instructions that are easily understood by the individuals taking the tests whose first language may not be English. This will facilitate proper execution of the test protocol which will validate the results.

Lastly, students involved in the study were informed of the design method for the research and perhaps the knowledge that they would be tested at the completion of the semester by the researcher provided an incentive and motivation to improve their fitness levels and healthy behaviors. This is known as attention bias because the students involved in the study are aware of their involvement and they may perform better than if they were tested without being part of a research study (Hartman, Forsen, Wallace \& Neely, 2002). However this was true for both the treatment and comparison group. Therefore, this influence was assumed to be similar across groups.

\section{Summary}

In summary, the study demonstrated that physical interventions conducted in campus settings could positively influence the level of physical activity in students, teach them to make healthier nutritional choices and increase their exercise self-efficacy. The potential benefits of a required instructional course of health and wellness merits further research and serious policy consideration. Further, this study provides strong support for 
conceptually based health and wellness courses that include actual physical activity as part of the class as well as health knowledge. Combined with prior research that emphasized White students, this study suggests that this coursework is valuable for most students regardless of race or ethnicity.

The college campus offers the possibility of creating an environment that encourages physical activity and a healthy lifestyle. However, as research has shown, long-term maintenance of physical activity in the college student population is difficult to maintain, Calfas et al.(2000). Regardless of the methods that are implemented, successful interventions need to be created for the collegiate student population to engage in regular amounts of appropriate physical activity during their college years. As previously stated, a conceptually-based health and wellness course is the only academic unit that deals directly with the body and as such it can serve as a vehicle to help students develop the knowledge, attitudes, motor skills, behavioral skills, and confidence needed to adopt and maintain physically active lifestyles.

The United States spends more on health care annually than 12 other industrialized countries, and one of the main reasons is due to the large number of Americans being overweight or obese which increases health spending due to more doctor visits and more medical interventions. In spite of the high cost, the quality of health care in the U.S. is not much better than many other industrialized countries (Squires, 2012). If the national health is to improve and health care costs are to diminish for all Americans, it would seem appropriate to begin overweight and obesity prevention at the K-12 and collegiate level with mandatory physical education courses every year in $\mathrm{K}-12$, regardless of budget cuts and the requirement of a conceptually-based wellness 
course at the college level. The outcomes of a conceptually-based wellness course can include the development of students' physical competence, health-related fitness, selfesteem, self-confidence and overall enjoyment of physical activity. These outcomes along with meaningful content on health related topics could enable students to make informed decisions and choices about leading a physically active lifestyle during their college years and throughout life. It is imperative for this type of course to be included in the general education requirements of every college and university in the United States. To not do so, will only exacerbate the obesity and metabolic syndrome epidemic currently undergoing in the United States. 


\section{REFERENCES}

Adams, T. (2007). Predicting 1 year change in BMI among college students. Journal of American College Health, 55(6), 361-366.

Adams, T. M., \& Bryntenson, P. (1992). A comparison of attitudes and exercise behaviors of alumni from universities with varying degrees of physical education activity programs. Research Quarterly for Exercise and Sport, 63, 148-152.

Adams, T. M., \& Bryntenson, P. (1995). The effects of two types of required physical education programs on attitudes and exercises habits of college alumni. The Physical Educator, 52, 203-210.

Adams, T., Graves, M., \& Adams, H. (2006). The effectiveness of a university level conceptually-based health-related fitness course on health-related fitness knowledge. The Physical Educator, 63, 104-112.

Adams, II T., Higgins, P., Adams, H., \& Graves, M. (2004, April). Effects of a required conceptually-based basic physical education course on university students' attitudes, exercise habits, and health related fitness knowledge. Poster Session at annual meeting of the American Alliance of Health, Physical Education, Recreation and Dance, New Orleans, LA.

Ainsworth, B. E., Berry, C. B., Schnyder, V. N., \& Vickers, S. R. (1992). Leisure-time physical activity and aerobic fitness in African-American young adults. Journal of Adolescent Health, 13, 606-611.

American College Health Association. (2010). Leading health indicators. Retrieved from http://www.acha.org/info resources/hc2010.cfm

American College Health Association. National College Health Assessment. (2007). Reference Group Executive Summary, Fall 2007. Retrieved from http://www.acha-ncha.org/index.html.

American College of Sports Medicine. (2006). ACSM's guidelines for exercise testing prescription $\left(7^{\text {th }}\right.$ ed). Philadelphia, PA: Linpicott Williams \& Wilkins.

Avans, D. (2003). Knowledge of college students enrolled in a general fitness course. Research Quarterly for Exercise and Sport, 74(1), 1-4.

Bandura, A. (1986). Social foundations of thought and action: A social cognitive theory. Englewood Cliffs, NJ: Prentice- Hall.

Bandura, A. (1997). Self-efficacy: The exercise of control. New York, NY: W.H. Freeman. 
Blanchard, C., Fisher, J., Sparling, P., Nehl, E., Rhodes, R., Courneya, K., \& Baker, F. (2008). Understanding physical activity behavior in African American and Caucasian college students: An application of the theory of planned behavior. Journal of American College Health, 56 (4) 341-346.

Blaser, L.M. (2005). The impact of a university wellness requirement on student nutrition and physical activity behavior. (Master of Science Thesis, Brigham Young University). http://contentdm.lib.byu.edu/ETD/image/etd735.pdf

Body Composition Analyzer. Tanita body fat analyzer. Retrieved from http://www.tanita.com/es/body-composition-analyzer/

Bray, S.R.,\& Born, H.A. (2004). Transition to university and vigorous physical activity: Implications for health and psychological well-being. Journal of American College Health, 52(4), 77-82.

Bryntenson, P. (1985). The aerobics program at Oral Roberts University. In. D. Cundiff (Ed).Implementation of health fitness exercise programs (pp. 79-83). Reston, VA: American Alliance for Health, Physical Education, Recreation and Dance.

Bryntenson, P., \& Adams, T.M. (1993). The effects of conceptually based physical education programs on attitudes and exercises habits of college alumni after 2 to 11 years of follow-up. Research Quarterly for Exercise and Sport, 64, 208-213.

Bryntenson, P., Adams, T.M., \& Schollmeier, S. (1990). A university health fitness program revisited. Journal of Physical Education, Recreation \& Dance, 62, 7377.

Buckworth, J. (2001). Exercise adherence in college students: Issues and preliminary results. Quest, 53, 335-345.

Buckworth, J., Granello, D.H., \& Belmore, J. (2002). Incorporating personality assessment into counseling to help college students adopt and maintain exercise behaviors. Journal of College Counseling, 5 (1), 15-25.

Buckworth, J., \& Nigg C. (2004). Physical activity, exercise and sedentary behavior in college students. Journal of American College Health, 53, 28-34.

Butte, N.F., Puyau, M.R., Adolph, A.L., Vohra, F.A., \& Zakeri, I. (2007). Physical activity in nonoverweight and overweight Hispanic children and adolescents. Medicine in Science and Sports Exercise, 39,1257-1266.

Calfas, K.J., Sallis, J.F., Nichols, J.F., Sarkin, J.A., Johnson, M.F., Caparosa, J., Thompson, S., Gehrman,C.A., \& Alcaraz, J.E. (2000). Two-year outcomes of a randomized controlled physical activity intervention among young adults. American Journal of Preventive Medicine, 18, 28-37. 
Cardinal, B.J., Jacques, K.M., \& Levy, S.S. (2002). Evaluation of a university course aimed at promoting exercise behavior. Journal of Sports Medicine and Physical Fitness, 42, 113-119.

Cardinal, B.J., \& Kosma, M. (2004). Self-efficacy and the stages and processes of change associated with adopting and maintaining muscular fitness-promoting behaviors. Research Quarterly for Exercise and Sport, 75(2), 186-196.

Cardinal, B.J., \& Spaziani, M.D. (2007). Effects of classroom and virtual "lifetime fitness for health" instruction on college students' instruction on college students' exercise behavior.The Physical Educator, 64, 205-212.

Center for Disease Control and Prevention - USDHHS. (1996). Surgeon General's Report on Physical Activity and Health. Retrieved from http://wonder.cdc.gov/wonder/prevguid/m0042984/m0042984.asp

Center for Disease Control and Prevention (1999) Physical Activity and Health: A Report of the Surgeon General. Patterns and Trends in Physical Activity. Retrieved from http://www.cdc.gov/nccdphp/sgr/sgr.htm

Center for Disease Control and Prevention. (2006). Health, United States, 2006. Retrieved from http://www.cdc.gov/nchs/data/hus/hus06.pdf\#highlights.

Center for Disease Control and Prevention. (2008). Chronic Diseases and Health Promotion. Retrieved from http://www.cdc.gov/chronicdisease/overview/index.htm

Center for Disease Control and Prevention. (2009). Summary Health Statistics for U.S. Adults: 2007, Table 31. Retrieved from http://www.cdc.gov/nchs/data/series/sr 10/sr10 240.pdf

Chepyator-Thomson, J.R., Russell, J.A., \& Culp, B.O. (2007). African American college women's reflections on physical activity involvement during public school years. Journal of African American Studies, 11, 101-116.

Claxton, D., \& Wells, G. M. (2009). The effect of physical activity homework on physical activity among college students. Journal of Physical Activity Health, 6(2), 203-210.

Coe, R. (2002,Sep.). It's the effect size, stupid. What effect size is and why it is important. Paper presented at the Annual Conference of the British Educational Research Association, University of Exeter, England.

Corbin, C.B. (2002). Physical education as an agent of change. Quest, 54, 182-195. 
Cohen, J. (1988). Statistical power analysis for the behavioral sciences (2nd ed.). Hillsdale, NJ: Lawrence Earlbaum Associates.

Crespo C.J., Smith E., Carter-Pokras, O., \& Andersen, R. (2001). Acculturation and leisure-time physical inactivity in Mexican American adults: results from NHANES III, 1988-1994. American Journal of Public Health, 91(8), 1254-1257.

Creswell, J.W. (2008). Educational research: Planning, conducting and evaluating quantitative and qualitative research $\left(4^{\text {th }} \mathrm{ed}\right)$. Boston, MA: Pearson Education.

D’Alonzo, K.T., \& Fischetti, N. (2008). Cultural beliefs and attitudes of Black and Hispanic college-age women toward exercise. Journal of Transcultural Nursing, 19, 175-182.

DeLong, L.L. (2006). College students' motivation for physical activity. (Doctoral dissertation, Louisiana State University). (AAT3244949)

Despues, D. \& Friedman, H. (2007). Ethnic differences in health and behaviors among college students. Journal of Applied Social Psychology, 37 (1), 131-142.

Dishman, R.K., Motl, R.W., Sallis, J.F., Dunn, A.L., Birnbaum, A.S., Welk, G.J., Bedimo-Rung, A.L., Voorhees, C.C., \& Jobe, J.B. (2005). Self-management strategies mediate self-efficacy and physical activity. American Journal of Preventive Medicine, 29 (1), 10-18.

Doerksen, S., Umstattd, M.R., \& McAuley, E. (2009). Social cognitive determinants of moderate and vigorous physical activity in college freshmen. Journal of Applied SocialPsychology, 39 (5), 1201- 1213.

Dwyer, J.J.M., Allison, K.R., \& Makin, S. (1998). Internal structure of a measure of selfefficacy in physical activity among high school students. Science \& Medicine, 46 (9), 1175-1182.

Eckel, P.D., \& King, J.E. (2004). An overview of higher education in the U.S. diversity, access and the roles of the market place. Washington, DC: American Council on Education.

Eyler, A.E., Wilcox, S., Matson-Koffman, D., Evenson, K.R., Sanderson, B., Thompson, J., Wilbur, J., \& Rohm-Young, D. (2002). Correlates of physical activity among women from diverse racial/ethnic groups. Journal of Women's Health and Gender-Based Medicine, 3, 239-253.

Ermler, K., \& Kovar, S.K. (1993). The effect of three different lifetime fitness class of college Students. Physical Educator, 50 (1), 52-56. 
Fahey, T.D., Insel, P.M., \& Roth, W.T. (2008). Total wellness. San Francisco, CA: McGraw-Hill.

Fahey, T.D., Insel, P.M., \& Roth, W.T. (2009). Fit \& well: core concepts and labs in physical fitness and wellness $\left(8^{\text {th }} \mathrm{ed}\right)$. New York, NY: McGraw-Hill.

Fahey, T.D., Insel, P.M., \& Roth, W.T. (2011). Fit \& well: Core concepts and labs in physical fitness and wellness $\left(9^{\text {th }}\right.$ ed). New York, NY: McGraw Hill.

Ferrara, C.M. (2009). The college experience: Physical activity, nutrition, and implications for intervention and future research. Journal of Exercise Physiology, $12(1), 23-35$.

Field, T. Diego, M., \& Sanders, C. E. (2001 b). Exercise is positively related to adolescents' relationships and academics. Adolescence, 36(141), 105-110

Flay B.R. (1993). Youth tobacco use: Risks, patterns, and control. In Orleans, C.T., \& Slade J. (eds.), Nicotine addiction: Principles and management. New York, NY: Oxford University Press.

Flegal, K.M., Carroll, M.D., Ogden, C.L., \& Curtin, L.R. (2010). Prevalence and trends in obesity among US adults 1999-2008. JAMA, 303 (3), 235-241.

Gans, K.M., Burkholder, G.J., Risica, P.M., \& Lasater, T.M. (2003). Baseline fat-related dietary behaviors of white, Hispanic, and black participants in a cholesterol screening and education project in New England. American Dietetic Association, 103 (6), 699-706.

Giardina, E.V., Laudano, M., Hurstak, E., Saroff, A., Fleck, E., Sciacca, R., BodenAlbala, B., \& Cassetta, J. (2009). Physical activity participation among Caribbean Hispanic women living in New York: Relation to education, income, and age. Journal of Womens Health, 18 (2), 187-193.

Grubbs, L., \& Carter, J. (2002). The relationship of perceived benefits and barriers to reported exercise behaviors in college undergraduates. Family Community Health, 25 (2), 76-84.

Guan, J., Keating X. D., Pinero, J.C., \& Bridges, D.M. (2005). A meta-analysis of college students' physical activities behaviors. Journal of American College Health, 54 (2), 116-125.

Green, S.B., \& Salkind, N.J. (2010). Using SPSS for Windows: Analyzing and understanding Data (6th Edition). Upper Saddle River, NJ: Prentice Hall.

Gyurcsik, N.C., Spink, K., Bray, S.R., Chad, K., \& Kwan, M. (2006). An ecologically 
based examination of barriers to physical activity in students from grade seven through first-year university. Journal of Adolescent Health, 38 (6), 705-711.

Hall, A. E., Kuga, D. J., \& Jones, D. F. (2002). A multivariate study of determinants of vigorous physical activity in a multicultural sample of college students. Journal of Sport and Social Issues, 26, 66-84.

Hartman, J.M., Forsen, J.W., Wallace, M.S., \& Neely, J.G. (2002). Tutorials in clinical research: Part IV: Recognizing and controlling bias. Laryngoscope, 112, 23-31.

Hazelwood, V. (2007). Do college students benefit from school required activity? A Clinical trial. (Doctoral dissertation, Stevens Institute of Technology, 2007). ProQuest Dissertation \& Theses. UMI 3269202.

He X., \& Baker, D. (2005). Differences in leisure-time, household, and work PA by race, ethnicity, and education. Journal of General Internal Medicine, 20 (3) 259-266.

Healthy people 2000. (n.d.). Obesity and physical inactivity. Retrieved from http://www.surgeongeneral.gov/topics/obesity/calltoaction/CalltoAction.pdf

Healthy People 2010. (2000). Understanding and improving health and objectives for improving health, $2^{\text {nd }}$ ed, Vol.2, Goal 26-11: "Reduce the proportions of persons engaging in binge drinking of alcoholic beverages." US Department of Health and Human Services. Washington, DC: US Government Printing Office. Retrieved from: http://www.health.gov/healthypeople

Healthy Campus 2010. (2007). American College Health Association. Health Objectives. Retrieved from http://www.acha.org/Info resources/hc2010.cfm .

Healthy People 2020 (2011). Improving the Health of Americans. Nutrition and weight status. U.S. Department of Health and Human Services. Washington DC: U.S. Government Printing Office. Retrieved from: http://healthypeople.gov/2020/topicsobjectives2020/overview.aspx?topicId=29

Hensley, L. (2000). Current status of basic instruction programs in physical education at American colleges and universities. Journal of Physical Education, Recreation, and Dance, 71(9), 30-36.

Hildebrand, K.M. (1995). Relationships between motivation factors and exercise participation of college students. (Doctoral dissertation). ProQuest Dissertation \& Theses. (AAT9541711).

Hildebrand, K.M., \& Johnson, D.J. (2001). Determinants of college physical education class enrollment: Implications for high school physical education. The Physical Educator, 58, 51-56. 
Hinkle, D.E., Wiersma, W., \& Jurs, S.G. (2003). Applied statistics for the behavioral sciences. Boston, MA: Cengage Learning.

Hoeger, W.K., \& Hoeger, S.A. (2007). Lifetime physical fitness \& wellness. Belmont, CA: Thomson, Wadsworth.

Hortz, B. V. (2005). Evaluation of a social cognitive theory based physical activity intervention targeting leisure time physical exercise. (Doctoral dissertation, Ohio State University). Retrieved from http://etd.ohiolink.edu/sendpdf.cgi/Hortz\%20Brian\%20Vincent.pdf?acc num=os u1 123087047

Hu, L., Motl, R.W., McAuley, E., \& Konopack. J.F. (2007). Effects of self-efficacy on physical activity enjoyment in college-aged-women. International Journal of Behavioral Medicine, 14 (2) 92-96.

Johnston, J., Thosar, S., Agley, J., Gassman, R., Middlestadt, S.E., Van Puymbroeck, M.E., \& Youssefagha, A. (2010, Nov.). Physical activity and sedentary patterns during college transition years. APHA annual meeting presentation number 223500. American Public Health Association, Denver, CO.

Keating, X.D., Guan, J., Castro Piñero, J., \& Bridges, D.M. (2005). A meta-analysis of college students' physical activity behaviors. Journal of American College Health, $54(2), 116-126$.

Kelley, G.A., \& Kelley, K.S. (1994). Physical activity habits of African-American college students. Research Quarterly for Exercise and Sport, 65 (3), 207-212.

Kim, Y.H. (2007). Application of the transtheoretical model to identify psychological construct influencing exercise behavior: A questionnaire survey. International Journal of Nursing Studies, 44, 936-944.

Kiple, K., \& Ornelas, K.C. (2000). The Cambridge world history of food. New York, N.Y: Cambridge University Press.

Kittler, P.M., \& Sucher, K.P. (2001). Food and culture. Belmont, CA: Wadsworth/ Thomson Learning.

Kriska, A.M., \& Rexroad, A. R. (1998). The role of physical activity in minority populations. Women's Health Issues, 8(2), 98-103.

Kristal, A.R., Shattuck, A.L., \& Patterson, R.E. (1999). Differences in fat-related dietary 
patterns between black, Hispanic and white women: results from the Women's Health Trial Feasibility Study in minority populations. Public Health Nutrition, 2, 253-262.

Leenders, N., Sherman, W.M., \&Ward, P. (2003). College physical activity courses: Why do students enroll, and what are their health behaviors? Research Quarterly for Exercise and Sport, 74, 313-318.

Leslie, E., Sparling, P.B., \& Owen, N. (2001). University campus settings and the promotion of physical activity in young adults: Lessons from research in Australia and the USA. Health Education, 101(3), 116-125.

Let's Move: Active Schools. (2011). Retrieved from http://www.letsmove.gov/activeschools

Levitsky, D.A., Halbmaier, C.A., \& Mrdjenovic. (2004) The freshman weight gain: a model for the study of the epidemic of obesity. International Journal of Obesity, $28,1435-1442$.

Liua, J., Probst, J.C., Haruna, N., Bennett, K.J., \& Torresa, M.E. (2009). Acculturation physical activity, and obesity among Hispanic adolescents. Ethnicity \& Health, 14 (5), 509-525.

Mack, M. G., \& Shaddox, L. A. (2004). Changes in short-term attitudes toward physical activity and exercise of university personal wellness students. College Student Journal, 38 (4),587-594.

Marquez, D.X., McAuley, E., \& Overman, N. (2004). Psychosocial correlates and outcomes of physical activity among Latinos: A review. Hispanic Journal of Behavioral Sciences, 26, 195-229.

Marshall, S.J., Jones, D.A., Ainsworth, B.E., Reis, J.P., \& Macera, C.A. (2007). Race/ethnicity, social class and leisure-time physical inactivity. Medicine \& Science in Sports \& Exercise, 39 (1), 44-51.

McArthur, L.H., \& Raedeke, T.D. (2009). Race and sex differences in college student physical activity correlates. American Journal of Health Behaviors, 33(1), 80-90.

McAuley, E. (1993). Self-efficacy and the maintenance of exercise participation in older adults. Journal of Behavioral Medicine, 16, 103-113

McCormick, J., \& Lockwood, P. (2006). College student perception of wellness concepts. The Physical Educator, 63, 78-103.

McMahan, S., Cathorall, M., \& Romero, D. (2007). A comparison of Hispanic and White 
college students in a Hispanic-Serving institution. Journal of Higher Education, 6 (1) $5-18$.

Miami Dade College Institutional Research Home. (2009). Retrieved from http://www.mdc.edu/ir/

Mitchell, B.D., Stern, M.P., Haffner, S.M., Hazuda, H.P., \& Patterson, J.K. (1990). Risk factors for cardiovascular mortality in Mexican Americans and non-hispanic Whites. American Journal of Epidemiology, 131 (3), 423-433.

Muth, N.D. (2008). Help fight freshman weight gain. IDEA Fitness Journal, 5 (9).

Nahas, M.V., Goldfine, B., \& Collins, M.A. (2003). Determinants of physical activity in adolescents and young adults: The basis for high school and college physical education to promote active lifestyles. Physical Educator, 60 (1), $42-56$.

National Association for Sport and Physical Education. (2007). College/university physical activity programs. A critical piece in the education of young adults [position paper]. Reston, VA: author.

National Association for Sport and Physical Education. (2010). Shape of the nation report. Retrieved from http://www.aahperd.org/naspe/publications/Shapeofthenation.cfm?cid=00007

NCES (2007). Status and trends in the education of racial and ethnic minorities. Retrieved July 14, 2009, from National Center for Education Statistic. Web site: http://nces.ed.gov/pubs2007/minoritytrends/ind_6 23.asp) .

Neighbors, C.J., Marquez, D.X., \& Marcus, B.H. (2008). Leisure-time physical activity disparities among Hispanic subgroups in the United States. American Journal of Public Health, 98, 1460-1464.

NHANES III (1988-1994). National Health and Nutrition Examination Surveys. Retrieved from http://www.cdc.gov/nchs/data/nhanes/databriefs/overwght.pdf

NHANES (NCHS) 2003-2006. Overweight and obesity statistics. Retrieved from http://www.cdc.gov/nchs/nhanes.htm

Nies, M.A., Vander Wal, J.S., Schim, S.M., Artinian, N.T., \& Sherrick-Escamilla, S.A. (2005). Physical activity in an urban Hispanic community. Hispanic Health Care International, 3 (1), 15-20.

Pajares, F. (2002). Overview of social cognitive theory and of self-efficacy. Retrieved from http://www.emory.edu/education/mfp/eff.html 
Pearlman, S.N., Valois, R.F., Sargent, R.G., Saunders, J., Drane, W., \& Macera, S.A. (1997). The impact of a required college health and physical education course on the health status of alumni. Journal of American College Health, 46, 77-85.

Petosa, R.L., Suminsky, R., \& Hortz, B. (2003). Predicting vigorous physical activity using social cognitive theory. American Journal of Health Behavior, 27, 301-10.

Pliner, P., \& Saunders, T. (2006). Vulnerability to freshman weight gain as a function of dietary restraint and residence. Physiology \& Behavior, 93, 76-82.

Popkin, B.M., Duffey, K., \& Gordon, P. (2005). Environmental influences on food choice, physical activity and energy balance. Physiology \& Behavior, 86, 603613.

Powers, S.K., \& Dodd, S.L. (2009). Total fitness and wellness. San Francisco, CA: Pearson.

Presley, C.A., Leichliter, J.S. \& Meilman, P.W. (1999). Alcohol and drugs on American college campuses: Findings from 1995, 1996, 1997. A report to college presidents. Carbondale, IL: Southern Illinois University.

Pribis, P., Burtnack, C.A., McKenzie, S., \& Thayer, J. (2010). Trends in body fat, body mass index and physical fitness among male and female college students. Nutrients, 2, 1075-1085.

Ratey, J.J. (2008). SPARK, The Revolutionary new science of exercise and the brain. New York: Little, Brown \& Co.

Reynolds, K.D., Killen, J.D., Bryson, S.W., Maron, D,J, Taylor, C.B., Maccoby, N., \& Farquhar,J.W. (1990). Psychosocial predictors of physical activity in adolescents. Preventive Medicine, 19 (5), 541- 551.

Saffer, H., Dave, D.M., \& Grossman, M. (2011). Racial, ethnic, and gender differences in physical activity. Working paper from the National Bureau of Economic Research, Cambridge, MA. Retrieved from http://www.nber.org/papers/w17413

Sallis, J.F.\& Owen, N.(1999).Physical Activity and Behavioral Medicine. Thousand Oaks, CA:SAGE publications.

Sanderson, B.K., Foushee, H.R., Bittner, V., Cornell, C.E., Stalker, V., Shelton, S., \& Pulley, L. (2003) Personal, social, and physical environmental correlates of physical activity in rural African-American women in Alabama. American Journal of Preventive Medicine, 3 (1), 30-37.

Sidman, C.L., D’Abundo, M.L., \& Hritz, N. (2009). Exercise self-efficacy and perceived 
wellness among college students in a basic studies course. International Electronic Journal of Health Education, (12), 162-174.

Siu, W. L. \& Doyle, K. O. ( 2003). Examining the correlates of physical activity for Whites, Blacks and Hispanics in a national sample: The role of demographics, social connections and self-efficacy. Paper presented at the annual meeting of the International Communication Association, Marriott Hotel, San Diego, CA. Retrieved from http://www.allacademic.com/meta/p112002 index.html

Snyder, T.D. (2003). Digest of education statistics, 2002, NCES 2003-060. Washington, DC: U.S. Department of Education, National Center for Education Statistics. Retrieved from http://nces.ed.gov/pubsearch.

Sparling, P.B. (2007). Obesity on campus. Preventing Chronic Disease, 4 (3). Retrieved October 3, 2009 from http://www.cdc.gov/pcd/issues/2007/jul/06_0142.htm

Sparling,P.B., \& Snow, T.K.(2002). Physical Activity Patterns in Recent College Alumni. Research Quarterly for Exercise and Sport, 73, 200-205.

Squires, D.A. (2012, May). Explaining High Health Care Spending in the United States: An International Comparison of Supply, Utilization, Prices, and Quality. The Commonwealth Fund. Retrieved from www.commonwealthfund.org/.../1595_Squires_explaining_high_hlt...

Stimpson, T.S., (2000). Physical activity stages of change, self-efficacy, and perceived needs and interests of cooperative extension family and consumer sciences agents and clientele (Thesis). Retrieved September 15, 2009 from scholar.lib.vt.edu/theses/available/etd-08202000.../Thesis11.pdf -

Stokes, R., Schultz, S., \& Rothstein, B. (2009). In pursuit of fitness $\left(3^{\text {rd }}\right.$ ed). WinstonSalem, NC: Hunter Textbooks.

Sullivan, S.L., Keating, X.D., Chen, L., Guan, J., Delzeit-McIntyre, \& L., Bridges, D. (2008). Physical education and general health courses and minority community college student risk levels for poor health and leisure-time exercise patterns. College Student Journal, 42 (1), 132-151.

Sullum, J., Clark, M.M,. \& King, T.K. ( 2000). Predictors of exercise relapse in a college population. Journal of American College Health, 48 (4), 41-50.

Suminski, R. R., Petosa, R., Utter, A. C., \& Zhang, J. J. (2002). Physical activity among ethnically diverse college students. Journal of American College Health, 51(2), 75-80. 
Torres, V. (2004). The diversity among us: Puerto Ricans, Cuban Americans, Caribbean Americans, and Central and South Americans. New Directions for Student Services, 105, 5-16.

Tyson, M.L. \& Chalmers, G.R. (2007). The Relationship Between Academic Achievement and Physical Fitness. Physical Educator. 64,(4), 214- 221.

U.S. Bureau of Labor Statistics. (2008). College enrollment and work activity of 2008 high school graduates. Retrieved from http://www.bls.gov/news.release/archives/hsgec 04282009.pdf

U.S. Census Bureau. (2003). Educational attainment. Retrieved from http://www.census.gov/prod/2003pubs/c2kbr-24.pdf

U.S. Census Bureau. (2007). Facts for features, Hispanic heritage month 2007. Retrieved from http://www.census.gov/newsroom/releases/pdf/cb07-ff14.pdf

U.S. Census Bureau News. (2009). Census Bureau releases state and county data depicting nation's population ahead of 2010 Census. Retrieved from http://www.census.gov/PressRelease/www/releases/archives/population/013734.html

U.S. Census Bureau. (2010). The Hispanic Population: 2010. Retrieved from http://www.census.gov/

U.S. Department of Agriculture and Health and Human Services. (2008). Physical Activity Guidelines for Americans. Washington, DC, USA: US Department of Agriculture and Health and Human Services. http://www.health.gov/paguidelines/guidelines/summary.aspx

U.S. Department of Education, National Center for Education Statistics. (2009). Digest of Education Statistics, 2008 (NCES 2009-020), Table 226. Retrieved from http://nces.ed.gov/fastfacts/display.asp?id=98

U.S. Surgeon General. (2001). The Surgeon General's Call to Action: Healthy School Nutrition Environments. Alexandra, VA: U.S. Department of Agriculture, Food and Nutrition Service.

Valois, R.F., Umstattd, M.R., Zullig, K.J., \& Paxton, R.J. (2008). Physical activity behaviors and emotional self-efficacy: Is there a relationship for adolescents? Journal of School Health, 78 (6), 321-327.

Von Ah, D., Elbert, S., Ngamvitroj, A., Park, N., \& Kang, D. (2004). Predictors of Health Behaviors in College Students. Journal of Advanced Nursing. 48 (5), 463-474. 
Wharf Higgings, S.J., Lauzon, L.L., Yew, A.C., Bratseth, C.D., \& McLeod, N. (2010). Wellness 01: health education for the university student. Health Education, 110 (4), 309-327.

Weschsler, H., Lee, J.E., Kuo, M., \& Lee, H. (2000). College binge drinking in the 1990's: A continuing problem : Results of the Harvard School of Public Health 1999 College Alcohol Study. Journal of American College Health, 48, 199-210.

Weschsler, H., Lee J.E., Nelson, T.F.,\& Kuo, M. (2002). Underage college students' drinking behavior, access to alcohol, and the influence of deterrence policies, finding from the Harvard School of Public Health College Alcohol Study. Journal of American College Health, 50 (5), 37-66. 
APPENDICES 


\section{APPENDIX A}

Indicate how confident you are that you can participate in vigorous physical activity in the instances listed below:

Please use the following scale to indicate your answers:
a) Not at all confident
b) Not confident
c) Somewhat confident
d) Confident
e) Very confident

1. At least three days per week.

2. If there is lack of time due to schoolwork.

3. If there is a lack of time due to part-time work.

4. If there is a lack of time due to family responsibilities.

5. If there is a lack of time due to other interests.

6. If you lack energy (too tired).

7. If you lack athletic ability.

8. If there is a lack of programs.

9. If there is a lack of facilities.

10. If you lack a partner.

11. If there is a lack of support from family.

12. If there is a lack of support from friends.

13. If participation costs money.

14. If you lack self-discipline or willpower.

15. If you are self-conscious (feeling uncomfortable).

16. If you have a long-term illness, disability, or injury.

17. If you have a fear of injury.

18. If you feels stressed.

19. If you do not feel in the mood.

20. If you feel discomfort (for example, soreness).

21. If you do not have fun. 


\section{FREQUENCY OF PARTICIPATION IN VIGOROUS PHYSICAL ACTIVITY}

How many days in an average week do you normally participate in vigorous physical activity at the present time?

Vigorous physical activity: 20 minutes or more and intense enough to cause sweating and rapid heart rate.

\begin{tabular}{|l|l|l|l|l|l|}
\hline & \multicolumn{5}{|c|}{ Days of participation: } \\
\hline & 0 & 1 & 2 & 3 & $>3$ \\
\hline $\begin{array}{l}\text { Physical activity class (non- } \\
\text { required) }\end{array}$ & & & & & \\
\hline Other settings (e.g., intramurals) & & & & & \\
\hline $\begin{array}{l}\text { Outside of school (e.g., fitness } \\
\text { center) }\end{array}$ & & & & & \\
\hline
\end{tabular}

Days of participation in vigorous physical activity in the physical activity class, in other settings, or outside of school setting. $1=0$ times, $2=$ once per week, $3=$ twice per week, 4= three times per week, $5=$ more than 3 times per week, scores range from 1 to 5 , where 5 indicates maximum performance of physical activities. 
1. If you must temporarily stop exercising regularly, which of the following factors should be maintained while the others are curtailed?
A. frequency
B. intensity
C. time
D. specificity

2. A person with a body mass index of 26.5 is classified as
A. normal weight.
B. obese.
C. underweight.
D. overweight.

3. A person with diabetes may benefit from all of the following lifestyle changes EXCEPT
A. choosing monounsaturated fats in place of saturated fats.
B. increasing physical activity.
C. increasing intake of refined carbohydrates.
D. increasing fiber intake.

4. Which of the following patterns of eating is best for weight management?
A. one small meal per day
B. one large meal in the evening
C. three planned meals per day plus planned snacks
D. three larger meals per day with no snacks

5. Protein makes up all of the following EXCEPT
A. muscles.
B. bones.
C. blood.
D. adipose tissue. 
6. Exercise is a subset of physical activity that is
A. random or unstructured.
B. discontinuous and unplanned.
C. not a contributor to physical fitness.
D. planned, structured, and repetitive.

7. Healthy body composition is best characterized by a
A. high proportion of bone, fat, and water and a low proportion of muscle.
B. high proportion of muscle, fat, and bone and a low proportion of water.
C. high proportion of muscle and bone and a low proportion of fat and water.
D. high proportion of muscle, bone, and water and a low proportion of fat.

8. Controlling body weight is best accomplished by:
A. eating a low-carbohydrate diet.
B. taking dietary supplements and eating a low-calorie diet.
C. balancing calories consumed with calories expended.
D. following the latest commercial weight-loss program.

9. Metabolic rate is lower for all of the following groups EXCEPT
A. people who exercise on a regular basis.
B. people with a history of weight loss.
C. women, as compared to men.
D. sedentary people.

10. Approximately what percentage of Americans are NOT regularly physically active?
A. $30 \%$
B. $80 \%$
C. $20 \%$
D. $60 \%$

11. Cardiovascular disease risk is greatest for people who tend to store body fat in the
A. Hips
B. Abdomen
C. Thighs
D. Shoulders 
12. All of the following are considered skill-related fitness components EXCEPT
A. Coordination
B. Agility
C. Balance
D. Flexibility

13. Strategies for boosting self-efficacy include
A. Developing an internal locus of control.
B. Using visualization and self-talk.
C. Obtaining encouragement from supportive people.
D. All of the above.

14. To significantly increase the amount of fiber in your diet, consumption of all of the following is helpful EXCEPT
A. bean dip.
B. whole grain foods.
C. peeled fruit.
D. raw vegetables.

15. Strength training helps in the prevention and management of chronic disease by
A. Decreasing bone density
B. Increasing LDL cholesterol
C. Improving glucose metabolism
D. Increasing systolic blood pressure

16. Flexibility is best developed by
A. Stretching once a month
B. Stretching major muscle groups regularly
C. Stretching only a few muscles
D. Stretching only when muscles feel tight

17. The three leading causes of death in the United States are
A. cancer, diabetes, and cirrhosis.
B. heart disease, stroke, and cancer.
C. diabetes, osteoporosis, and cirrhosis.
D. hypertension, stroke, and heart disease 
18. If you have cardiovascular disease or diabetes, your target LDL level is less than
A. $200 \mathrm{mg} / \mathrm{dl}$
B. $100 \mathrm{mg} / \mathrm{dl}$
C. $160 \mathrm{mg} / \mathrm{dl}$
D. $65 \mathrm{mg} / \mathrm{dl}$

19. The first step in creating a successful fitness program is to
A. Set specific fitness goals
B. Determine your training intensity
C. Plan your fitness program
D. Assess your current fitness level

20. Optimism, trust, and self-confidence are components of
A. physical wellness.
B. spiritual wellness.
C. emotional wellness.
D. interpersonal wellness. 
APPENDIX C

\section{Assessing Nutritional Habits}

Read the following scenarios and select which option applies to you.

1. You don't have time to make dinner, so you run out to get "fast food." What do you get?

a. grilled chicken breast sandwich

b. supersized burger

2. You go to a movie, find yourself hungry, and cannot resist a snack. Which do you buy?

a. unbuttered popcorn

b. candy

3. You're late for work and realize you forgot breakfast. You decide to stop and grab something to eat. What do you pick up?

a. a banana

b. a sausage biscuit

4. You decide to go out for a nice dinner at an Italian restaurant. What do you order?

a. spaghetti with red sauce

b. five-cheese lasagna

5. It's 3:00 PM, and you didn't have much lunch and need an afternoon snack. What do you reach for?

a. an apple

b. M\&Ms

6. You stop for ice cream. Which do you pick?

a. a fruit sorbet

b. regular ice cream 
7. What kind of dessert would you normally choose to eat?

a. a bowl of mixed berries with a sprinkling of sugar

b. chocolate cake with frosting

8. What do you use to stir fry vegetables?

a. olive oil

b. margarine

9. Which of the following salty snacks would you prefer?

a. pretzels

b. potato chips

10. You want cereal for breakfast. Which would you choose?

a. whole-grain flakes

b. peanut butter puffs 
VITA

\section{ILIDA MEDERO}

Birthplace

1980

1984

1988-Present

2012
Cienfuegos, Cuba

Bachelor of Science in Physical Education and Coaching. University of Miami Miami, Florida

Master of Science in Physical Education

University of Miami

Miami, Florida

Associate Professor Health \& Wellness, Nutrition Miami Dade College

Miami, Florida

Doctoral Candidate in Higher Education Administration Florida International University

Miami, Florida 